\section{Pacific Northwest}

National Laboratory

Operated by Battelle for the

U.S. Department of Energy

\title{
Vadose Zone Transport Field Study: FY 2003 Test Plan
}

\author{
A.L. Ward \\ G.W. Gee
}

April 2003

Prepared for the U.S. Department of Energy under Contract DE-AC06-76RL01830 


\section{DISCLAIMER}

This report was prepared as an account of work sponsored by an agency of the United States Government. Neither the United States Government nor any agency thereof, nor Battelle Memorial Institute, nor any of their employees, makes any warranty, expressed or implied, or assumes any legal liability or responsibility for the accuracy, completeness, or usefulness of any information, apparatus, product, or process disclosed, or represents that its use would not infringe privately owned rights. Reference herein to any specific commercial product, process, or service by trade name, trademark, manufacturer, or otherwise does not necessarily constitute or imply its endorsement, recommendation, or favoring by the United States Government or any agency thereof, or Battelle Memorial Institute. The views and opinions of authors expressed herein do not necessarily state or reflect those of the United States Government or any agency thereof.

PACIFIC NORTHWEST NATIONAL LABORATORY

operated by

BATTELLE MEMORIAL INSTITUTE

for the

UNITED STATES DEPARTMENT OF ENERGY

under Contract DE-AC06-76RL1830 


\title{
Vadose Zone Transport Field Study FY 2003 Test Plan
}

\author{
A. L. Ward \\ G. W. Gee
}

April 2003

Prepared for the U.S. Department of Energy

under Contract DE-AC06-76RL01830

Pacific Northwest National Laboratory

Richland, Washington 99352 


\section{Summary}

Conceptual models have been identified as one of the sources of uncertainty in the interpretation and prediction of contaminant migration through the vadose zone at the Hanford Site in southeastern Washington State. Current conceptual models are limited, partly because they often do not account for the random heterogeneity that occurs under the extremes of very nonlinear flow behavior typical of the Hanford vadose zone. Over the last two years, significant progress has been made in characterizing physical heterogeneity and in developing techniques for incorporating this heterogeneity into predictive and inverse models for field-scale subsurface flow. One of the remaining pieces of the puzzle is the impact of heterogeneity on the distribution of reactive contaminants. Reactive transport occurs over a wide range of spatial and temporal scales. However, the manner in which the various subsurface physical and chemical processes interact to influence transport is not very well understood. Hydrogeologic characterization and model analysis, however, have traditionally focused on measuring physical properties and predicting the effects of variability in these properties on flow and transport. As a result, the role of geochemical heterogeneity on solute transport has remained largely unexplored. The project described in this paper, led by Pacific Northwest National Laboratory, will use a combination of geophysical and soil-physics techniques to investigate the infiltration and redistribution of water and reactive tracers in a controlled field experiment at the Army loop Road clastic dike site. In the FY 2003 tests, surface-deployed ground-penetrating radar will be used to identify the discrete three-dimensional (3-D) pattern of horizonation and small-scale heterogeneities that characterize the test site and to develop a lithofacies map. The transect will be instrumented to allow water to be applied along its length from a line source. Local-scale water content, matric potential, and tracer concentrations will be monitored as a function of spatial scale by multipurpose time-domain reflectometry probes and suction lysimeters. A tension infiltrometer will be used to measure mobile-immobile parameters. The resulting data will be used to characterize fine-scale heterogeneity as well as correlation lengths of hydraulic and transport parameters. Tracer breakthrough data will be used to determine longitudinal and transverse dispersivities and their scale dependence. Parameters will be analyzed to identify a suitable averaging (upscaling) procedure for field-scale infiltration predictions. A combination of in situ permeability, water content, and resistivity measurements will be combined with the granulometry and core analysis to quantify hydraulic geochemical properties in the laboratory. These data will be coupled with the field-measured hydraulic and transport parameters and the 3-D lithofacies map to generate a 3-D hydrofacies map of the site that includes the distribution geochemical properties controlling sorption. This map, along with measured distributions of water and solute, will be used to validate (1) a numerical model for forward predictions and (2) the applicability of upscaled parameters to reactive transport processes that typically occur under transient flow and at large spatial and temporal scales. The results of this study will help to bridge the gap between local-scale transport observations and field-scale transport behavior. It will allow the validation of recently developed inverse procedures for predicting field-scale parameters and will improve our prediction capability for reactive transport in heterogeneous sediments at Hanford. The improved conceptualizations will permit the U.S. Department of Energy to make defensible corrective and remedial action decisions at Hanford and other waste sites. 


\section{Glossary}

1-D, 2-D, 3-D One, Two, or Three Dimensional

AGU

ASTM

BHI

CDE

CEC

CMP

CPT

DOE

DOE-RL

EMSP

EPA

FIR

GPR

$\mathrm{GW} / \mathrm{VZ}$

HMS

ILAW

IR

MEPAS

PNNL

QA

RPP

SAC
American Geophysical Union

American Society for Testing and Materials

Bechtel Hanford Incorporated

Convective Dispersive Equation

Cation Exchange Capacity

Common Midpoint

Cone Penetrometer

U.S. Department of Energy

U.S. Department of Energy-Richland Operations

Environmental Management Science Program

U.S. Environmental Protection Agency

Field Investigation Report

Ground-Penetrating Radar

Groundwater/Vadose Zone

Hanford Meteorological Station

Immobilized Low Activity Waste

Infrared

Multimedia Environmental Pollutant Assessment System

Pacific Northwest National Laboratory

Quality Assurance

River Protection Project

System Assessment Capability 
SBMS

SBMS

S\&T

TDR

VZTFS

WMA

XRD
Standards Based Management System

Standards-Based Management System

Science and Technology

Time-Domain Reflectometry

Vadose Zone Transport Field Study

Waste Management Area

X-Ray Diffraction 


\section{Contents}

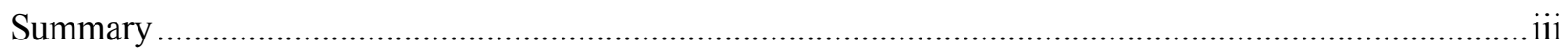

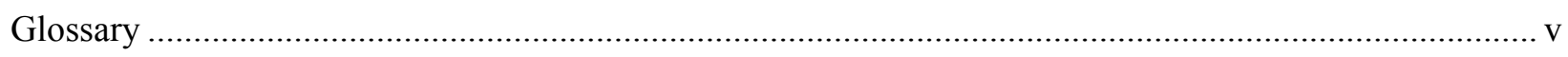

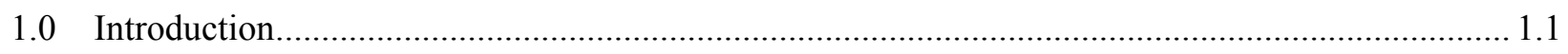

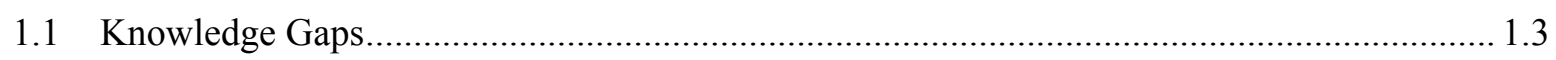

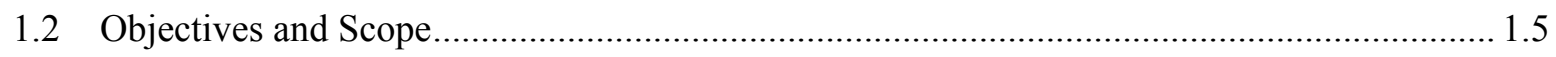

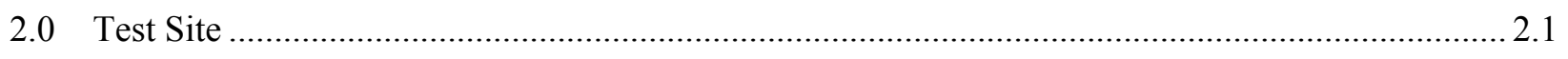

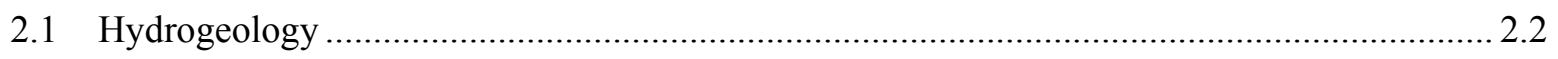

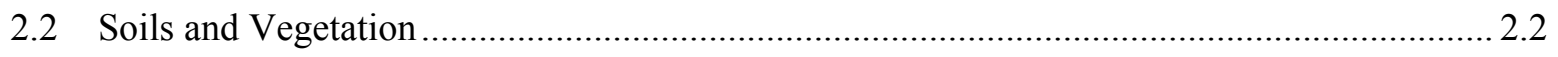

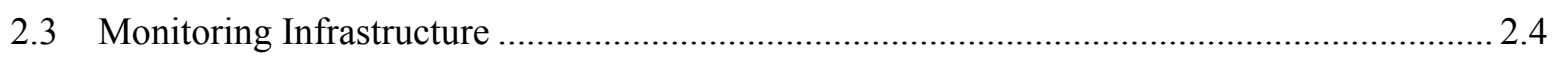

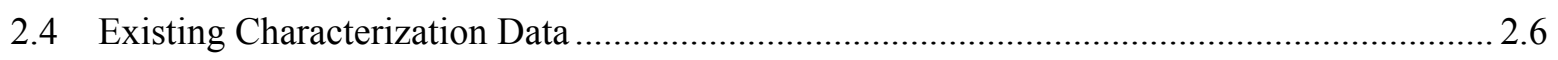

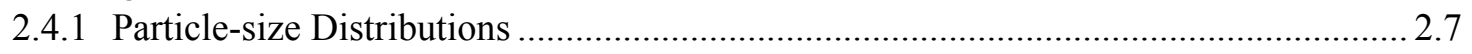

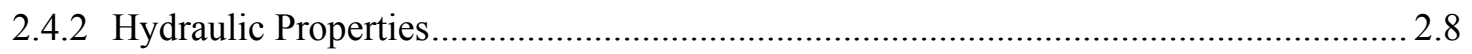

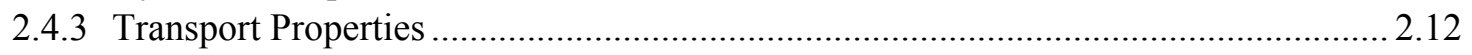

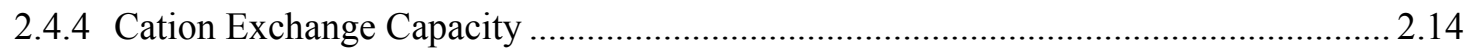

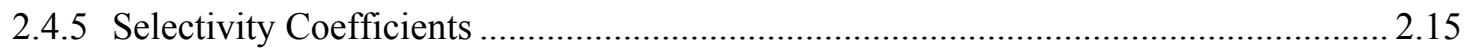

2.4.6 Surface Ground-Penetrating Radar .................................................................. 2.17

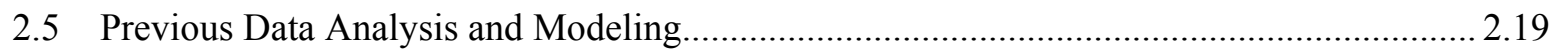

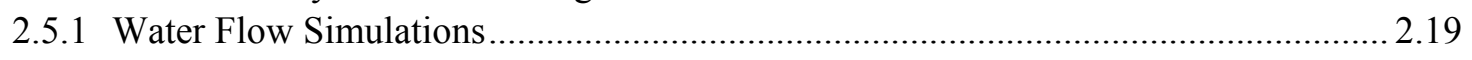

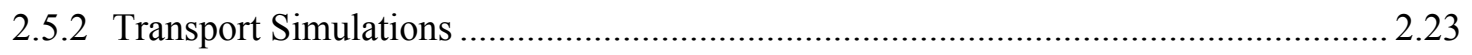

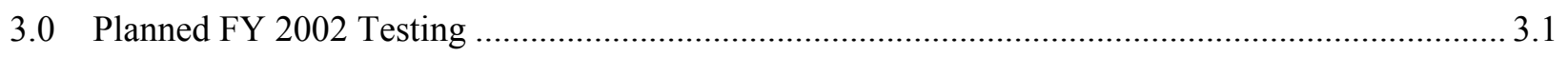

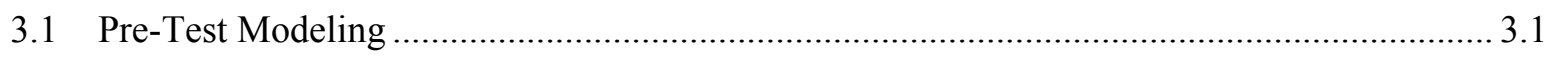

3.2 Measurements of Cation Exchange Capacity .............................................................. 3.2

3.3 Measurements of Particle-Size Distributions ................................................................ 3.3

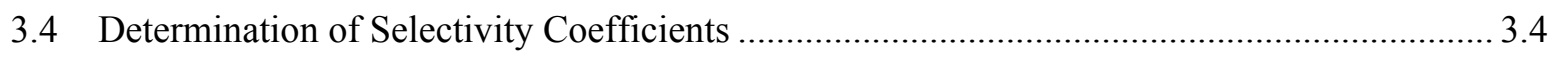

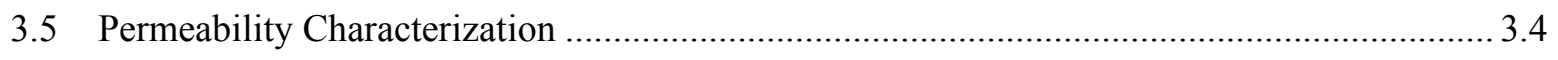

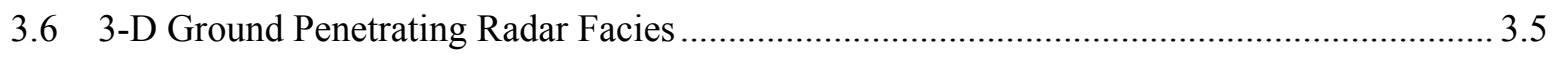

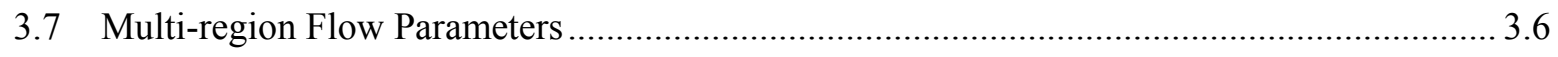

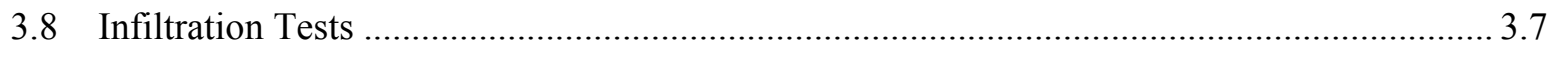




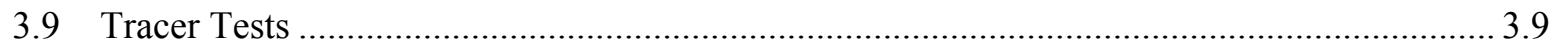

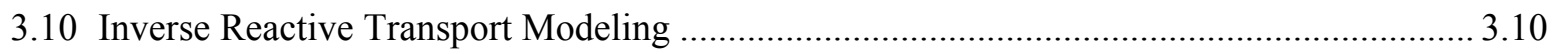

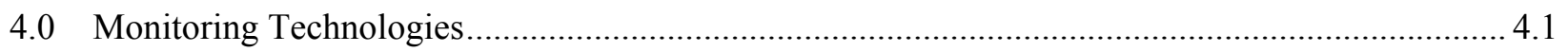

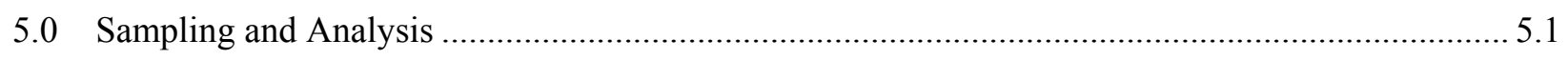

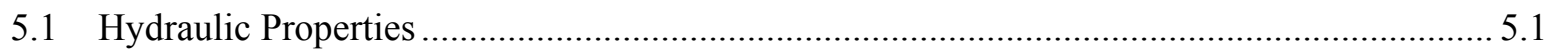

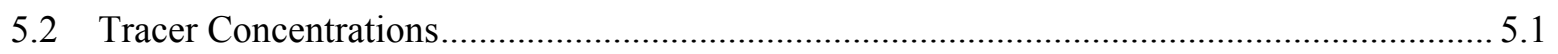

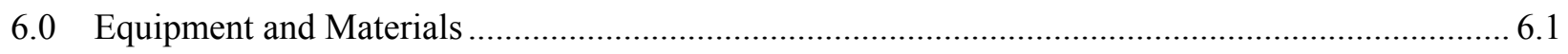

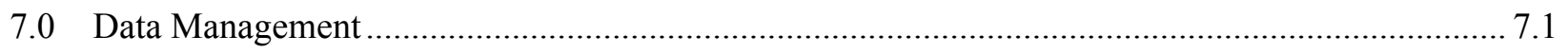

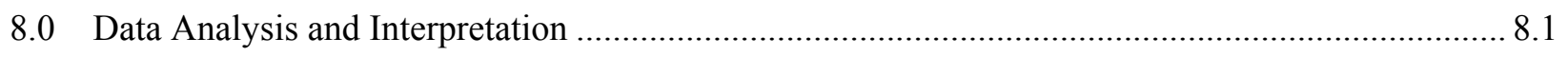

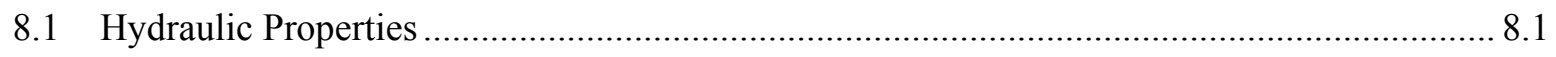

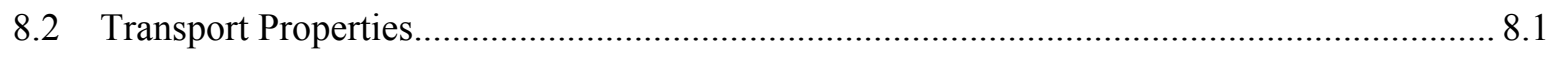

8.3 Geostatistical Determination of Spatial Correlation ...................................................... 8.2

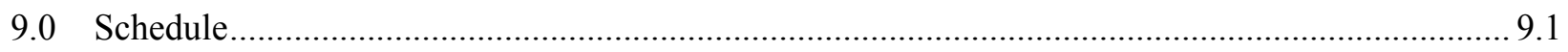

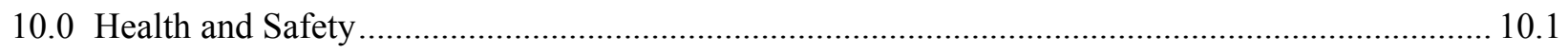

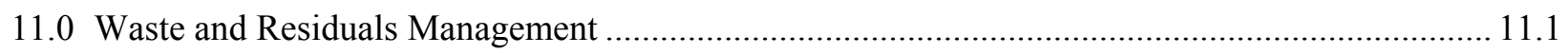

11.1 Management Activity A - Solid Waste Management Plan for Cone Penetrometer/ Tensiometer Installation ...................................................................................... 11.1

11.2 Management Activity B - Soil Management Plan ....................................................... 11.1

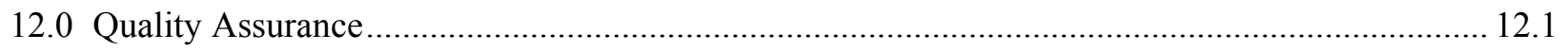

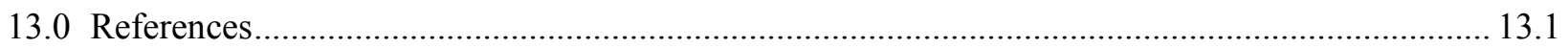

Appendix A: Excavation Permit (Dan 1737) ............................................................................. A.1

Appendix B: Clastic Dike: Antiaircraft Site H-42-Army Loop Road Site Access and Conduct

Requirements Health and Safety Plan and Site Briefing ............................................................. 1 


\section{Figures}

2.1. Location of the Primary and Secondary Sites for the Clastic Dike Study 2.1

2.2. Aerial Photograph from July 13, 1996, Showing the Location of the test Site.

2.3. The Borders of Typical Vegetation Polygons at the Army Loop Road Site.

2.4. Schematic of Probe Installations.

2.5. Schematic Layout Showing Common Offset Profiles and Borehole Radar Locations

2.6. The FIELD SITE During Instrumentation Looking in an Easterly Direction Along the Transect

2.7. Vertical Section of Tier 2 of the Army Loop Road Excavation Showing the Small-Scale Structure of Heterogeneity.

2.8. Graphical Comparison of Particle-size Distribution from $<2 \mathrm{~mm}$ Fractions from the Army Loop Road Field Site. Essentially five textures were identified from the analyses - silt loam (e.g., IN-A1-5, •), loam (e.g., AL-CD-T3-1,ш ); sandy loam (e.g., AL-CD-T2-8, •); loamy sand (e.g., AL-CDT2-5, ○); and sand (e.g., Al-HT4-1, $\square$ ).

2.9. Observed and Predicted Relationship Between Air Permeability $\left(\mathrm{mm}^{2}\right)$ and Geometric Mean Diameter (mm): (a) Fine-Textured Sediments, (b) Coarse-Textured Sediments

2.10. Spatial Variability at Tier2 Outcrop: (a) Visible Image Showing Spatial Variation in Soil Textures, (b) Measured Infrared Temperatures, and (c) Upscaled Vertical Saturated Hydraulic Conductivity, Inferred from the Relationship Between Geometric Mean Grain Size and Intrinsic Permeability .

2.11. Relationship Between CEC Corrected for Gravel and Geometric Mean Grain Diameter Obtained for Samples from Borehole 41-09-39 in the S-SX Waste Management Area.

2.12. Spatial Variability at Tier2 Outcrop: (a) Infrared Image Showing Spatial Variation in Soil Textures, (b) Geometric Mean Particle Diameter, $d_{g}$, and (c) CEC, Inferred from $d_{g}$ 2.15

2.13. Schematic Layout Showing Common Offset Profiles and Borehole Radar Locations 2.18

2.14. Common Offset GPR Data Collected Along Profile\#1 on May 21, 2002

2.15. Distributions of Volumetric Water Content During Steady Infiltration Under a Constant Surface Flux of (a) $1.0 \mathrm{~mm} \mathrm{yr}^{-1}$, (b) $10 \mathrm{~mm} \mathrm{yr}^{-1}$, (c) $10^{2} \mathrm{~mm} \mathrm{yr}^{-1}$, and(d) $10^{3} \mathrm{~mm} \mathrm{yr}^{-1}$

2.16. Distributions of Dimensionless Water Flux, $\log _{10}\left(\left|j_{w}\right| / j_{w}^{0}\right)$, During Steady Infiltration at an Input Flux, $j_{\mathrm{w}}^{0}$, of (a) $1.0 \mathrm{~mm} \mathrm{yr}^{-1}$, (b) $10 \mathrm{~mm} \mathrm{yr}^{-1}$, (c) $10^{2} \mathrm{~mm} \mathrm{yr}^{-1}$, and (d) $10^{3} \mathrm{~mm} \mathrm{yr}^{-1}$ 2.22 
2.17. Strontium Breakthrough and Subsequent Desorption in Experiments 1 Through 4 $\left(0.01,0.1,1\right.$, and $5 \mathrm{M} \mathrm{NaNO}_{3}$, respectively, in the sorption stage and $0.01,0.1,1$, and $1 \mathrm{M} \mathrm{KNO}_{3}$, respectively, in the desorption stage) (after Steefel et al. 2002)

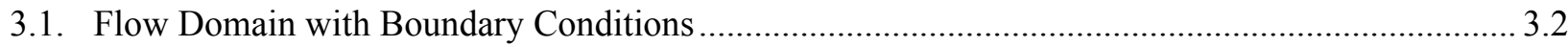

3.2. Schematic of 1-D Advection and 2-D Dispersion in a Half Plane of a Porous Medium ................. 3.3

3.3. Three Dimensional Chair Diagram of the 216-S-16 Pond Data. The upper $2 \mathrm{~m}$ of data

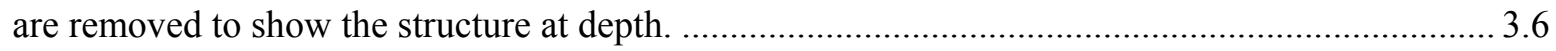

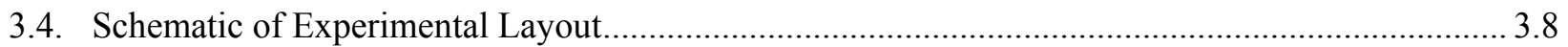

4.1. Field Setup for High-Resolution Digital Photography and Small-Scale Permeability Measurements

\section{Tables}

2.1. Measured Grain Size Characteristics, Permeability, and Predicted Hydraulic Properties for Representative Textures at the Army Loop Road Site

2.2. Fitted Transport Parameters for the 2-D CDE from the First Experiment

2.3. Fitted Transport Parameters for the 2-D CDE from the Second Experiment

2.4. Selectivity Coefficients and Exchanger Activity Corrections Based on Batch Exchange Experiments 2.16

2.5. Selectivity Coefficients Based on Individual Column Experiments 2.17

9.1. Preliminary Schedule for FY 2003 Experiment. 


\subsection{Introduction}

The United States Department of Energy's (DOE's) Hanford Site in southeastern Washington State contains, within its vadose zone, wastes created from nine nuclear reactors and four reprocessing plants. The reactors and processing plants were used for plutonium production during the Cold War and generated nearly $2 \cdot 10^{6} \mathrm{~m}^{3}\left(5.283 \cdot 10^{8}\right.$ gal $)$ of high-level tank waste. Liquid evaporation, discharge to the ground, and tank leakage has reduced that volume by $90 \%$ to about $2 \cdot 10^{7} \mathrm{~m}^{3}\left(5.283 \cdot 10^{7} \mathrm{gal}\right)$, the remainder of which is currently stored in underground tanks. The stored waste at Hanford is nearly $60 \%$ of all the tank waste that exists in the DOE complex (Gephart 2001). The tanks contain about 195 million curies of radioactivity and 220,000 metric tons of chemicals. The discharged and leaked wastes are estimated to contain several times these amounts of radioactive and hazardous wastes. Massive cleanup efforts are underway to remediate the Hanford Site. Improved conceptual and predictive models are needed to guide the selection, development, and deployment of the most effective remediation technologies. However, the formulation of a good conceptual model requires sound theory and sufficient data of good quality (National Academy of Science 2000). The vadose zone transport field studies (VZTFS) were initiated under the Science and Technology Program of Hanford's Ground Water Protection Project to provide these data and to support the development of improved conceptual and predictive models.

In FY 2000, studies initiated at the Hanford Site by Pacific Northwest National Laboratory (PNNL) evaluated the processes controlling subsurface transport, and they form the basis for developing a reliable database for vadose-zone transport-model calibration. The well-characterized "Sisson and Lu" site, located in the $200 \mathrm{E}$ Area, was the site used for a series of leak-simulation tests. To assess the importance of subsurface features and fluid properties on field-scale solute transport, injections of solute-free and hypersaline waters were made in two consecutive years. Data from these tests clearly show that an interaction between small-scale horizontal stratification and fluid properties controlled the subsurface distribution of both fluid types. These observations emphasize the need to consider local-scale textural discontinuities in conceptual models of field-scale transport at the Hanford Site because they appear to cause lateral spreading of vadose-zone plumes. These studies have provided much insight into the effect of heterogeneity on subsurface flow and the transport of mobile contaminants and have led to the development of improved conceptual models of unsaturated flow (Ward et al. 2002; Zhang et al. 2003).

High performance computing has made possible the development of high resolution, multidimensional, unsaturated flow models capable analyzing the complex, physically heterogeneous porous media typical of Hanford (Ward et al. 2003; Murray et al. 2003). Coupling of the parameter scaling technique, a product of our research, has made inverse modeling of large vadose-zone flow experiments for estimating field-scale parameters a reality (Ward et al. 2002; Zhang et al. 2002a,b,c; Zhang et al. 2003). One of the remaining pieces of the puzzle is the impact of heterogeneity on the distribution of reactive contaminants. Reactive transport occurs over a wide range of spatial and temporal scales. However, the manner in which the various subsurface physical and chemical processes interact to influence transport is not very well understood. As with physical and hydraulic properties, chemical properties typically vary in three-dimensional (3-D) space and may show heterogeneity from the porescale up to the formation scale. Physical heterogeneity can therefore lead to non-uniform flow, bypass of reactive sites, and non-ideal transport behavior. 
Reactive contaminants also make up a large part of the inventory at Hanford, and the key radionuclides of concern in the vadose zone at Hanford have been discussed by several authors (Gephart and Lundgren 1998; Hartman et al. 2002). Apart from technetium-99 and tritium, strontium-90 and uranium are the two primary radionuclides measured in Tank Farms (Knepp 2002). Strontium-90 was a major fission product generated in large quantities at the Hanford Site, and its overall activity in the irradiated uranium fuel was second only to cesium as an intermediate half-life contaminant (Zachara et al. 2002). Strontium- 90 was discharged to a variety of cribs, retention basins, and other soil sites in the 200 Areas, and there are large inventories in the vadose zone. Strontium-90 is also present in the groundwater at numerous sites on the 200 Area plateau (Waite 1991; DOE 1997; Todd 2000). One major groundwater plume exists near the 100-N Area as a result of cooling-water discharge to the 1325-N liquid waste disposal facility (Alexander and Johnson 1993). This plume is the source of discharges into the Columbia River and has been undergoing remediation by pump-and-treat. However, this remedial action has not been particularly effective, perhaps due to strong adsorption of strontium.

Detailed characterization and ion exchange experiments conducted on strontium-contaminated sediments from borehole 299 -E33-46 show that $25 \%$ of strontium-90 is co-precipitated in a carbonate phase, and $75 \%$ is present in ion exchangeable form on large silicate minerals (Zachara et al. 2002; Serne and LeGore 1996). Laboratory data suggest that the sorption of strontium in Hanford sediment is moderate, but field data show that it has migrated appreciable distances from the suspected sources. Although the rate of migration appears to depend on waste composition, hydrogeological characteristics, and the volume of liquid discharge, plume characteristics suggest an enhanced mobility in the vadose zone, at least for some unknown period after the release (Zachara et al. 2002).

Multi-component $\left(\mathrm{Na}^{+}, \mathrm{K}^{+}, \mathrm{Ca}^{2+}, \mathrm{Mg}^{2+}, \mathrm{Sr}^{2+}\right)$ cation exchange models were recently developed to describe the distribution of stable strontium and strontium- 90 between the aqueous and solid phases of Hanford sediments (Lichtner and Zachara 2002; Steefel et al. 2002). Model analyses were successful and showed that strontium-90 should be stable and immobile in the vadose zone with calcium and sodium being important competitive ions. The analyses also showed that increased porewater concentrations of $\mathrm{Ca}^{2+}$ could mobilize a portion of the sorbed strontium- 90 while infiltration of meteoric water could increase retardation through the dilution of porewater $\mathrm{Na}^{+}$to concentrations below $0.1 \mathrm{~mol} / \mathrm{L}$. Additional transport analyses are needed to determine whether the current vadose-zone distributions of reactive contaminants and competing ions are consistent with multicomponent ion exchange and to what extent the distributions are influenced by physical and geochemical heterogeneity.

Hydrogeologic characterization efforts have traditionally focused on measuring physical properties while modeling efforts have focused on the effects of variability in these properties on flow and transport. As a result, the role of geochemical heterogeneity on solute transport has remained largely unexplored. Analysis of the effects of geochemical heterogeneity, however, is not an easy task as the complexity of reactive transport models makes their application to natural environments non trivial (Steefel and MacQuarrie 1996). Thus, to extrapolate the laboratory findings about reactive transport to a relevant scale in the field and determine the impact of heterogeneities on the transport behavior, the minimum requirement is an accurate database of field-scale flow-and-transport observations obtained under controlled conditions. An equally important need for such a database lies in the need to develop techniques for upscaling the laboratory-based models for field-scale application. With the development of multicomponent models for high-performance computing architectures, coupled flow and reactive 
transport models can now be applied to multi-dimensional, unsaturated flow models to analyze complex physically and chemically heterogeneous porous media. Such tools are ideal for gauging our understanding of field-scale transport, guiding the controlled field-scale experiments, and predicting the fate and transport of contaminants discharged to the vadose zone during the production years at Hanford. These needs are the basis of the FY 2003 Vadose Zone Transport Field Study (VZTSF) experiments, which will focus on a detailed study of the field-scale fate and transport of a well-understood reactive tracer in a heterogeneous, unsaturated system. Given the obvious importance of strontium 90, and the depth of knowledge about is behavior under laboratory conditions, the FY 2003 VZTFS tests will focus on the field-scale migration of stable strontium.

\subsection{Knowledge Gaps}

Ward et al. (2002) summarized hydrogeological knowledge gaps relating to subsurface flow in heterogeneous unsaturated soils. In relation to field-scale flow processes, some of the primary issues included multi-region flow, state-dependent anisotropy, upscaling; field-scale parameter estimation, and adequate characterization of subsurface heterogeneity for inclusion in numerical models. Significant progress has been made in these areas over the last three years. Similar issues obviously exist for transport with additional challenges when the interest is reactive transport. The description of dispersion relates to transport in general. The principal physical effect of the field-scale application of the convective dispersive equation (CDE) is the temporal growth in the dispersion tensor (Kabala and Sposito 1991). In heterogeneous soils, the temporal growth in dispersion has been described using stochastic theory with the assumption that the growth is due to the random spatial variability in the advective velocity. While information on the spatial variation in the velocity can be derived from the infiltration tests performed in FY 2002, the information on its own may be of limited application to reactive tracers. As with conservative tracers, it is expected that the dispersion tensor will grow temporally in response to spatially variable advective velocities. However, solute spreading is further complicated by the variability in the parameters that characterize the reactivity of the porous medium and the accessibility of reactive surfaces. Thus, the distribution of reactive tracers is controlled by the physical heterogeneity, its effect on the velocities, and its interaction with geochemical heterogeneity.

Such interactions have not been widely studied although recent activities on site have focused on measuring $K_{d}$ for different sediments. To this end, a large amount of $K_{d}$ data have been collected for radionuclides and toxic metals that have the greatest risk drivers in the vadose zone and groundwater at the Hanford Site (Kaplan and Serne 1999). Other data required for interpretation of $\mathrm{K}_{\mathrm{d}}$ values have also been compiled and documented. These studies have culminated in the development of a multicomponent cation exchange model to describe the distribution of both stable strontium, strontium-90, cesium, and uranium between porewater/wastewater and sediment (Zachara et al. 2002; Lichtner and Zachara 2002; Steefel et al. 2002). This model has been tested using small column experiments packed with homogenized, repacked samples. However, given the extreme heterogeneity of sediments of the Upper Hanford Formation, it is conceivable that subsurface flow regime and water-distribution patterns could limit access to reactive surfaces, thereby affecting the distribution of sorbed contaminants and rendering predictions of transport invalid at the field scale.

Predicting reactive contaminant transport requires accurate description of the sorption processes for conditions where the soil is not saturated, and water content is changing, i.e., transient flow in unsaturated systems. However, this aspect of transport has received little attention in experimental procedures. The 
closest analogy is the study of the relationship between saturated hydraulic conductivity, $\mathrm{K}_{\mathrm{s}}$, and the distribution coefficient $\mathrm{K}_{\mathrm{d}}$. Field-scale studies of strontium migration at the Borden Site in southern Ontario show significant spatial variability in what appears to be a homogeneous sand at the macroscopic scale (Robin et al. 1991). Observed $K_{d}$ values ranged over seven fold from the largest to smallest value and with horizontal correlation lengths ranging from 0.3 to $2 \mathrm{~m}$ (1 to $6.6 \mathrm{ft}$ ) and vertical correlation lengths ranging from 0.30 to $0.70 \mathrm{~m}$ ( 1 to $2.3 \mathrm{ft}$ ). Numerical simulations show that the variability of $\mathrm{k}_{\mathrm{s}}$ and $\mathrm{K}_{\mathrm{d}}$, as well as the correlation between the two, are key factors controlling solute behavior (Burr et al. 1994; Rabideau and Miller 1994).

The limitations of applying current reactive transport theories to the unsaturated zone become quite clear when one examines the two basic assumptions commonly employed. At present, the two common assumptions for most reactive tracer modeling are 1) the system is at steady-state moisture conditions and 2) all of the pore space is contributing to transport. In other words, all reactive sites are expected to be equally accessible, regardless of saturation. Experimental and numerical simulations also show that porescale variation in the retardation factor can cause non-ideal reactive breakthrough in unsaturated porous media (Sugita and Gillham 1995a,b; Sugita et al. 1995). Yet, there are few options for accounting for bypass, diffusion-limited mass transfer between pores, or the effects of flow regime in heterogeneous soils. Both assumptions are invalid for Hanford's conditions, and the resulting errors will hinder our ability to interpret and predict distributions of reactive contaminants. There is laboratory evidence of an immobile water fraction affecting solute distribution under transient flow conditions, but not steady-flow conditions (Bond and Wierenga 1990).

This apparent conflict may be due to different water-flow patterns arising from the two flow regimes and raises questions about current conceptual models used at Hanford. Multi-region (mobile-immobile water) transport and the exchange of solutes between regions of high pore water velocities and comparatively immobile regions may give rise to early breakthrough and asymmetric breakthrough curves if the time required for complete mixing between the two regions is large compared with the time for advection of solute over a similar distance. Such a phenomenon would limit exposure to the bulk of reactive sites in an unsaturated system and in systems exposed to unsteady flow. This aspect of transport has received little attention in terms of theoretical development or experimental procedures, and little is known about the importance of initial saturation, flow regime, and sensitivity to micro-structural variability. It is clear, however, that if advective velocity, distributions of reactive surfaces, and the percentages of immobile water are significantly different for steady and unsteady flow, then there is a need for extreme caution in extrapolating the results of studies carried out under one flow regime to a different flow regime and in extrapolating results from one waste-management scenario to the next.

The effect of these phenomena can be easily determined by analyzing the cross correlation between advective velocity and the effective retardation coefficient and how it relates to the growth in the dispersion tensor as a function of spatial scale. Robin et al. (1991) reported a weak but significant negative correlation between $\mathrm{K}_{\mathrm{s}}$ and $\mathrm{K}_{\mathrm{d}}$ for strontium at Borden. Theoretically, a weak relationship between $\mathrm{K}_{\mathrm{s}}$ and $\mathrm{K}_{\mathrm{d}}$ in the saturated zone is not implausible because $\mathrm{K}_{\mathrm{d}}$ is dependent on mineralogy while $\mathrm{K}_{\mathrm{s}}$ is related to pore structure. In the vadose zone, it is possible that the relationship between pore structure, flow regime, and wetted (reactive) surface area may lead to a time dependent but stronger relationship between advective velocity and $\mathrm{K}_{\mathrm{d}}$. The distribution of the reactive sites at the pore or "subgrid" scale could be where correlations between advective velocity and $\mathrm{K}_{\mathrm{d}}$ are the most variable, but what happens when the density of reactive surface sites is preferentially distributed in pore sizes that are 
not strongly participating in the transmission of liquids is as yet unknown. Another unknown is how the local-scale heterogeneity (fines and textural breaks) affects access to reactive sites. Identification of the relationships identified above is needed as a precursor to a more rigorous method of modeling reactive transport in heterogeneous systems. Also needed is an improved methodology for upscaling sorption heterogeneity.

In addition to convection, which results from spatially variable pore water velocity, large-scale dispersion of reactive solutes is controlled by sorption reactions and decay. Sorption reactions typically involve the exchange of solutes between the aqueous and solid phases of porous media and are therefore subject to the effects of heterogeneity. While there is evidence that small-scale variations in the physical and chemical properties of the medium can be accounted for with a macro-scale dispersion at the field scale, the prediction of transport over the multiple scales controlling the process remains a challenge. The most common approach to modeling reactive transport in soils is still based on the assumption that sorption reactions are sufficiently fast so that equilibrium conditions are valid, and the process can be described by sorption isotherms (Bottcher 1997). Field studies have shown that the sorption of heavy metals varies spatially (Boekhold et al. 1991), and a number of approaches to modeling the effects of heterogeneity have been proposed. Heterogeneity effects are typically modeled with spatially variable $\mathrm{K}_{\mathrm{d}}$ (Cvetkovic and Dagan 1994; Burr et al. 1994; Bosma and van der Zee 1993). In most cases, variation in $\mathrm{K}_{\mathrm{d}}$ is related to the variation of the soils' $\mathrm{H}+$ activity and organic matter content and under the exponent $n$ is assumed to be constant. This approach provides little information on the true variability in the isotherms, and there is little evidence to support a constant exponent $\mathrm{n}$ (Bottcher 1997). Another approach has been to generalize variable isotherms into an adsorption density (Schulte 1995). The introduction of a sorption density isotherm simplifies the problem of describing variability to one of determining the variability in surface areas. While surface areas can be obtained relatively easily from particle-size distributions, which are readily available onsite, there is evidence to suggest that measured surface areas often do not match the true surface areas (Petersen et al. 1996). At this point, inverse reactive transport modeling in heterogeneous unsaturated systems is hampered by the inability to adequately handle spatially variable $\mathrm{K}_{\mathrm{d}}$ for large systems. Techniques are needed to allow the scaling of reactive transport parameters across the multiple scales at which sorption is active.

Such relationships can be derived only from field-scale tests where variations in local pore-water velocities and reactivity parameters can be measured simultaneously. The inclusion of reactive tracers in a field test will help identify the relationship between flow regime and the pore class accessed by migrating liquids. The resulting information will provide considerable insight into the fundamental behavior of reactive contaminants in unsaturated systems.

\subsection{Objectives and Scope}

The objective of the FY 2003 field test is to improve our understanding of the hydrogeological constraints and geochemical heterogeneity on reactive transport in the vadose zone at Hanford. The scope includes the performance of a series of field-scale tracer experiments with stable strontium at the Army Loop Road field site. The field experiments will be coupled with laboratory studies to collect the necessary data to describe heterogeneity in physical and chemical properties, and multi dimensional, multicomponent transport modeling to validate concepts and theories developed from laboratory measurements. In this work, we will develop the data set for evaluating models of competitive binding 
and exchange of reactive contaminants in chemically and physically heterogeneous soils as well as the techniques for obtaining field-scale parameters through the use of inverse modeling techniques.

The product will be an improved understanding of the relationships between the spatial variations in constitutive properties, observed flow, and reactive transport phenomena, and their scale dependence. This will improve our ability to develop representative conceptual and numerical models of vadose-zone flow and transport. Consequently, the VZTFS will support the core projects and ultimately the system assessment capability (SAC) through the identification of advanced monitoring and characterization technologies, provision of data for testing assessment models, and improved conceptual models based on observations from controlled field experiments. Conceptual models generally simplify the real system and provide a description of system geometry, initial and boundary conditions as well as physical and chemical processes occurring within the system, and constitutive properties that describe these processes. The parameter-scaling technique, developed to simplify the mathematical description of heterogeneous soils and to facilitate inverse modeling, was a result of research on this project (Ward et al. 2002; Zhang et al. 2002a,b,c). A new concept for state-dependent anisotropy was also developed under the EMSP following recognition that a more robust model was needed for interpretation of field experiments at Hanford (Ward et al. 2002; Zhang et al. 2003). This concept has been incorporated into STOMP and has already been successfully applied to the simulation of field-scale subsurface flow-and-transport simulations (Meyer et al. 2002; Rockhold et al. 2002; Murray et al. 2003; Ward et al. 2003). The improved conceptual model, including the new model for state-dependent anisotropy, is currently being applied to an analysis of the BC Cribs and Trenches with the goal of predicting subsurface distribution of ${ }^{99} \mathrm{Tc}$ that may have been discharged in these facilities. 


\subsection{Test Site}

The distribution of lithofacies, their sedimentary architecture, and other structural features are of fundamental importance to the analysis of transport behavior. However, many of the important subsurface features are often deep in the vadose zone and not directly accessible for observation. Representative outcrop analogues are the next best option for studying these features at the local scale. One such outcrop is located at the Clastic Dike Site on Army Loop Road.

The Clastic Dike Site was used as the primary test site for an EMSP-funded study (70193) of the effects of clastic dikes on vertical transport (Murray et al. 2001). The site is located near Antiaircraft Site H-42. The Washington State Plane coordinates are approximately $128500 \mathrm{~N}$ and $573500 \mathrm{E}$. Figure 2.1 shows the location of the site as just off the Army Loop Road due south of the 200 East Area. The site is essentially clean with no documented history of contamination. Ecological and Cultural Resource reviews of the site conducted during FY2000 and FY2001 found no impact due to proposed project activities.

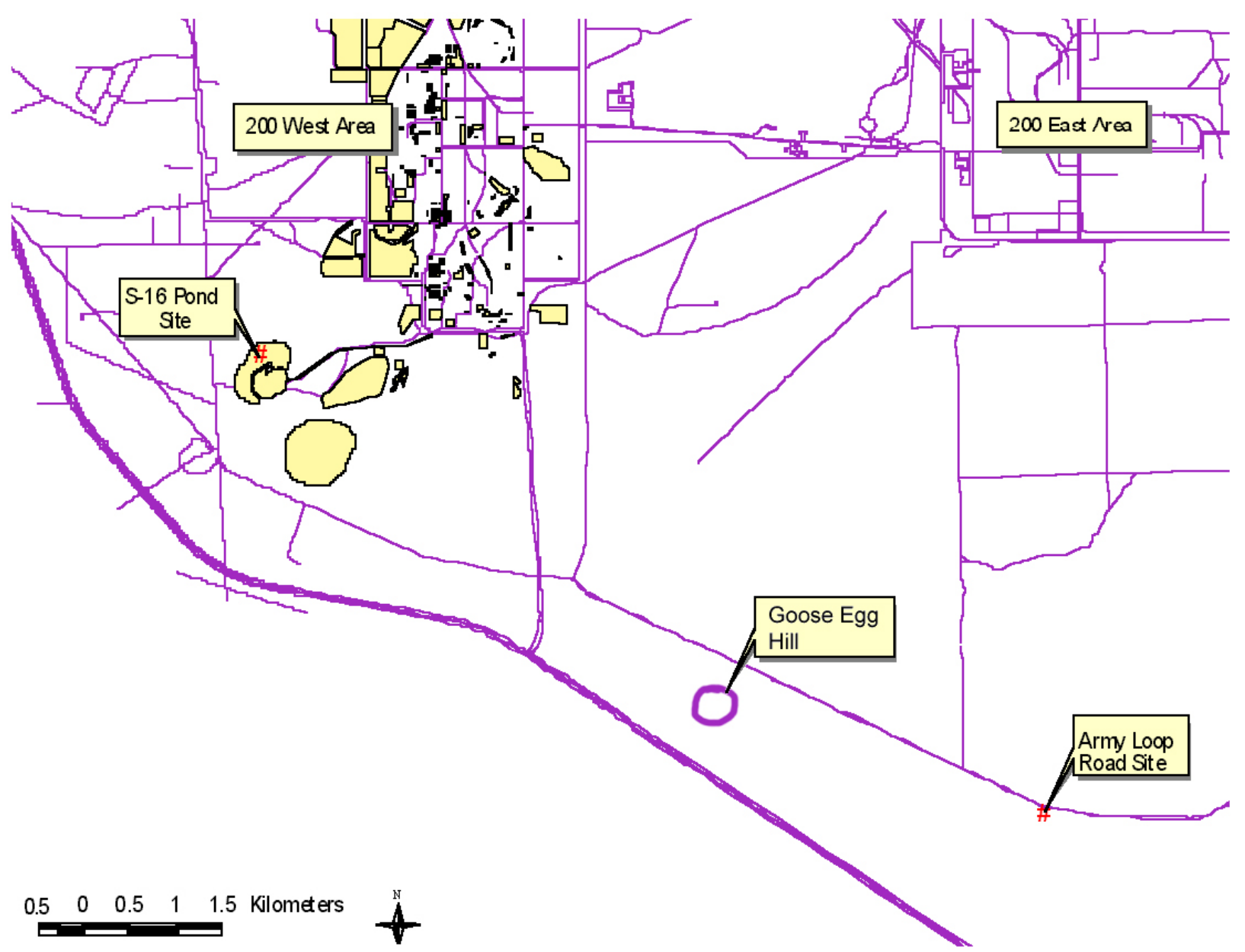

Figure 2.1. Location of the Primary and Secondary Sites for the Clastic Dike Study 


\subsection{Hydrogeology}

The site is located in the 200 East Area of Hanford's elevated 200-Area (Figure 2.1). More specifically, it is about $3 \mathrm{~km}(1.9 \mathrm{mi})$ south of the 200 East Separations Area, about $100 \mathrm{~m}(328 \mathrm{ft})$ south of Army Loop Road and $1.5 \mathrm{~km}(0.9 \mathrm{mi})$ east of Goose Egg Hill. The climate at the Hanford Site is arid with cool, wet winters and hot, dry summers. Precipitation at the Hanford Meteorological Station (HMS), located about $10 \mathrm{~km}(6.2 \mathrm{mi})$ west of the test site, has averaged $174 \mathrm{~mm}\left(6.85 \mathrm{in}\right.$.) $\mathrm{yr}^{-1}$ since 1946 . Nearly half of the precipitation normally comes in winter months (November through February). Average monthly temperature ranges from $-1.5^{\circ} \mathrm{C}$ in January to $25^{\circ} \mathrm{C}$ in July. Humidity ranges from $75 \%$ in winter to $35 \%$ or less in summer.

The upper portion of the 200-Area plateau formed during catastrophic glacial flooding. Flood sediments were deposited when ice dams in western Montana and northern Idaho were breached, and massive volumes of water spilled across eastern and central Washington. This process repeated itself numerous times before about 13,000 years, bringing to the Plateau a thick sequence of sediments known as the Hanford formation (Reidel and Horton 1999). The hydrogeology of clastic dikes, however, is uncertain. In plan view, the dikes form polygonal structures at the surface known as patterned ground identified by lush vegetation growth on the periphery of the polygons that are formed by the dikes. In the Columbia Basin, dikes typically occur in swarms and form four types of networks: 1) regular-shaped polygonal-patterns, 2) irregular-shaped, polygonal-patterns, 3) pre-existing fissure fillings, and 4) random occurrences. Regular polygonal networks, which are the most common type near the 200 West Area, resemble 4- to 8-sided polygons. Figure 2.2 shows an aerial photograph of the site in which the vegetation polygons are clearly visible. The demarcated circles (e.g. LF-KS, KS-KF) represent the end points of transects surveyed by surface-ground penetrating radar (GPR) and seismic methods (Ward and Gee 2002). The pattern of lush vegetation cover is referred to as a vegetation polygon, an example of which is shown in Figure 2.3.

Clastic dikes are typically vertical, sedimentary features that crosscut horizontal lithologic bedding. They are thought to have been caused by surface loading that caused a vertical injection of fine particulate material from below, but several different theories exist with regard to their origin. These events occurred due to cataclysmic flooding 13,000 years ago during the Pleistocene period. Dikes generally consist of laminated sand and silt, often with sand at the center and silt along the outer edges (silt/clay skins). The dikes in these networks typically range from $3 \mathrm{~cm}(1.2 \mathrm{in}$.) to $1 \mathrm{~m}(3.3 \mathrm{ft})$ in width, from $2 \mathrm{~m}(6.6 \mathrm{ft})$ to greater than $55 \mathrm{~m}(180 \mathrm{ft})$ in depth, and from 1.5 to $100 \mathrm{~m}(5.0$ to $328 \mathrm{ft})$ along strike. The material adjacent to the dikes in this area is sand to gravelly sand.

\subsection{Soils and Vegetation}

The surface soil at the site is a coarse sand, locally known as a Quincy sand, which is associated with the Quincy soil series (mixed, mesic, Xeric Torripsamments). The sand matrix has a high infiltration capacity $\left(>50 \mathrm{~mm}\left[>2 \mathrm{in}\right.\right.$. $\left.\mathrm{hr}^{-1}\right)$; thus, precipitation infiltrates readily with little or no runoff. At the microscopic or local scale, the clastic dike is composed of an outer lining or skin of clay and/or silt with coarser in-filling material or inclusions (Figure 2.3). The linings are commonly 0.03 to $1.0 \mathrm{~mm}(0.0012$ to $0.04 \mathrm{in}$.) in thickness, but can be as thick as $10 \mathrm{~mm}(0.4 \mathrm{in}$.). These linings may have a great influence on water flow and transport. The width of individual in-filling layers ranges from as little as $0.01 \mathrm{~mm}$ (0.0004 in.) to more than $30 \mathrm{~cm}(11.8 \mathrm{in}$.$) , and their length can vary from about 0.2 \mathrm{~m}(0.66 \mathrm{ft})$ to more 


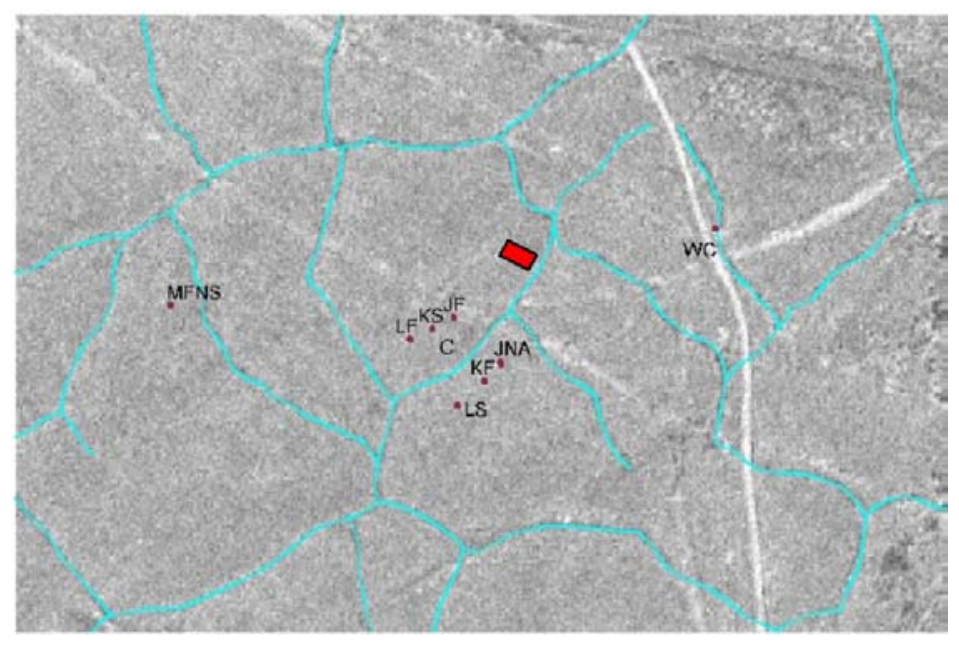

Figure 2.2. Aerial Photograph from July 13, 1996, Showing the Location of the test Site. The site is located near Anti-Aircraft Site H-42 at Coordinates $128500 \mathrm{~N}$ and $73500 \mathrm{E}$ on the Washington State Grid. Red lettered circles represent the end points of transects surveyed by GPR and seismic methods.

than $20 \mathrm{~m}$. In-filling sediments are typically poor to well-sorted sand, but may contain clay, silt, and gravel. At the macroscopic or regional scale, the vertical structures may serve as preferential paths, or impediments to flow, depending on the flow regime, whether conditions are saturated or unsaturated. The horizontal structures may act as capillary breaks, redirecting flow laterally until conditions are such that these layers can be penetrated. Given the range of structural, hydrogeological features present at this site, a wide range of geochemical characteristics might be also be expected. However, very little is known about transport properties at this time.

Vegetation at the site was originally a mixture of sagebrush, tumble mustard (Sisymbrium altissimum), cheatgrass (Bromus tectorum), Sandberg's bluegrass (Poa secunda), and bulbous bluegrass (Poa bulbosa). Tumble mustard is a summer annual species with a rooting depth of $1 \mathrm{~m}(3.3 \mathrm{ft})$ and greater and typically grows on the dikes, forming a outline of the polygons (Figure 2.3). Cheatgrass is a winter annual species with roots to $0.75 \mathrm{~m}(2.5 \mathrm{ft})$ and typically grows on the host matrix on the inside of the polygon. Sandberg's bluegrass is a native perennial bunchgrass with roots to $0.45 \mathrm{~m}(1.5 \mathrm{ft})$ while bulbous bluegrass a non native biennial grass with roots to $0.25 \mathrm{~m}(0.8 \mathrm{ft})$. Both of these species are typically found on the insides on the polygons growing on the host matrix. Much of the shrub population was removed by fire in the mid 80s and again in June 2000. Before the tests in FY 2001, remaining vegetation on the infiltration plot and the area to be excavated to expose the dike were cleared of any remaining vegetation. 


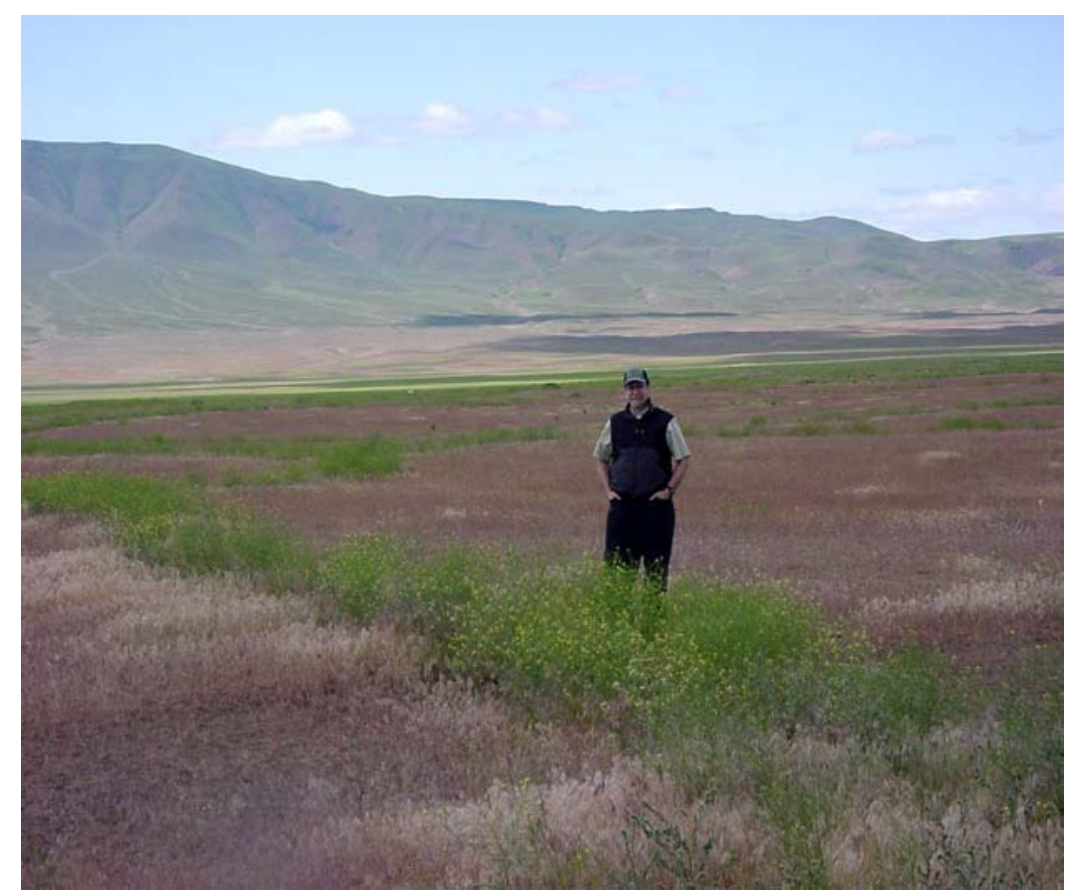

Figure 2.3. The Borders of Typical Vegetation Polygons at the Army Loop Road Site. The green shrub outlining the polygons is tumble mustard. The grasses growing in the polygon include cheatgrass, Sandberg's bluegrass and bulbous bluegrass. Rattlesnake Mountain is shown in the background while Mike Thompson of the DOE-RL is shown in the foreground.

\subsection{Monitoring Infrastructure}

Following the FY 2002 infiltration test, the experimental site is well instrumented. The experiments were conducted on a 60-m (197-ft) long transect at the Army Loop Road. Twin-rod time-domain reflectometry (TDR) probes are installed at $0.5-\mathrm{m}(1.6-\mathrm{ft})$ intervals along the transect to depths of $1.0 \mathrm{~m}(3.3 \mathrm{ft}), 0.8 \mathrm{~m}$ $(2.6 \mathrm{ft}), 0.4 \mathrm{~m}(1.3 \mathrm{ft})$, and $0.2 \mathrm{~m}(0.66 \mathrm{ft})$. The probes are constructed of $1 / 4$-in.-diameter stainless steel rods spaced $7.6 \mathrm{~cm}(3 \mathrm{in}$.) apart parallel to the transect. Probes are spaced $0.15 \mathrm{~m}(0.5 \mathrm{ft})$ apart perpendicular to the transect. The longest $(1 \mathrm{~m}[3.3 \mathrm{ft}])$ probe is installed along the mid line of the transect, near the line source, with probes of decreasing length installed with increasing distance from the line-source increase (Figure 2.4). At the outer edge of the transect, a second set of 1-m (3.3-ft) long probes were installed to capture any deeper lateral movement from the line source. These probes are installed on a 2-m (6.6-ft) interval along the transect. At 2-m $(6.6-\mathrm{ft})$ intervals along the transect, one stainless steel rod of the two-wire TDR probe was replaced with a stainless steel suction lysimeter configured to form a multipurpose TDR probe. This configuration was used only at the $0.4-$ and $0.8-\mathrm{m}$ (1.3- and 2.6-ft) depths. The probes served the dual purpose of monitoring matric potential, $\psi$, and collecting pore-water samples for tracer analysis. Measurements of $\psi$ are typically made during the transient phase of the experiment until steady-flow conditions are attained. At steady state, the tensiometers are drained and converted to suction lysimeters. At a location $30 \mathrm{~m}(98 \mathrm{ft})$ along the transect, sets of bimetallic thermocouples have been installed to depths of $0.1 \mathrm{~m}(0.3 \mathrm{ft}), 0.2 \mathrm{~m}(0.7 \mathrm{ft})$, and $0.8 \mathrm{~m}(2.6 \mathrm{ft})$ to monitor soil temperature. A miniature tipping bucket was also installed midway along each $10-\mathrm{m}(32.8-\mathrm{ft})$ block to monitor the flowrate from the irrigation system. Eight 2-in.-diameter 
PVC tubes, part of the infrastructure from the FY 2000 EMSP experiment, remained as part of the monitoring system for use with a cross-borehole GPR neutron probe. The layout of the transect, including the location of instrumentation and the PVC access tubes, is illustrated in Figure 2.5. A polyethylene surface cover is used to minimize evaporation, keep out natural precipitation, and insulate electrical connections from contact with the soil surface.

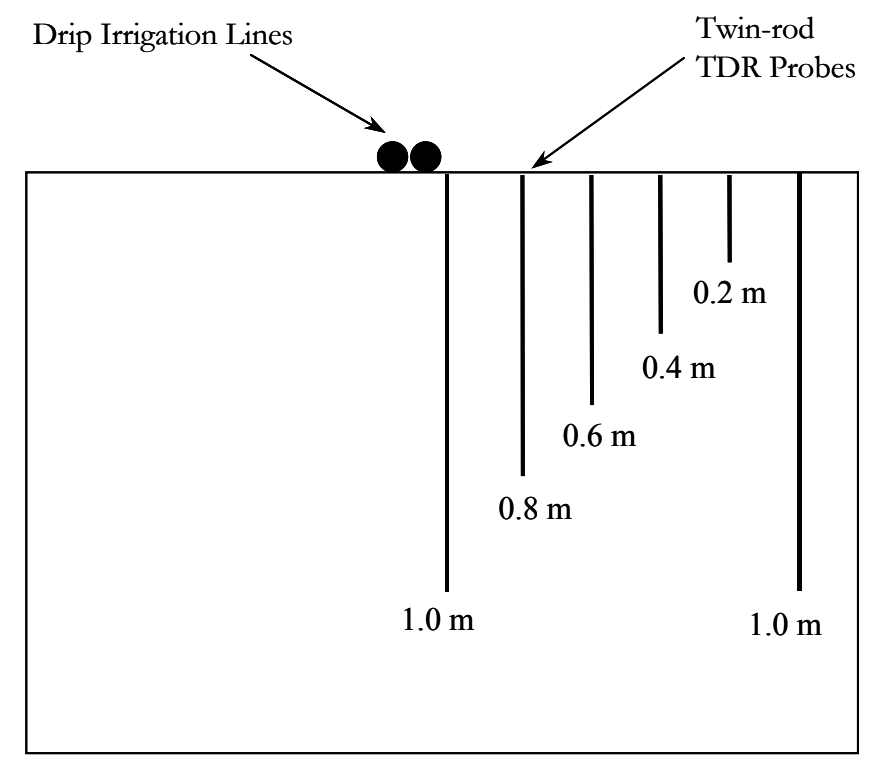

Figure 2.4. Schematic of Probe Installations. Each probe consists of a 2-rod TDR probe with a 5-cm (2-in.) inter rod spacing. Probes are spaced $0.5 \mathrm{~m}$ (1.6-ft) apart, parallel to the long axis of the trench, and $0.15 \mathrm{~m}(0.5 \mathrm{ft})$ perpendicular to the long axis.

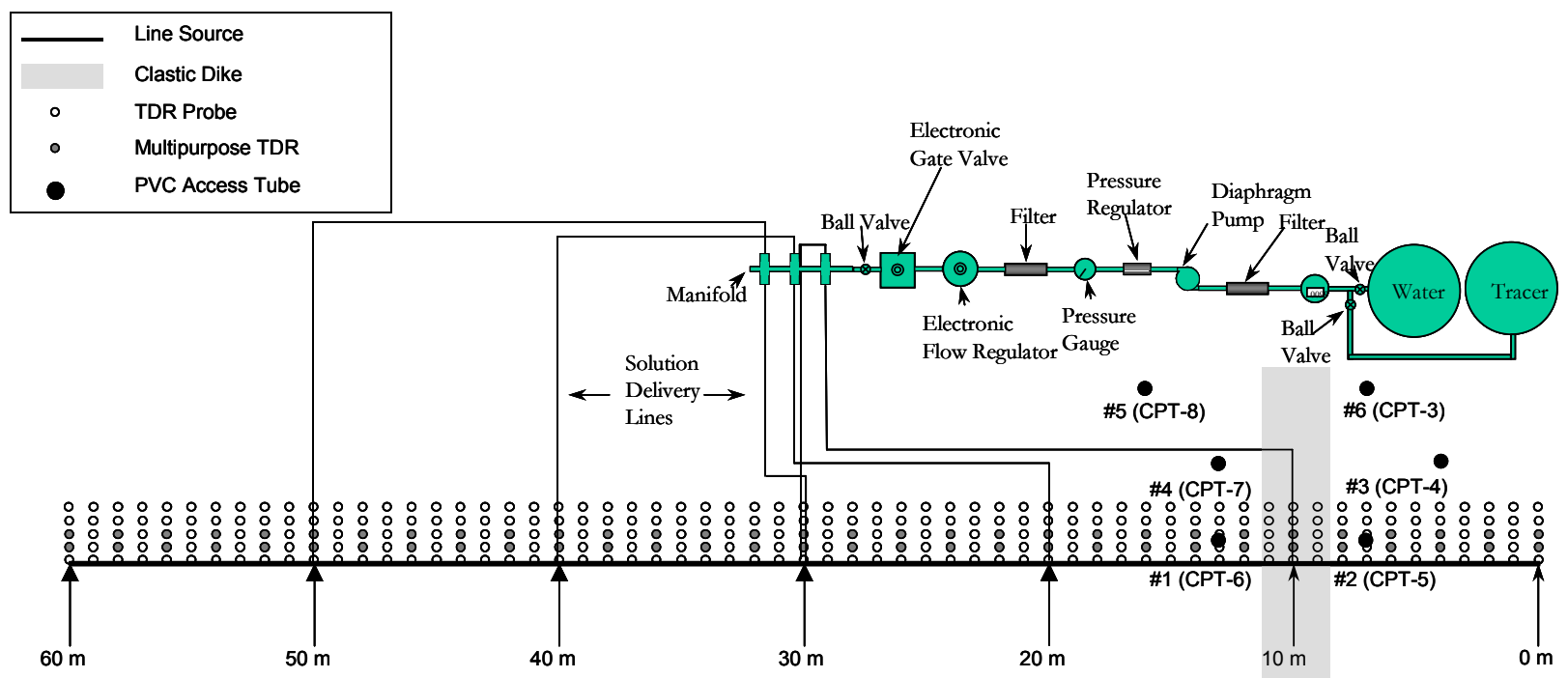

Figure 2.5. Schematic Layout Showing Common Offset Profiles and Borehole Radar Locations 
The upper surface boundary condition is a controlled drip-irrigation system, programmable to apply water at different input fluxes. Figure 2.6 is a photograph of the plot, just before it was covered with the plastic sheeting. Additional details on the instrumentation, experiment design, and monitoring protocol are discussed by Ward et al. (2002).

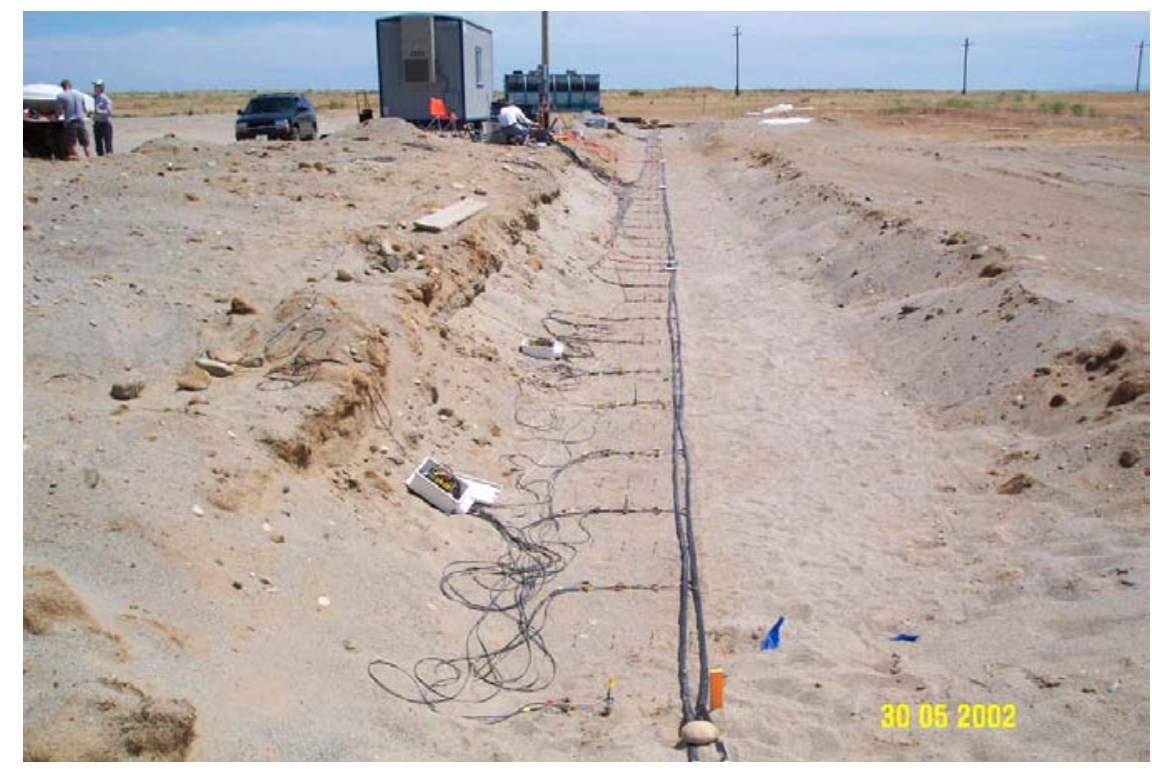

Figure 2.6. The FIELD SITE During Instrumentation Looking in an Easterly Direction Along the Transect. The TDR Probes were installed at 50-cm (20-in.) spacing, but measurements were made at 1.0-m (3.3-in.) spacing. Intermediate probes were used for High Resolution Resistivity Measurements. Multipurpose TDR (TDR + tensiometer) were installed on a 2.0-m (6.6-ft) spacing. A 16-channel TDR multiplexer is shown in the foreground at the left.

\subsection{Existing Characterization Data}

Efforts to measure the hydraulic properties of clastic dikes have been limited. Until recently, the only known measurements were those reported by Fecht et al. (1998), who used laboratory and small-scale field tests to determine the effective hydraulic conductivity of clastic dikes and their host sediments. At the center of dikes, the average saturated hydraulic conductivity was reported to be about $10^{-5} \mathrm{~m} \mathrm{~s}^{-1}$. Across the clay linings, the saturated hydraulic conductivity was reported to vary from $10^{-6}$ to $10^{-9} \mathrm{~m} \mathrm{~s}^{-1}$. The saturated hydraulic conductivity of the host sediment was reported to be about $10^{-5} \mathrm{~m} \mathrm{~s}^{-1}$.

In 2001, under the EMSP project, the small-scale hydrogeologic properties of clastic dikes were investigated at the existing field site at Army Loop Road (Ward et al. 2003; Murray et al. 2003). The site was trenched with a backhoe to a depth of $\sim 3.5 \mathrm{~m}$. The exposed clastic dike, which is in sand-dominated facies of the Hanford formation, was characterized using a variety of techniques. In situ techniques employed included air permeability as well as visible and infrared (IR) imagery. Laboratory analyses included granulometry, moisture contents, x-ray diffraction (XRD) measurements of the mineralogy, GPR, neutron probe log, TDR, and tensiometetry (Murray et al. 2003). In the FY2002 experiments, the characterization work continued with in situ measurements of hydraulic and transport properties under a 
rage of fluxes (Ward et al. 2003). In addition, a number of soils samples were collected for laboratory determination of water retention, directional hydraulic conductivities, and physical and chemical properties. Figure 2.7 shows a vertical section of the dike outcrop on Tier 2 and the areas where samples were taken for laboratory characterization.

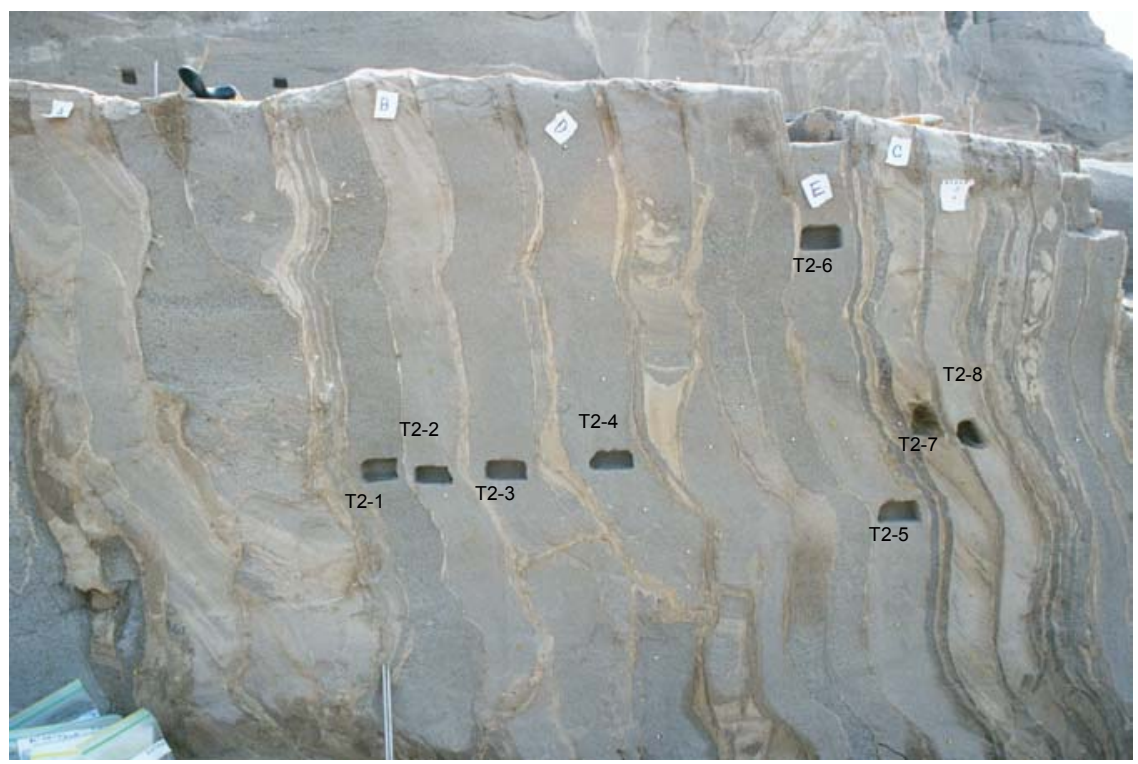

Figure 2.7. Vertical Section of Tier 2 of the Army Loop Road Excavation Showing the Small-Scale Structure of Heterogeneity. Note the vertical and horizontal structures, the finetextured skins, and the inclusions of varying texture. The rectangular holes are areas where samples were collected for granulometric analysis.

\subsubsection{Particle-size Distributions}

A total of 77 samples were collected from the site and analyzed for particle-size distributions. Particlesize analyses were conducted on the $<2 \mathrm{~mm}(<0.08 \mathrm{in}$.) size fraction using a combination of sieving and hydrometer techniques (Gee and Bauder 1986). Dry sieving was performed using sieves with openings of $2,1,0.5,0.25,0.106,0.075$, and $0.053 \mathrm{~mm}(0.08,0.04,0.02,0.01,0.004,0.003$, and $0.002 \mathrm{in}$.) with final collection in the pan. Silt- and clay-sized fractions were determined by hydrometer. Particle density was also performed on the $<2 \mathrm{~mm}(<0.08 \mathrm{in}$.) size fraction using the pycnometer method (Blake and Hartge 1986, pp. 363-375). Bulk-density measurements were conducted on undisturbed samples using the clod method, and porosity was estimated using the bulk density of undisturbed samples and the average particle density as $\phi=1-\rho_{\mathrm{b}} / \rho_{\mathrm{s}}$. Additional samples collected at the end of the last field tests are currently being analyzed. Figure 2.7 shows the locations where samples were collected for granulometric analysis.

Figure 2.8 shows a log-probability plot of particle diameter, $d$, as a function of cumulative mass percent less than $d$ for samples. The wide range of textures exemplifies the variability at the field site. Even though these samples were all from material that is from the sand-dominated Upper Hanford formation, or appears to be derived from that material, there were many samples with size distributions reflecting a finer texture relative to the typical Hanford sand. Soil textures, derived from the ratio of sand, silt, and clay, ranged from coarse sands (AL-HT2-1) with over $95 \%$ sand for matrix sample, to medium and fine sands (AL-CDT2-2) in coarse segments of the clastic dike, to loam and silt loam (AL-CD-T2-7) 
with as much as $19 \%$ clay in the fine-grained portions of the clastic dike. This wide variation in particlesize distribution can be expected to influence water-retention characteristics and permeability and ultimately the flow-and-transport properties under unsaturated conditions.

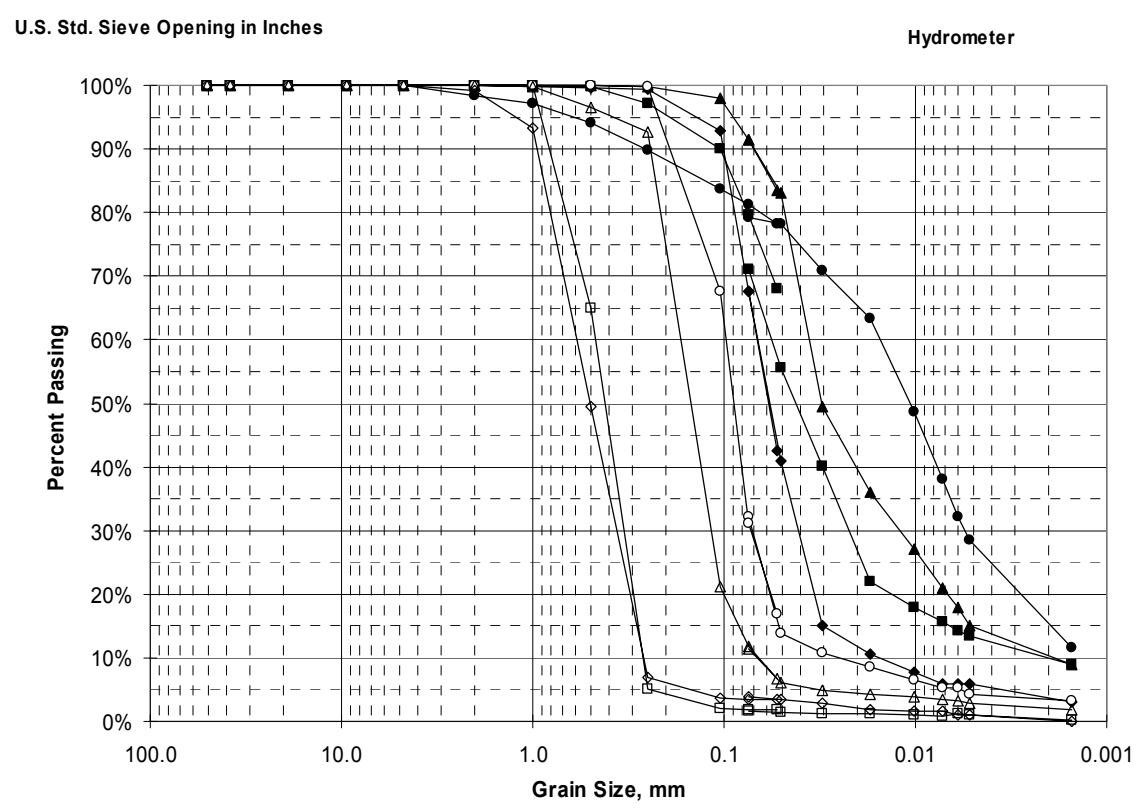

Figure 2.8. Graphical Comparison of Particle-size Distribution from $<2 \mathrm{~mm}$ Fractions from the Army Loop Road Field Site. Essentially five textures were identified from the analyses - silt loam (e.g., IN-A1-5, •), loam (e.g., AL-CD-T3-1,匹 ); sandy loam (e.g., AL-CD-T2-8, ); loamy sand (e.g., AL-CDT2-5, ○); and sand (e.g., Al-HT4-1, $\square$ ).

\subsubsection{Hydraulic Properties}

Efforts to measure the hydraulic properties of clastic dikes have been limited. Until recently, the only known measurements were those reported by Fecht et al. (1998), who used laboratory and small-scale field tests to determine the hydraulic conductivity of clastic dikes and their host sediments. At the center of dikes, the average saturated hydraulic conductivity was reported to be about $10^{-5} \mathrm{~m} \mathrm{~s}^{-1}$. Across the clay linings, the saturated hydraulic conductivity varied from $10^{-6}$ to $10^{-9} \mathrm{~m} \mathrm{~s}^{-1}$. The saturated hydraulic conductivity of the host sediment was about $10^{-5} \mathrm{~m} \mathrm{~s}^{-1}$. Given the range of particle-size distributions and the strong dependence of hydraulic properties on particle-size distributions, sharp contrasts in porosity, pore size, and pore continuity can be expected. At the local scale, not even the primary regions can be regarded as homogenous media, so it is unlikely that a spatially averaged set of properties can adequately describe flow-and-transport behavior at this site or typical waste sites at Hanford. Collecting undisturbed samples for laboratory measurement of hydraulic properties has also proven quite difficult and was only completed at the end of the last experiment. These samples are currently being analyzed. In the interim, hydraulic properties for use as input into numerical models have been derived from the granulometric data using methods described by Campbell (1974).

Particle-size distributions are mostly log normally distributed and are described with a geometric mean grain diameter, $d_{g}$, and a geometric standard deviation, $\sigma_{\mathrm{g}}$. These parameters were computed from particle distributions by calculating the contribution of each of the textural fractions of sand, silt, and clay. The model of Brooks and Corey (1964) has been used to represent the relationship between relative 
permeability, saturation, and matric potential. The relationship between saturation and matric potential is written as:

$$
\mathrm{S}_{\mathrm{w}}(\psi)=\frac{\theta-\theta_{\mathrm{r}}}{\theta_{\mathrm{s}}-\theta_{\mathrm{r}}}=\left(\frac{\psi_{\mathrm{e}}}{\psi}\right)^{\lambda} ; \quad \psi \geq \psi_{\mathrm{ae}}
$$

where $\mathrm{S}_{\mathrm{w}}=$ effective saturation

$\psi=$ capillary pressure

$\psi_{\mathrm{ae}}=$ air entry matric potential

$\lambda=$ empirical parameter related to the pore size distribution

$\theta=$ volumetric water content

$\theta_{\mathrm{s}}=$ water content at saturation

$\theta_{\mathrm{r}}=$ irreducible water content.

The power of the $\theta(\psi)$ function, $\lambda$, was also estimated from the particle-size data according to

$$
\lambda=\left[\mathrm{d}_{\mathrm{g}}^{-0.5}+0.2 \sigma_{\mathrm{g}}\right]^{-1}
$$

Similarly, the matric potential at air entry, $\psi_{\text {ae }}$, was also estimated from particle-size information according to

$$
\psi_{\mathrm{ae}}=-0.5 \mathrm{~d}_{\mathrm{g}}^{-0.5}\left(\frac{\varrho_{\mathrm{b}}}{1.3}\right)^{\frac{0.67}{\lambda}}
$$

where $\rho_{\mathrm{b}}$ is bulk density. Relative permeabilities were computed as a function of saturation using a modified form of the Burdine (1953) relative permeability model that was integrated using the Brooks and Corey (1964) $\theta(\psi)$ function defined in Eq. 2. The relative permeability model is written as

$$
\mathrm{k}_{\mathrm{r}}=\frac{\mathrm{K}\left(\mathrm{S}_{\mathrm{w}}\right)}{\mathrm{K}_{\mathrm{s}}}=\left(\mathrm{S}_{\mathrm{w}}\right)^{\varepsilon+2 / \lambda}
$$

where $\mathrm{K}_{\mathrm{s}}=$ saturated hydraulic conductivity

$\mathrm{K}\left(\mathrm{S}_{\mathrm{w}}\right)=$ unsaturated hydraulic conductivity

$\varepsilon=l+1$ for the Burdine (1953) model and $l+2$ for the Mualem (1976) model

$l=$ pore interaction term.

The pore interaction term may take values of 1.0 (Burdine 1953); 0.5 (Mualem 1976), or -2.0 (Miller and Miller 1956). In anisotropic soils, both $\mathrm{k}_{\mathrm{s}}$ and $\mathrm{m}$ can be tensors, with a different value of $\mathrm{m}$ being assigned to each principle direction (Ward et al. 2002; Zhang et al. 2003). The saturated water content, $\theta_{\mathrm{s}}$, was estimated as the product of $\phi$ and the effective porosity. Typical values of effective porosity range from 0.80 to 0.95 (Arya et al. 1999).

In situ measurements of saturated hydraulic conductivity, $\mathrm{K}_{\mathrm{s}}$, have been made using the Guelph Permeameter (Reynolds and Elrick 1985). The mean $\mathrm{K}_{\mathrm{fs}}$ for the host matrix from the Guelph Permeameter measurements is $3.24 \cdot 10^{-4} \mathrm{~m} \mathrm{~s}^{-1}$; the mean $\mathrm{K}_{\mathrm{fs}}$ of the dike was $2.58 \times 10^{-5} \mathrm{~m} \mathrm{~s}^{-1}$ while the mean $\mathrm{K}_{\mathrm{fs}}$ of the sill was $5.9 \cdot 10^{-6} \mathrm{~m} \mathrm{~s}^{-1}$ (Ward et al. 2003). Several measurements of $\mathrm{k}_{\mathrm{s}}$ were also made 
along the Tier 2 transect with a mini-disk infiltrometer according to the method of Zhang (1997). Measurements were taken every $0.3 \mathrm{~m}(1 \mathrm{ft})$ along a $7.5-\mathrm{m}(24.6-\mathrm{ft})$ transect using mini-permeameters filled with deionized water. There is an order of magnitude difference between the sand $\left(2.29 \times 10^{-4} \mathrm{~m} \mathrm{~s}^{-1}\right)$ to the dike composite $\left(2.04 \times 10^{-5} \mathrm{~m} \mathrm{~s}^{-1}\right)$ with the lens $\left(9.68 \times 10^{-5} \mathrm{~m} \mathrm{~s}^{-1}\right)$ being almost five times slower. The mean $\mathrm{K}_{\mathrm{s}}$ in the dike material was $1.48 \times 10^{-8} \mathrm{~m} \mathrm{~s}^{-1}$. Details of the conductivity measurements and their statistics were summarized in Ward et al. (2003). Several hundred airpermeability measurements were also conducted with a mini air permeameter and the method described by Tidwell and Wilson (1997). Air-permeability measurements show a strong correlation with the infiltrometer measurements and are summarized by Murray et al. (2003). Table 2.1 provides a summary of granulometric and the calculated properties. A more in-depth discussion of these properties and their derivation is presented by Ward et al. (2003).

Table 2.1. Measured Grain Size Characteristics, Permeability, and Predicted Hydraulic Properties for Representative Textures at the Army Loop Road Site. Water retention is described by the Brooks and Corey (1964) Function.

\begin{tabular}{|c|c|c|c|c|c|c|c|c|c|c|c|c|c|}
\hline Sample & $\%$ \% & $\%$ si & \% cl & Class & $\mathbf{d}_{\mathrm{g}}(\mathbf{m m})$ & $\sigma_{\mathrm{g}}$ & $\mathrm{k}_{\mathrm{a}}\left(\mathrm{mm}^{2}\right)$ & $\bar{~} \mathrm{k}_{\mathrm{w}}\left(\mathrm{mm}^{2}\right)$ & $\mathrm{K}_{\mathrm{s}}\left(\mathrm{cm} \mathrm{s}^{-1}\right)$ & $\lambda$ & $\psi_{\text {ae }}(\mathrm{cm})$ & $\theta_{\mathrm{s}}$ & $\theta_{\mathrm{r}}$ \\
\hline INFII & 0.24 & 0.58 & 0.19 & si loam & 0.0342 & 9.5528 & $1.137 \cdot 10^{-7}$ & $7.839 \cdot 10^{-8}$ & $8.615 \cdot 10^{-5}$ & 0.14 & 67.40 & .42 & 090 \\
\hline$\overline{A L-C}$ & 0.31 & 0.58 & 0.11 & si loam & 0.0570 & 8.7240 & $2.855 \cdot 10^{-7}$ & $9.559 \cdot 10^{-8}$ & $1.051 \cdot 10^{-4}$ & \begin{tabular}{|l|}
0.17 \\
\end{tabular} & 44.12 & 0.413 & 0.090 \\
\hline AL-C & 0.44 & 0.45 & 0.11 & loam & 0.0937 & 10.3986 & $1.833 \cdot 10^{-7}$ & $1.316 \cdot 10^{-7}$ & $447 \cdot 10^{-4}$ & \begin{tabular}{|l|}
0.19 \\
\end{tabular} & 2.03 & 0.413 & 0.035 \\
\hline AL-CDT2-8 & 0.64 & 0.32 & 0.04 & s loam & 0.2434 & 7.4220 & 6.10 & 4.85 & 5.33 & 0.28 & 15.88 & 0.413 & 0.035 \\
\hline AL-CDT2-5 & 0.86 & 0.10 & 0.04 & 1. sand & 0.5466 & 5.2172 & $10^{-6}$ & 6.81 & 7.49 & 0.42 & 9.25 & 0.42 & 0.027 \\
\hline AL-CDT2-2 & 0.90 & 0.07 & 0.03 & $\mathrm{~s}$ & 0.6557 & 4.1797 & 1.6 & 1.7 & 1.9 & 0.48 & 8.11 & 0.405 & 0.020 \\
\hline AL-HT4-1 & 0.95 & 0.01 & 0.04 & $\mathrm{~s}$ & 0.7546 & 3.9771 & $10^{-5}$ & $4.172 \cdot 10^{-5}$ & $\cdot 10^{-2}$ & 0.51 & 7.45 & 0.35 & 0.020 \\
\hline AL-H & 0.97 & 0.01 & 0.02 & $\mathrm{~s}$ & 0.8542 & 2.9114 & $8.250 \cdot 10^{-5}$ & $9.947 \cdot 10^{-5}$ & $1.093 \cdot 10^{-1}$ & 0.60 & 6.76 & 0.350 & 0.017 \\
\hline AL-HT1-1 & 0.98 & 0.02 & 0.00 & $\mathrm{~s}$ & 0.9478 & 1.7931 & $1.750 \cdot 10^{-5}$ & $2.248 \cdot 10^{-4}$ & $2.471 \cdot 10^{-1}$ & 0.72 & 6.21 & 0.35 & 0.015 \\
\hline
\end{tabular}

The geometric mean diameter, $\mathrm{d}_{\mathrm{g}}$, clearly is a good indicator of permeability. In general, permeability increases with an increase in $\mathrm{d}_{\mathrm{g}}$. Thus, in highly complex sediments in which heterogeneity is manifested at multiple scales, estimates of $d_{g}$ may prove useful for estimating permeability, or vice versa, in, for example, thin lenses that cannot be characterized by conventional vadose-zone techniques. Figure 2.9 shows a plot of air permeability as a function of $d_{g}$ for the experimental site. A scatter plot of the entire data set showed distinct populations of $\mathrm{k}_{\mathrm{a}}$, one with a range of $10^{-6}$ to $10^{-5}$, corresponding to the sand measurements, and another in the range of $10^{-11}$, corresponding to the very fine sand and silt measurements. The sums of square residual error resulting from fitting a single curve to the entire data set was quite large, and the two ranges were fit separately. Figure $2.9 \mathrm{a}$ shows a semi $-\log$ plot of $\mathrm{k}_{\mathrm{a}}$ as a function of $\mathrm{d}_{\mathrm{g}}$ for the fine-textured sediments while Figure $2.9 \mathrm{~b}$ shows the relationship for the coarser sediments. The resulting coefficient of determination, $\mathrm{r}^{2}$, was $96 \%$ for the fine-textured sediments and $90 \%$ for the coarse sediments. These values represent a significant improvement over the $16 \%$ that resulted from a fit of the entire data set as a single population. The somewhat lower value of $\mathrm{r}^{2}$ for the coarse sediments is most likely due to the existence of sub populations. These sub populations are the result of the range of $d_{g}$ in this population as textures ranged from fine sands to very coarse sands. However, the number of observations was not large enough to warrant further separation. 

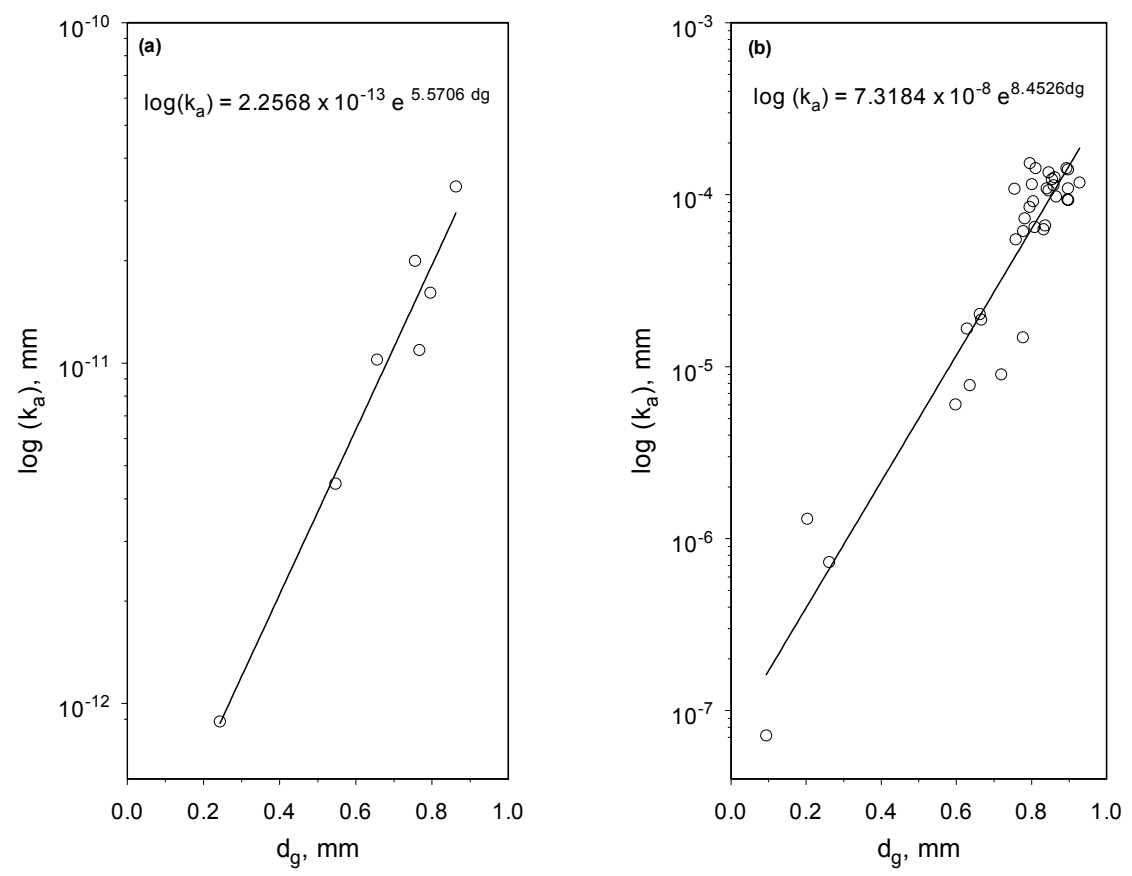

\section{Figure 2.9. Observed and Predicted Relationship Between Air Permeability $\left(\mathrm{mm}^{2}\right)$ and Geometric Mean Diameter (mm): (a) Fine-Textured Sediments, (b) Coarse-Textured Sediments}

However, it should be noted that while permeability increases with geometric mean grain size, it may decrease with the degree of sorting decreases. In poorly sorted sediments, i.e., sediments with a wide range of particle sizes, finer materials can occupy the large pores between the larger particles, leading to a reduction in permeability. Thus, $\mathrm{d}_{\mathrm{g}}$ alone may be inadequate for estimating the permeability of unsampled locations. As observed in many of the samples, natural sediments can have a common $\mathrm{d}_{\mathrm{g}}$ but have wide range in the amount of fines. Both permeability and pore size are influenced by the grain-size distribution, and to further quantify the distribution, we use the geometric standard deviation, $\sigma_{\mathrm{g}}$. Perfectly sorted sediments, i.e., with a single grain size, would have a low $\sigma_{\mathrm{g}}$ while imperfectly sorted sediments would show larger values of $\sigma_{\mathrm{g}}$. The latter case implies that pores between large grains are filled with smaller grains that might reduce permeability. As a result, $\sigma_{\mathrm{g}}$ could be expected to vary inversely with permeability.

Thus, there are two parameters derived from particle-size distributions could be used to estimate permeability: $\mathrm{d}_{\mathrm{g}}$, which varies directly with pore size and permeability, and $\sigma_{\mathrm{g}}$, a measure of the range of particle sizes in the distribution, or an index of sorting, which might be expected to vary inversely with permeability. A plot of permeability versus a ratio of $\mathrm{d}_{\mathrm{g}}$ to $\sigma_{\mathrm{g}}$ provides an index of permeability dependence on particle size and sorting. A perfectly sorted sediment with a single grain size would have an index equal to the geometric mean, resulting in a $\mathrm{d}_{\mathrm{g}} / \sigma_{\mathrm{g}}=1$. In sediments with the same $\mathrm{d}_{\mathrm{g}}, \mathrm{d}_{\mathrm{g}} / \sigma_{\mathrm{g}}$ would be expected to decrease as the index increases. In this regard, soils with small geometric mean diameter show lower permeabilities than coarse soils even when $\mathrm{d}_{\mathrm{g}} / \sigma_{\mathrm{g}}=1$, simply because the pores are smaller. Conversely, soils with large $\mathrm{d}_{\mathrm{g}}$ could be slowly permeable when $\mathrm{d}_{\mathrm{g}} / \sigma_{\mathrm{g}}$ is large because the large pore spaces are filled with finer-texture materials that impede flow. Using these relationships, either $\mathrm{d}_{\mathrm{g}}$ or permeability could be predicted for an entire heterogeneous outcrop based on well-distributed measurements of one of these variables. Figure 2.10 compares the distribution of permeability for the 
outcrop, derived from the correlations described above. Modeling reactive transport under such heterogeneity will require distributions of transport properties on a similar spatial scale or techniques to upscale a smaller number of observations to the scale of the model grid block.

\subsubsection{Transport Properties}

To date, only a preliminary analysis of transport properties has been completed for the study site (Ward et al. 2003). Parameter estimation was limited to fitting the CDE under the assumption of a uniform moisture-content distribution to the depth of observation and time-moment analysis. Although limiting, these assumptions can be used to provide bounding values for transport properties while the inverse model for transport is being completed. Local-scale parameters estimated from flux-averaged and volume-averaged breakthrough curves are summarized in Table 3.2. There is need for caution in the interpretation of the spatially averaged transport parameters. While the resident concentrations can be easily averaged to obtain the field-scale values, simple averages of the flux concentrations may not be physically meaningful. Physically meaningful flux-averaged flux concentrations require weighting of the local concentrations by the local-scale hydraulic fluxes so that the transformation of the CDE remains
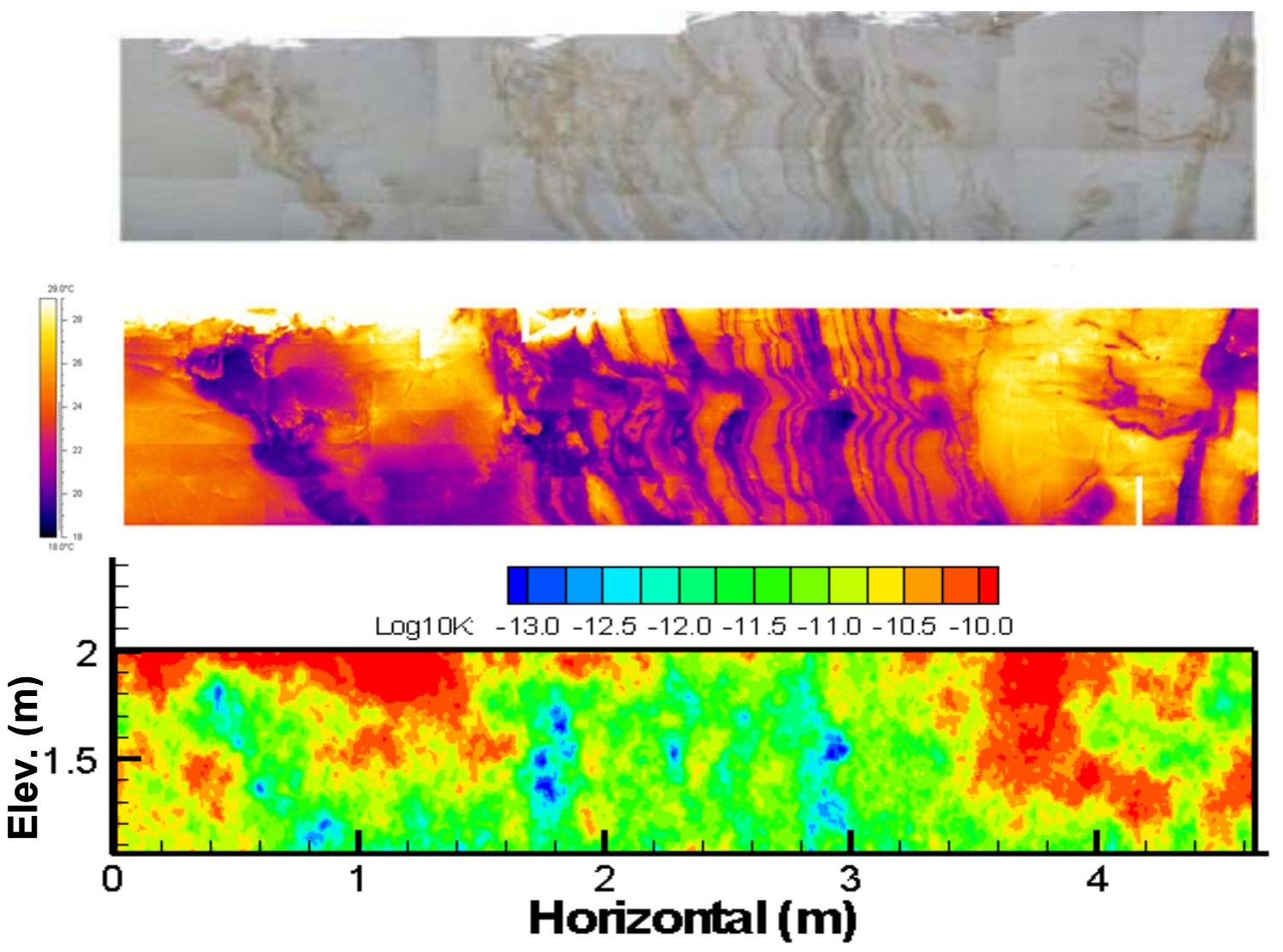

Figure 2.10. Spatial Variability at Tier2 Outcrop: (a) Visible Image Showing Spatial Variation in Soil Textures, (b) Measured Infrared Temperatures, and (c) Upscaled Vertical Saturated Hydraulic Conductivity, Inferred from the Relationship Between Geometric Mean Grain Size and Intrinsic Permeability 
valid. Local-scale fluxes have not been determined at this stage, but can be easily calculated from the local-scale changes in water storage derived from TDR measurements. These data, coupled with estimates of hydraulic properties, are sufficient to allow performance of pre-injection modeling of the reactive transport experiment. The only other requirement is information on the reactive transport parameters, including cation exchange capacity (CEC) for the site and selectivity coefficients for the cations of interest.

Table 2.2. Fitted Transport Parameters for the 2-D CDE from the First Experiment

\begin{tabular}{|c|c|c|c|c|c|c|c|c|c|c|c|c|c|c|}
\hline \multirow[b]{2}{*}{ Analysis } & \multirow[b]{2}{*}{ Parameter } & \multicolumn{13}{|c|}{ Horizontal Distance (m) } \\
\hline & & 0.0 & 2.0 & 4.0 & 6.0 & 8.0 & 10.0 & 12.0 & 14.0 & 16.0 & 18.0 & 20.0 & 22.0 & 24.0 \\
\hline \multirow[t]{7}{*}{ 2-D CDE } & $V_{z}\left(m^{-1}\right)$ & 0.117 & 0.088 & 0.078 & 0.071 & 0.114 & NA & 0.034 & 0.001 & $\overline{\mathrm{NA}}$ & $\overline{N A}$ & 0.083 & \begin{tabular}{|l|}
0.090 \\
\end{tabular} & 0.139 \\
\hline & $V_{y}\left(m^{-1}\right)$ & 0.024 & 0.016 & 0.014 & 0.007 & 0.012 & NA & 0.000 & 0.003 & NA & NA & 0.014 & \begin{tabular}{|l|}
0.017 \\
\end{tabular} & 0.026 \\
\hline & $D_{z}\left(m^{2} d^{-1}\right)$ & 0.016 & 0.008 & 0.005 & 0.000 & 0.020 & NA & 0.000 & \begin{tabular}{|l|l|}
0.109 \\
\end{tabular} & NA & NA & 0.005 & \begin{tabular}{|l|}
0.011 \\
\end{tabular} & 0.019 \\
\hline & $D_{y}\left(m^{2} d^{-1}\right)$ & 0.001 & 0.000 & 0.000 & 0.000 & 0.000 & NA & 0.000 & 0.000 & NA & NA & 0.000 & \begin{tabular}{|l|}
0.000 \\
\end{tabular} & 0.000 \\
\hline & $\lambda_{z}(\mathrm{~m})$ & 0.137 & 0.091 & 0.064 & 0.005 & 0.175 & NA & 0.011 & 101.77 & NA & NA & 0.059 & 0.122 & 0.137 \\
\hline & $\lambda_{y}(m)$ & 0.026 & 0.019 & 0.020 & 0.004 & 0.025 & NA & 5.049 & 0.024 & NA & $\mathrm{NA}$ & 0.012 & \begin{tabular}{|l|}
0.021 \\
\end{tabular} & 0.018 \\
\hline & & \multicolumn{13}{|c|}{ Horizontal Distance (m) } \\
\hline \multirow[t]{6}{*}{ 2-D CDE } & $V_{z}\left(m^{-1}\right)$ & 0.131 & 0.011 & .169 & 0.024 & 0.085 & 0.066 & 0.090 & 0.241 & 0.214 & 0.144 & 0.231 & 0.464 & $\overline{\mathrm{NA}}$ \\
\hline & $V_{y}\left(m^{-1}\right)$ & 0.030 & 0.003 & 0.126 & 0.004 & 0.008 & 0.012 & 0.021 & 0.028 & 0.013 & 0.027 & 0.040 & 0.050 & $\overline{\mathrm{NA}}$ \\
\hline & $D_{z}\left(m^{2} d^{-1}\right)$ & 0.011 & 0.008 & 0.005 & 0.006 & 0.021 & 0.003 & 0.003 & 0.019 & 0.089 & 0.016 & 0.030 & 0.067 & $\overline{\mathrm{NA}}$ \\
\hline & $D_{y}\left(m^{2} d^{-1}\right)$ & $\overline{001}$ & 001 & 0.018 & 0.000 & 0.001 & 0.002 & 0.001 & 0.001 & 0.001 & 0.001 & 0.001 & 0.000 & $\overline{\mathrm{NA}}$ \\
\hline & $\lambda_{z}(\mathrm{~m})$ & 0.084 & 0.733 & 0.032 & 0.248 & 0.247 & 0.050 & 0.038 & 0.079 & 0.416 & 0.111 & 0.130 & 0.144 & NA \\
\hline & $\lambda \lambda_{y}(m)$ & 0.019 & 0.273 & 0.143 & 0.033 & 0.085 & 0.132 & 0.026 & 0.030 & 0.052 & 0.021 & 0.023 & 0.005 & NA \\
\hline
\end{tabular}

Table 2.3. Fitted Transport Parameters for the 2-D CDE from the Second Experiment

\begin{tabular}{|c|c|c|c|c|c|c|c|c|c|c|c|c|c|c|}
\hline \multirow[b]{2}{*}{ Analysis } & \multirow[b]{2}{*}{ Parameter } & \multicolumn{13}{|c|}{ Horizontal Distance (m) } \\
\hline & & 0.0 & 2.0 & 4.0 & 6.0 & 8.0 & 10.0 & 12.0 & 14.0 & 16.0 & 18.0 & 20.0 & 22.0 & 24.0 \\
\hline \multirow[t]{7}{*}{ 2-D CDE } & $V_{z}\left(m^{-1}\right)$ & 0.243 & 0.041 & 0.038 & 0.730 & 0.000 & 0.009 & $\mathrm{NA}$ & 0.009 & 0.021 & 0.084 & 0.098 & 0.143 & 0.199 \\
\hline & $\mathbf{V}_{\mathrm{y}}\left(\mathrm{m} \mathrm{d}^{-1}\right)$ & 0.195 & 0.008 & 0.007 & 0.013 & 0.000 & 0.002 & $\mathrm{NA}$ & 0.002 & 0.008 & 0.015 & 0.021 & 0.026 & 0.037 \\
\hline & $D_{z}\left(m^{2} d^{-1}\right)$ & 0.020 & 0.000 & 0.015 & 0.037 & 0.091 & 0.179 & $\mathrm{NA}$ & 0.011 & 0.031 & 0.003 & 0.010 & 0.013 & 0.018 \\
\hline & $D_{y}\left(m^{2} d^{-1}\right)$ & 0.256 & 0.259 & 0.001 & 0.001 & 0.003 & 0.004 & NA & 0.001 & 0.000 & 0.000 & 0.001 & 0.008 & 0.003 \\
\hline & $\lambda_{\mathrm{z}}(\mathrm{m})$ & 0.082 & 0.005 & 0.395 & 0.051 & 1333 & 18.900 & $\mathrm{NA}$ & 1.161 & 1.476 & 0.035 & 0.101 & 0.091 & 0.090 \\
\hline & $\lambda_{y}(m)$ & 1.313 & 33.381 & 0.075 & 0.061 & 212.42 & 2.031 & NA & 0.247 & 0.005 & 0.014 & 0.061 & 0.309 & 0.090 \\
\hline & & \multicolumn{13}{|c|}{ Horizontal Distance (m) } \\
\hline Analysis & Parameter & 26.0 & 28.0 & 30.0 & 32.0 & 34.0 & 36.0 & 38.0 & 40.0 & 42.0 & 44.0 & 46.0 & 48.0 & 50.0 \\
\hline \multirow[t]{6}{*}{ 2-D CDE } & $V_{z}\left(m^{-1}\right)$ & 0.131 & 0.011 & 0.169 & 0.024 & 0.085 & 0.066 & 0.090 & 0.241 & 0.214 & 0.144 & 0.231 & 0.464 & $\widehat{N A}$ \\
\hline & 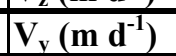 & 0.030 & 0.003 & 0.126 & 0.004 & 0.008 & 0.012 & 0.021 & 0.028 & 0.013 & 0.027 & 0.040 & 0.050 & NA \\
\hline & $D_{z}\left(m^{2} d^{-1}\right)$ & 0.011 & 0.008 & 0.005 & 0.006 & 0.021 & 0.003 & 0.003 & 0.019 & 0.089 & 0.016 & 0.030 & 0.067 & NA \\
\hline & $D_{y}\left(m^{2} d^{-1}\right)$ & 0.001 & 0.001 & 0.018 & 0.000 & 0.001 & 0.002 & 0.001 & 0.001 & 0.001 & 0.001 & 0.001 & 0.000 & $\mathrm{NA}$ \\
\hline & $\lambda_{\mathrm{z}}(\mathrm{m})$ & 0.084 & 0.733 & 0.032 & 0.248 & 0.247 & 0.050 & 0.038 & 0.079 & 0.416 & 0.111 & 0.130 & 0.144 & NA \\
\hline & $\lambda_{\mathrm{y}}(\mathrm{m})$ & 0.019 & 0.273 & 0.143 & 0.033 & \begin{tabular}{|l|}
0.085 \\
\end{tabular} & 0.132 & 0.026 & 0.030 & 0.052 & 0.021 & 0.023 & 0.005 & NA \\
\hline
\end{tabular}




\subsubsection{Cation Exchange Capacity}

Cation exchange capacity measurements for the test site have not been completed. Over 1200 CEC measurements, along with texture information, have been reported for Hanford sediments in the early fifties and again in seventies (McHenry 1957; Rouston and Fecht 1979). The CEC data reported by McHenry (1957) were determined with a modified version of the Bower's procedure (Bower et al. 1952; Richards 1954). The CEC data reported by Rouston and Fecht (1979) were determined using a procedure developed by Rouston et al. (1973). Measurements of CEC were conducted on the $<2$-mm $(<0.80$-in.) diameter fraction of the major lithofacies, and in many cases, particle-size distributions were completed on the same samples. Owing to the realization that in unsaturated soils, total specific area (SA) determines many physical and chemical properties, particularly the CEC, and that SA and $\mathrm{d}_{\mathrm{g}}$ are strongly correlated, it might be possible to determine a reasonable distribution of CEC to support the pre-injection modeling of the reactive transport experiment. Figure 2.11 shows the relationship between CEC, corrected for gravel content, and the geometric mean grain diameter for samples taken from the SX Tank Farm (Serne et al. 2002).

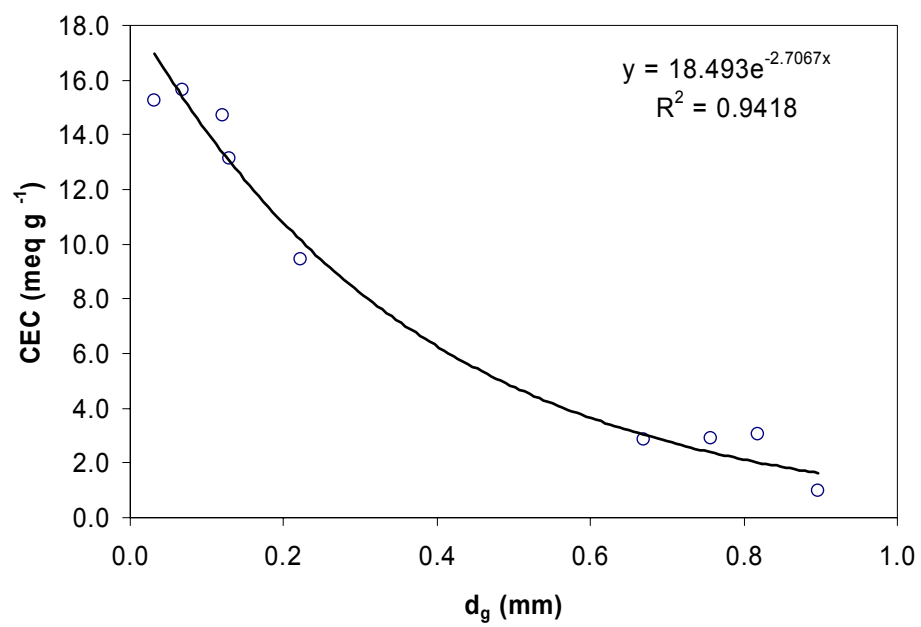

\section{Figure 2.11. Relationship Between CEC Corrected for Gravel and Geometric Mean Grain Diameter Obtained for Samples from Borehole 41-09-39 in the S-SX Waste Management Area}

The relationship between CEC and $\mathrm{d}_{\mathrm{g}}$ is best described by an exponential function. The coefficient of determination, $\mathrm{r}^{2}$, for the S-SX data is quite high at 0.94. A similar analysis of data for a wider range of Hanford soils, including soils from other waste-management areas (e.g., Rouston and Fecht 1979; McHenry 1957), also shows similar exponential relationships with $\mathrm{r}^{2}$ ranging from 0.70 to 0.95 . This relationship is a required first step in estimating the distributions of reactivity parameters in heterogeneous soils. Figure 2.12 shows plots of the permeability field and the predicted CEC based on these relationships compared to distributions of IR temperature. Lower temperatures correspond to higher water contents, within a drained state, that are associated with the low permeability of fine-textured facies, which have low $\mathrm{d}_{\mathrm{g}}$. Given the relationship between CEC and $\mathrm{d}_{\mathrm{g}}$, the distribution of CEC can be expected to be complementary to the pattern of $d_{g}$, and this is clearly shown in Figure 2.12. Spatial distributions of steady-state water content, coupled with node-centered velocity, CEC, and selectivity 

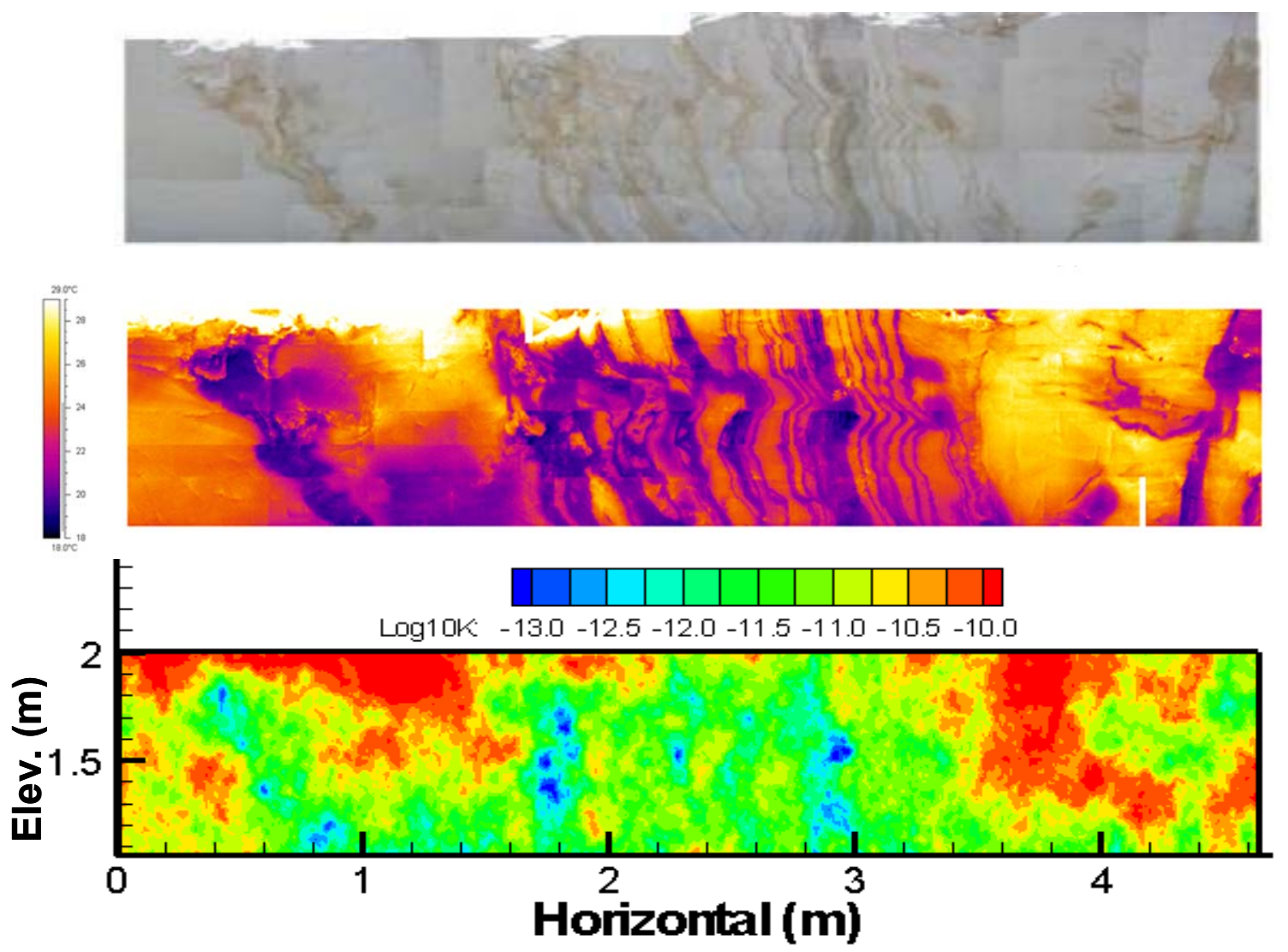

Figure 2.12. Spatial Variability at Tier2 Outcrop: (a) Infrared Image Showing Spatial Variation in Soil Textures, (b) Geometric Mean Particle Diameter, $d_{g}$, and (c) CEC, Inferred from $\mathbf{d}_{\mathrm{g}}$

coefficients, are required input for the general-purpose reactive transport code CRUNCH. Thus, at present, we are in a position to perform pre-injection transport analyses for the experiment, provided selectivity coefficients are available.

\subsubsection{Selectivity Coefficients}

In addition to the physical and hydrologic heterogeneity, natural soils and sediments are also chemically heterogeneous. A single particle can have different types of cation exchange sites exhibiting different exchange selectivities (McBride 1994). Thus, for $N$ different binding sites described by pairs of local isotherms, each isotherm is defined by a cation exchange and selectivity coefficients. Selectivity coefficients for strontium, sodium, potassium, calcium, and magnesium have been determined (Zachara et al. 2002). Coefficients were determined from nine multicomponent batch experiments in which strontium and sodium were varied systematically so as to sum up to $0.001,0.01$, and 0.1 equivalents per liter. Both aqueous and solid phase strontium, sodium, calcium, potassium, and magnesium were measured. However, data for higher sodium concentrations are lacking. Data from a variety of an earlier set of batch experiments carried out at higher strontium concentrations and a set of calcium-strontium binary experiments (Zachara et al. 2002; Knepp 2002) were used to fit a set of batch selectivity coefficients (Steefel et al. 2002). Table 2.4 summarizes the results of the global optimization of the selectivity coefficients and exchanger activity corrections. 
Table 2.4. Selectivity Coefficients and Exchanger Activity Corrections Based on Batch Exchange Experiments. Exchange activity corrections correspond to the "Bdot" term in Equation 6 of Steefel et al. (2002).

\begin{tabular}{|l|l|l||}
\hline \multicolumn{1}{|c|}{ Exchange Reaction } & Log K & K \\
\hline $0.5 \mathrm{SrX} 2_{2}+\mathrm{Na}^{+}=0.5 \mathrm{Sr}^{++}+\mathrm{NaX} 2$ & 0.238 & 1.729 \\
$0.5 \mathrm{SrX} 2_{2}+\mathrm{K}^{+}=0.5 \mathrm{Sr}^{++}+\mathrm{KX} 2$ & 0.000 & 1.000 \\
$\mathrm{SrX}_{2}{ }^{+}+\mathrm{Ca}^{++}=0.5 \mathrm{Sr}^{++}+\mathrm{CaX} 2_{2}$ & 0.094 & 1.242 \\
$\mathrm{SrX} 22+\mathrm{Mg}++=0.5 \mathrm{Sr}^{++}+\mathrm{MgX} 2_{2}$ & 0.006 & 1.014 \\
& & \\
Exchanger Activity Corrections & Bdot & \\
$\mathrm{Sr} \mathrm{X}_{2}$ & 0.989 & \\
$\mathrm{Ca}-\mathrm{X}_{2}$ & 0.989 & \\
$\mathrm{Mg}-\mathrm{X}_{2}$ & 0.989 & \\
$\mathrm{Na}-\mathrm{X}$ & 0.000 & \\
$\mathrm{~K}-\mathrm{X}$ & 0.000 & \\
\hline
\end{tabular}

To fit the $1 \mathrm{M} \mathrm{NaNO}_{3}$ data, it was necessary to include a large activity correction as a function of ionic strength for the divalent ions (Steefel et al. 2002). This correction increased the preference for the divalent cation relative to the monovalent cation over and above what would be predicted with a mass action equation based on classical ion exchange theory.

Selectivity coefficients have also been estimated for the Na-Sr and K-Sr systems based on column experiments by fitting all of the column experiments with a single value of the "Bdot" parameter (Steefel et al. 2002). The results of this analysis are summarized in Table 2.5. A larger value for the parameter was necessary to allow fitting of data from the $0.01,0.1$, and $1 \mathrm{M} \mathrm{NaNO}_{3}$ experiments. However, the $5 \mathrm{M}$ $\mathrm{NaNO}_{3}$ data could not be fit with this procedure. Thus, it appears that the dependence of the selectivity coefficients on ionic strength is nonlinear. The variable nature of the selectivity coefficients is indicative of the deviation from classical "mass action" behavior. Steefel et al. (2002) suggested that this deviation may be due to ion pair formation in the nitrate system and could explain part of the "ionic strength" effect for cases in which exchange of the strontium nitrate ion pair was neglected. Therefore, to reduce the uncertainty in the activity coefficients, it will be necessary to perform measurements of calcium, potassium, and magnesium in a set of sodium-strontium exchange experiments at higher concentrations, e.g., $\geq 1 \mathrm{M}$ of $\mathrm{NaNO}_{3}$. More data are also needed to determine whether strontium-nitrate ion pairs form.

Experiments completed and reported in the B-BX-BY FIR (Knepp 2002) have been used successfully to study the effect of competing $\mathrm{NaNO}_{3}$ and $\mathrm{KNO}_{3}$ concentrations on strontium sorption and desorption, respectively. These data were used to successfully simulate the transport of strontium in composite Hanford sediments with multicomponent ion exchange as the mode of sorption. The modeling captured both the strontium breakthrough and desorption reasonably well at $\mathrm{NaNO}_{3}$ and $\mathrm{KNO}_{3}$ concentrations of 0.01 and $0.1 \mathrm{M}$. However, the model under-predicted the retardation of strontium at elevated concentrations of $\mathrm{NaNO}_{3}$, even when a strong dependence of the divalent-monovalent cation selectivity coefficient on ionic strength was included. It is expected that a classical cation exchange model can be substantially improved by considering new batch and column experiments at higher salt concentrations and taking the geochemical heterogeneity of the different lithofacies into account. 
Table 2.5. Selectivity Coefficients Based on Individual Column Experiments

\begin{tabular}{|c|c|c|c|c|}
\hline Experiment & Sorption Stage & $\begin{array}{c}\text { Desorption Stage } \\
(\mathrm{M} \mathrm{KNO})\end{array}$ & $\mathbf{K}_{\mathrm{Na}-\mathrm{Sr}}$ & $\mathbf{K}_{\mathrm{K}-\mathrm{Sr}}$ \\
\hline 1 & $\begin{array}{l}0.01 \mathrm{M} \mathrm{NaNO}_{3} \\
10^{-5} \mathrm{M} \mathrm{Sr} \\
0.001 \mathrm{M} \mathrm{Ca}, \mathrm{Mg}\end{array}$ & 0.01 & 0.12 & -0.50 \\
\hline 2 & $\begin{array}{l}0.1 \mathrm{M} \mathrm{NaNO}_{3} \\
10^{-5} \mathrm{M} \mathrm{Sr} \\
0.001 \mathrm{M} \mathrm{Ca}, \mathrm{Mg}\end{array}$ & 0.1 & 0.22 & -0.25 \\
\hline 3 & $\begin{array}{l}1 \mathrm{M} \mathrm{NaNO}_{3} \\
10^{-5} \mathrm{M} \mathrm{Sr} \\
0.001 \mathrm{M} \mathrm{Ca}, \mathrm{Mg}\end{array}$ & 1 & 1.00 & 0.87 \\
\hline 4 & $\begin{array}{l}5 \mathrm{M} \mathrm{NaNO}_{3} \\
10^{-5} \mathrm{M} \mathrm{Sr} \\
0.001 \mathrm{M} \mathrm{Ca}, \mathrm{Mg}\end{array}$ & 1 & 1.50 & 1.25 \\
\hline 5 & $\begin{array}{l}1 \mathrm{M} \mathrm{NaNO}_{3} \\
10^{-6} \mathrm{M} \mathrm{Sr}\end{array}$ & 1 & 1.22 & 1.10 \\
\hline
\end{tabular}

\subsubsection{Surface Ground-Penetrating Radar}

A summary of the geophysical surveys conducted at the field site was presented by Ward and Gee (2002). Surveys included at least three surface-GPR surveys, several cross-hole radar surveys, a highresolution seismic survey, and electrical resistivity surveys during the last 3 years. These surveys all show that GPR can be effective for imaging the subsurface at the test site and can provide spatially continuous data to a depth of about $8 \mathrm{~m}$ in a manner that is non-intrusive and cost effective. In the FY 2002 test, surface radar surveys were also performed initially to aid in site instrumentation and then as a means of monitoring the infiltration experiment. Surveys were conducted using a Sensors and Software, Inc. PulseEKKO1000 GPR system equipped with both $450-\mathrm{MHz}$ and $225-\mathrm{MHz}$ antennas. Two lines were collected at frequencies of $450 \mathrm{MHz}$ and $225 \mathrm{MHz}$. The $450-\mathrm{MHz}$ data were acquired every $5 \mathrm{~cm}$ (2 in.) while the $225-\mathrm{MHz}$ data were acquired every $10 \mathrm{~cm}$ (4 in.). Surveys were conducted along two transects, parallel to the line source, at distances of $0.3 \mathrm{~m}(1 \mathrm{ft})$ and $0.8 \mathrm{~m}(2.6 \mathrm{ft})$ from the line source (Figure 2.13). Two types of surface GPR data processed during this investigation were common offset and common mid-point data. Analysis of the common offset GPR data show the 225-MHz data were poor quality and of limited use in the interpretation of the infiltration test. Due to its lower frequency content, the 225-MHz data were initially hoped to provide some information on that portion of the sediment sequence deeper than $\sim 1.5 \mathrm{~m}$. Unfortunately, the signal-to-noise ratio of the $225-\mathrm{MHz}$ data was particularly poor in this depth range (especially as the injection progressed) to the point that the resolution

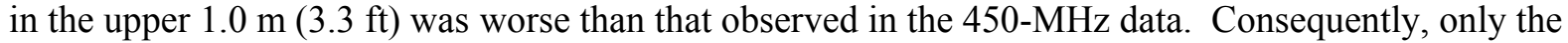
$450-\mathrm{MHz}$ data were used to support the interpretation of the field (Ward et al. 2002). Previous GPR work at this site indicated that these two frequencies would be most appropriate for sampling the upper 2 to $3 \mathrm{~m}$ (6.6 to $10 \mathrm{ft}$ ) of the sedimentary sequence. As shown in Figure 2.14, a series of strong reflectors exists in the baseline data occurring at times ranging from 10 to 20-ns. These reflectors were shown to be present over the duration of the experiment with the only change being a gradual decrease in the signal-to-noise ratio as the total fluid volume injected increased. 


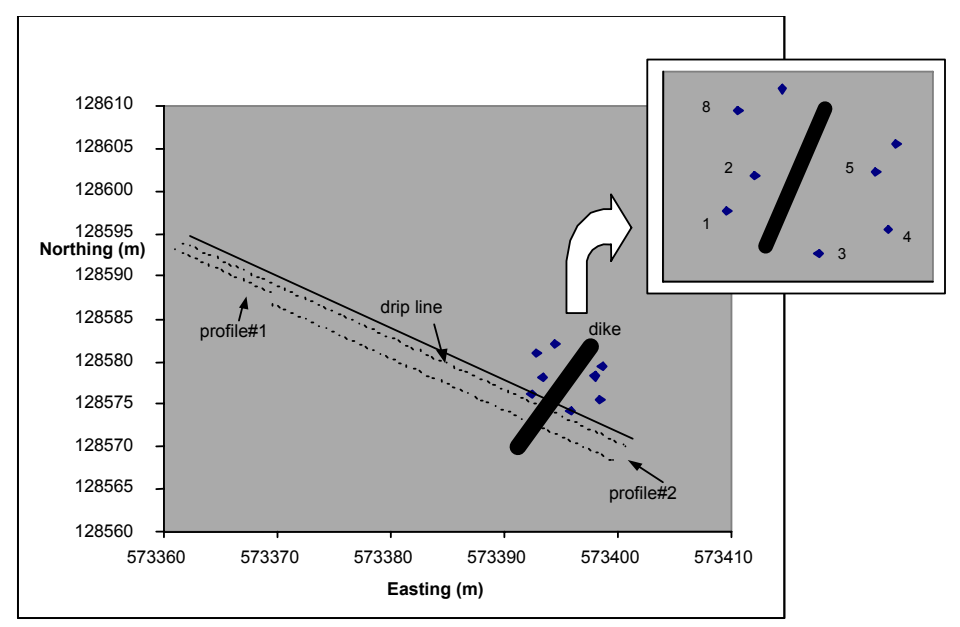

Figure 2.13. Schematic Layout Showing Common Offset Profiles and Borehole Radar Locations

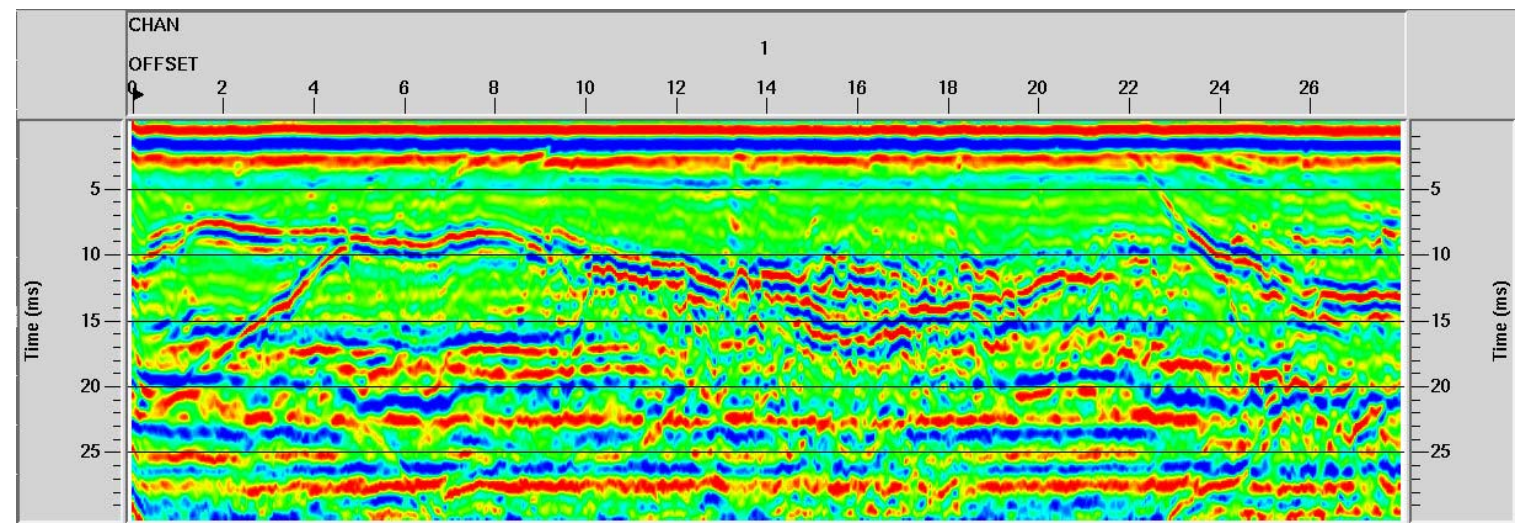

Figure 2.14. Common Offset GPR Data Collected Along Profile\#1 on May 21, 2002

The common offset technique is the principal survey methodology used in interpreting the surface radar data. It forms the basis for identifying discreet reflectors at a variety of depths in the sedimentary sequence, and it is the technique used to map the reflectors both spatially and temporally during the course of the experiment. The technique is based on measuring the velocity of the sediment overlying a given reflector, which then allows estimation of the average water content throughout this sediment. The common offset technique allows the estimate of water content to be made much more rapidly than with the common midpoint (CMP) technique.

The CMP data were collected at two specific locations along the profiles during each acquisition visit. One was located directly above the clastic dike ( $\sim 50 \mathrm{~m}[\sim 164 \mathrm{ft}]$ from the starting point), and the other at $\sim 40 \mathrm{~m}(\sim 131 \mathrm{ft})$ from the starting point. The $450-\mathrm{MHz}$ antennas started with an antenna separation of $26 \mathrm{~cm}$ (10 in.) and were moved away from one another in steps of $2 \mathrm{~cm}(0.8$ in.) (i.e., the transmitting antenna and receiving antenna each moved $1 \mathrm{~cm}[0.4 \mathrm{in}]$.$) . The 225-\mathrm{MHz}$ antennas started with an antenna separation of $26 \mathrm{~cm}$ (10 in.), and they were moved away from one another in steps of $4 \mathrm{~cm}$ (1.6 in.). The characteristic features of the CMP survey include the air and direct ground wave arrivals as well as any reflections that occur. The move-out (i.e., wavelet slope) of each of these arrivals defines the velocity of the arrival, or in the case of a reflector, the average velocity of the overlying sediments. 


\subsection{Previous Data Analysis and Modeling}

\subsubsection{Water Flow Simulations}

Most flow-and-transport models for contaminant migration in the vadose zone at the 200 Areas, including the Tank Farms, have been based on relatively simple hydrogeologic models that assume perfectly stratified sediments (DOE-GJPO 1998; Mann et al. 1998), with no allowance for preferential vertical flow paths. At least three modeling studies attempted to simulate the effects of clastic dikes on vertical transport through the vadose zone. The studies were sensitivity analyses within larger modeling studies and were based on the assumption of uniform material oriented vertically within a 1-m-thick (3.3-ft-thick) zone (Wood et al. 1996; DOE 1998b). Retrieval performance evaluations for the SX and AX tank farms were performed with the multimedia environmental pollutant assessment system (MEPAS) using a 1-D model (Jacobs 1997, 1998a,b).

Additional 2-D simulations were conducted but clastic dikes were simulated as thin, vertical, high permeability zones extending from the base of the subsurface tanks to the water table (Jacobs 1997, 1998a,b; White et al. 2001). However, no hard data on the dimensions or hydrogeologic properties of clastic dikes were used in developing the sensitivity analyses, and the fluxes were orders of magnitude lower than those expected under leaking tanks. The results of these studies showed minimal impact of the dikes on flow through the vadose zone, and it was concluded that dikes would have no effect on the first arrival or maximum contaminant concentration at the water table. Another modeling study was conducted in FY 2000 to address sloped layers and clastic dikes. The data package specified that a 0.3-mwide (1-ft-wide) dike must run vertically from the base of a single-shell tank to the Plio-Pleistocene layer. The data package called for the dike to be modeled with uniform properties and a $\mathrm{k}_{\mathrm{s}}$ value of $1.2 \times 10^{-4} \mathrm{~m}$ $\mathrm{s}^{-1}$ (Khaleel et al. 1999). As in the previous simulations, results essentially showed that as specified, the clastic dikes had no effect on flow and transport.

The conclusions above are inconsistent with observations from controlled, field-scale experiments conducted at clastic dike areas at the Hanford Site. Experiments have been conducted at the S-16 pond site and the Army Loop Road Site (Murray et al. 2001; Ward et al. 2002; Murray et al. 2003). It is our contention that the discrepancy between the model predictions and experimental observations can be resolved with a combination of improved conceptual and numerical models as well as improved estimates of flow and transport parameters.

With the recent availability of high-performance computing, the development of high-resolution, multi-dimensional models capable of analyzing flow and transport in heterogeneous unsaturated porous media has been proceeding at a rapid pace. High-performance computing has made possible the development of high-resolution, multi-dimensional, unsaturated flow models capable of analyzing complex physically heterogeneous porous media. These models allow analysis of the importance of processes that link smaller-scale subsurface material property features to a larger-scale flow behavior and techniques for upscaling. With these techniques, the potential impact of clastic intrusions on the flow of water through the vadose zone was recently analyzed in a series of detailed unsaturated flow simulations (Ward et al. 2003; Murray et al. 2003). Water flow was simulated on a 2-D vertical outcrop of the dike with dimensions $4.7 \mathrm{~m}(15.4 \mathrm{ft})$ long $\times 1 \mathrm{~m}(3.3 \mathrm{ft})$ deep. The number of domain nodes was upscaled from a grid spacing of $1.11 \mathrm{~mm}\left(0.04 \mathrm{in}\right.$.) $\left(>3.59 \cdot 10^{6}\right.$ nodes $)$ at the measurement scale to $2.22 \mathrm{~mm}(0.09$ 
in.) $\left(8.97 \cdot 10^{5}\right.$ nodes $)$ on the model grid. The model was parameterized using high resolution, multiparameter data sets, derived from a variety of measurements on a dike outcrop. A set of constant flux simulations was performed on input fluxes at the upper boundary, $j_{w}^{0} \in\left\{1,10,10^{2}, 10^{3}\right\} \mathrm{mm} \mathrm{yr}^{-1}$. These fluxes represent the range of recharge rates observed at the Hanford Site (Fayer and Walters 1995). A recharge of 1 to $10 \mathrm{~mm}$ ( 0.04 to $0.4 \mathrm{in}$.) $\mathrm{yr}^{-1}$ is typical of areas of undisturbed shrub steppe on site; $10^{2}$ $\mathrm{mm}$ (4 in.) $\mathrm{yr}^{-1}$ is typical of bare soils and gravel-covered tank farms; while $10^{3} \mathrm{~mm}$ (39.4 in.) $\mathrm{yr}^{-1}$ is estimated recharge near the periphery of storage tanks, due to the umbrella effect of the impermeable tank domes (Ward et al. 1997). Figure 2.15 shows typical subsurface distributions of $\theta(\mathrm{x}, \mathrm{z})$ in response to steady input fluxes. Simulated $\theta$ clearly covers a wide range of values, even at the $j_{w}^{0}$, and reflects the underlying structure of the heterogeneity. However, the degree to which this heterogeneity is expressed depends on $j_{w}^{0}$. At these low fluxes, water is easily redirected around less-permeable regions, and only the very smallest of coarse-textured inclusions are penetrated (Figure 2.15a,b). As the surface flux is increased, the effect of the fine-scale heterogeneities on $\theta$ becomes less apparent. As the flux increases, more water is available to start wetting larger and less-permeable areas because of funneling and the variation in $\mathrm{j}_{\mathrm{w}}$. Consequently, more of the local-scale heterogeneity is masked (Figure 2.15c) until finally at the highest $j_{w}^{0}$, only the large scale structures are evident (Figure 2.15d). However, consideration of distributions of $\theta$ in a vacuum can be quite misleading as higher $\theta$ does not necessarily mean high transport velocities in the vadose zone.

This apparent paradox is best illustrated with a plot of subsurface distributions of the dimensionless flux, $\log _{10}\left(\left|j_{w}\right| / j_{w}^{0}\right)$ where $j_{w}$ is the simulated node-centered flux. Distributions of $\log _{10}\left(\left|j_{w}\right| / j_{w}^{0}\right)$ are shown in Figure 2.16. At $j_{w}^{0}=1 \mathrm{~mm}\left(0.04 \mathrm{in}\right.$.) $\mathrm{yr}^{-1}$, the medium is mostly unsaturated. At the steady state $\psi, \mathrm{K}(\psi)$ is highest in the fine-textured sediments, and as a result, flow channels form near the upper boundary, predominantly in the fine-textured sediments, and propagate downward following the paths of highest conductivity (Figure 2.16a). In the early stages of infiltration, the distribution of the flow paths is clearly dependent on the underlying structure of the heterogeneity as water is redirected or funneled from regions of low conductivity to regions of high conductivity. At the low fluxes, there is insufficient water to overcome the entry pressure of the coarser sediments, and these regions are essentially bypassed, except for the small isolated inclusions. Following the formation of a channel, depending on its size, it may conduct enough water to overcome the entry pressure of low-permeability regions, resulting in wetting of small isolated regions. Larger regions of low permeability, however, require larger amounts of water to initiate wetting than might be available from these channels, and consequently, flow is diverted around the coarse-textured regions at low input fluxes. This can be clearly seen in Figure 2.16a,b in the

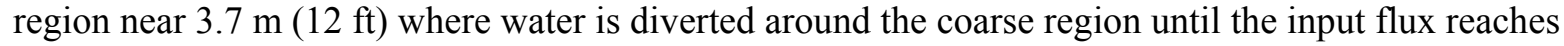
$10^{2} \mathrm{~mm}$ (4 in.) $\mathrm{yr}^{-1}$ (Figure $2.16 \mathrm{~b}$ ) while smaller coarse-textured regions within the dike, e.g., at $\mathrm{x}=2.5 \mathrm{~m}$ $(8.2 \mathrm{ft})$, show increasing velocities at much lower fluxes. As the input flux increases, the $\log (-\psi)$ continues to decrease, and the $\mathrm{K}(\psi)$ of the coarse-textured regions eventually surpasses that of the finetextured region. The high-conductivity regions can now carry more water, and larger areas of the coarse sediments start to wet up with a corresponding increase in $\mathrm{j}_{\mathrm{w}}$. The result is a decrease in the difference in $\mathrm{j}_{\mathrm{w}}$ between the fine and coarse textures.

This trend continues until a critical value of $j_{w}^{0}$ where $\mathrm{K}(\psi)$ for the coarse and fine sediments intersect and the difference in flux between the fine and coarse textures essentially disappears (Figure 
2.16c). As the $j_{w}^{0}$ increases further, the $\mathrm{K}(\psi)$ of the coarse sediments surpasses that of fine sediments, and a reversal in the distribution of $\log _{10}\left(\left|j_{w}\right| / j_{w}^{0}\right)$ becomes apparent (Figure 2.16d). Regions that were being bypassed earlier because of lower permeability become the dominant regions of transport. Thus, there exists two complementary flow networks whose operation depends on saturation and hence $j_{w}^{0}$. At fluxes less that the critical $j_{w}^{0}$, the dominant network is the high-permeability, fine-textured regions of the dike. At fluxes equal to the critical $j_{w}^{0}$, the difference between the networks decline but can never be eliminated. This is because with the range of soils observed in the dike, there is no single $\psi$ at which
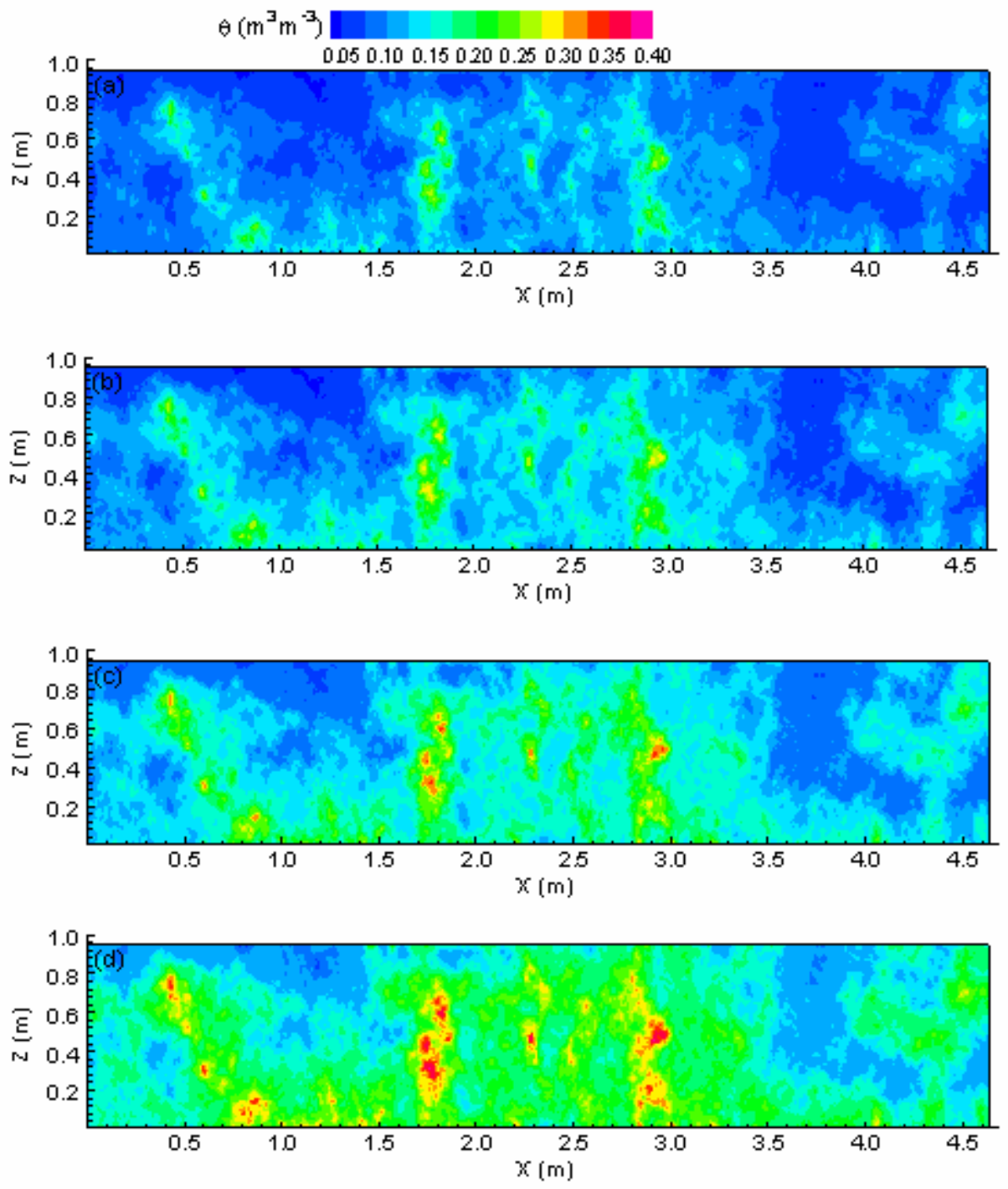

Figure 2.15. Distributions of Volumetric Water Content During Steady Infiltration Under a Constant Surface Flux of (a) $1.0 \mathrm{~mm} \mathrm{yr}^{-1}$, (b) $10 \mathrm{~mm} \mathrm{yr}^{-1}$, (c) $10^{2} \mathrm{~mm} \mathrm{yr}^{-1}$, and(d) $10^{3}$

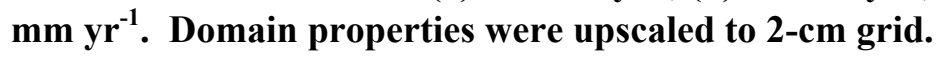


$\mathrm{K}(\psi)$ would be equal for all the of soils observed. At $j_{w}^{0}$ greater that the critical flux, the dominant network becomes the high-permeability, coarse-textured region, which is mostly the host matrix, but also includes the regions of the dike filled by coarser sediments.

These complementary flow networks can totally mask the underlying heterogeneity as water is redirected around regions of different texture, depending on $j_{w}^{0}$ and $\theta$. The phenomenon is a reflection of a fundamental characteristic of flow in heterogeneous systems and cannot be replicated with simplified models or systems in which the dike is rendered effectively homogeneous by assigning field-averaged
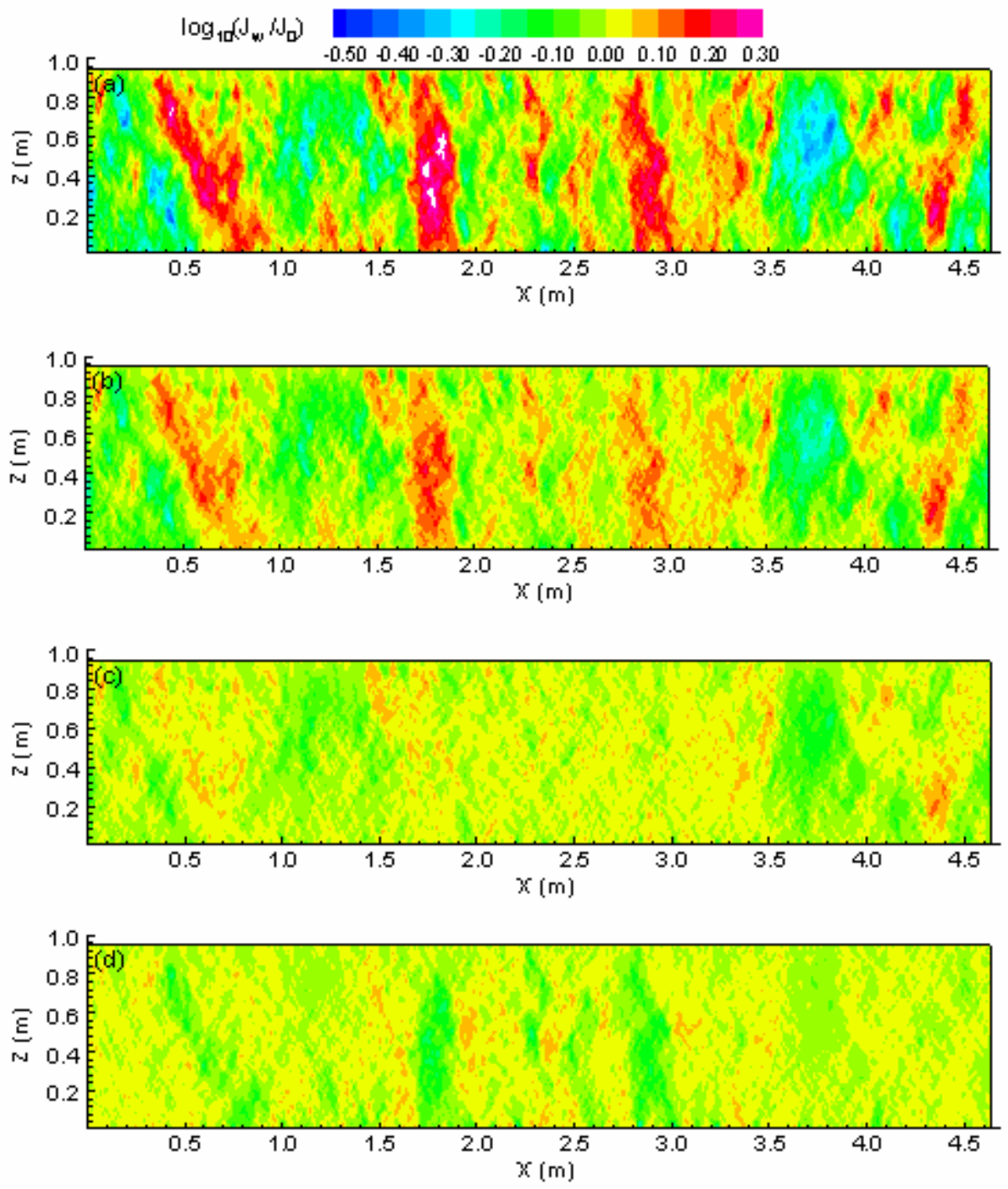

Figure 2.16. Distributions of Dimensionless Water Flux, $\log _{10}\left(\left|j_{w}\right| / j_{w}^{0}\right)$, During Steady Infiltration at an Input Flux, $j_{\mathrm{w}}^{0}$, of (a) $1.0 \mathrm{~mm} \mathrm{yr}^{-1}$, (b) $10 \mathrm{~mm} \mathrm{yr}^{-1}$, (c) $10^{2} \mathrm{~mm} \mathrm{yr}^{-1}$, and (d) $10^{3}$ $\mathrm{mm} \mathrm{yr}^{-1}$ 
hydraulic properties. Attempting to model a dike with a 1-D model (Jacobs 1997) or conceptualizing it as a thin, vertical structure with effective properties chosen to maximize permeability (Jacobs 1998a,b; CH2M Hill 2002) would fail to show any impact of a dike of subsurface flow. Given the existence of complementary flow networks, the choice of properties to maximize flux under one set of conditions would invariably lead to the minimization of fluxes under the other, and unless an adequate range on input fluxes were simulated, one could easily conclude that dikes had no effect on flow.

Microscale simulations appear to have potential for investigating the relationships between heterogeneity and unsaturated flow behavior. Coupled with the results of last year's conservative tracer experiments, these results provide some insight and guidance for the design of the FY 2003 field studies, which will focus on a reactive tracer.

\subsubsection{Transport Simulations}

Transport simulations for the test site have not yet been initiated as efforts initially focused on accurate description of the flow fields. Following the progress reported above, transport modeling should commence shortly, with an initial focus on conservative tracers used in the FY 2002 experiments. There has been much progress, however, in the application of a multi-component $\left(\mathrm{Na}^{+}, \mathrm{K}^{+}, \mathrm{Ca}^{2+}, \mathrm{Mg}^{2+}, \mathrm{Sr}^{2+}\right)$ cation exchange model to describe both stable strontium and strontium-90 between the solid and fluid phases in unsaturated sediments (Zachara et al. 2002).

The strontium column experiments completed to date evaluate the dependence of strontium retardation on sodium nitrate concentrations ranging from 0.01 to $5 \mathrm{M}$ (Steefel et al. 2002). The competition of potassium and strontium was also addressed using desorption experiments, with $\mathrm{KNO}_{3}$ concentrations ranging from 0.01 to $1 \mathrm{M}$. Most experiments were carried out with a concentration of strontium in the injection fluid of $10^{-5} \mathrm{M}$. Duplicate experiments at a strontium concentration of $10^{-6}$ and $10^{-7} \mathrm{M}$ were used to determine whether the strontium concentration affected its retardation. CECs were determined by measuring the equivalent sum of calcium, magnesium, and potassium eluted from the columns in 1 and $5 \mathrm{M} \mathrm{NaNO}_{3}$ solutions before strontium injection and in one experiment from the sum of strontium, calcium, magnesium, and sodium eluted by $1 \mathrm{M} \mathrm{KNO}_{3}$ after strontium injection. The sediment CEC was also determined by a separate isotopic equilibrium exchange column experiment using ${ }^{22} \mathrm{Na}$. Distribution of species calculations and the simulations of multicomponent ion exchange and transport in the column experiments were carried out with the general-purpose reactive transport code CRUNCH (Steefel et al. 2002), a combined and updated Fortran 90 version of the codes GIMRT and OS3D (Steefel and Yabusaki 1996). A single exchange site concentration (CEC) was used in all simulations. Selectivity coefficients for strontium, sodium, potassium, calcium, and magnesium were fitted to data reported Zachara et al. (2002).

The simulations of Steefel et al. (2002) showed that the reactive transport behavior of strontium in nitrate electrolyte through composite Hanford formation sediment from Waste Management Area (WMA) B-BX-BY can be simulated with a transport model that includes modified multi-component ion exchange as the only geochemical retardation process. For this model analysis, selectivity coefficients for the ion exchange of strontium with sodium, calcium, and magnesium were fitted from the batch experimental data reported by Zachara et al. (2002). The modeling captured both the strontium breakthrough and desorption reasonably well at $\mathrm{NaNO}_{3}$ and $\mathrm{KNO}_{3}$ concentrations of 0.01 and $0.1 \mathrm{~mol} / \mathrm{L}$ (Figure 2.17). However, the model underpredicted the retardation of strontium at $1 \mathrm{~mol} / \mathrm{L} \mathrm{NaNO}_{3}$, even when a strong 
dependence of the divalent-monovalent cation selectivity coefficient on ionic strength is included. The batch data also fail to capture the slow release of strontium during the desorption step using $1 \mathrm{M} \mathrm{KNO}_{3}$, although this is partly due to the lack of batch data on strontium-potassium exchange. While a classical cation exchange model may not be easily applicable over the entire range of ionic strengths possible, the ion exchange model successfully captured much of the dependence of strontium retardation on competing cation concentration, particularly at lower salt concentrations.
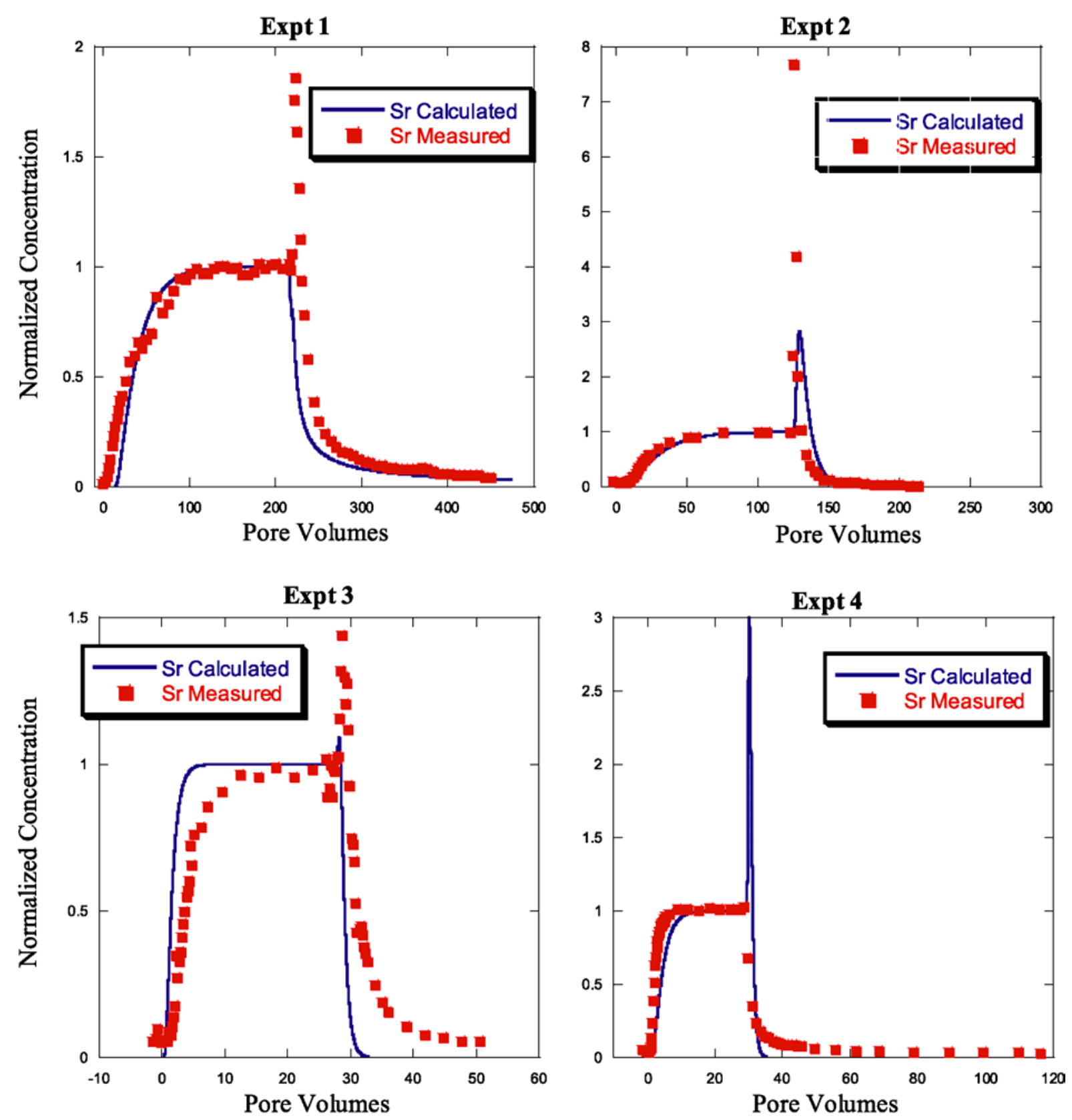

Figure 2.17. Strontium Breakthrough and Subsequent Desorption in Experiments 1 Through 4 $\left(0.01,0.1,1\right.$, and $5 \mathrm{MNaNO}_{3}$, respectively, in the sorption stage and $0.01,0.1,1$, and $1 \mathrm{M} \mathrm{KNO}_{3}$, respectively, in the desorption stage) (after Steefel et al. 2002) 
Column experiments showed evidence for a dependence of the divalent-monovalent cation on ionic strength. The dependence had the effect of making the higher charged cation more strongly favored than the monovalent cation (either sodium or potassium) as either the $\mathrm{NaNO}_{3}$ or the $\mathrm{KNO}_{3}$ concentration is increased. Such a preference might be expected to cause a deviation from the classical "mass action" behavior expected for ion exchange, which could be compounded further in heterogeneous systems in which access to sorption sites is restricted. 


\subsection{Planned FY 2003 Testing}

Accurate models of cation exchange models are a prerequisite for predicting reactive transport in Hanford sediments. To validate the capability of these models to predict field-scale transport, accurate data sets from well controlled field experiments are needed. Based on the review of data and analyses presented above, a number of criteria to be considered for designing such experiments readily emerge. A brief summary includes the lack of small-scale permeability characterization data, the need for correlations between small-scale heterogeneity and GPR soundings, the need for local-scale estimates of permeability anisotropy, the need for a tested relationship between CEC and easily measured indicators of heterogeneity like grain-size characteristics, the lack of exchange data for elevated concentrations of sodium nitrate, and of course, the need for field data on Sr transport in a heterogeneous soil derived from a controlled experiment to be used for model calibration.

This test plan describes a set of laboratory, field, and modeling tasks that will be performed in FY 2003 to fill the knowledge gaps discussed above. The tasks outlined in the following sections are intended to provide a data set to test hypotheses about flow and reactive transport while supporting the development of technologies for high-resolution characterization of heterogeneous media and upscaling methodologies to facilitate forward and inverse modeling. Tests will be conducted along the $60-\mathrm{m}$ (197-ft) transect at the Army Loop Road dike that was used in FY 2002. The first task to be performed in the FY 2003 field study will be a pre-test modeling of strontium migration at the test site to optimize the design of the experiment.

\subsection{Pre-Test Modeling}

Reactive transport occurs over a wide range of spatial and temporal scales, and the ability to incorporate the physical and chemical heterogeneity over the range of spatial scales into an unsaturated flow model provides a gauge of our understanding of these systems and the basis for designing the optimal field-scale transport experiment. Although the complexity of reactive transport models applied to natural environments is non trivial, modeling the transport of well understood reactive tracers like $\mathrm{Sr}^{++}$in a reasonably well understood flow field will provide insight useful for developing monitoring and sampling strategies. Thus, one objective of the plan is to complete modeling of the FY 2003 injection before performing the field tests. This modeling effort will be a joint effort between the S\&T VZTFS team and the S\&T Modeling team and will make use of the STOMP and CRUNCH simulators.

Two sets of 2-D simulations will be conducted to capture two aspects of the experimental design. In the first phase of this task, water flow was simulated on a 2-D vertical outcrop of the dike (Tier 2 of the Army Loop Road excavation) parallel to the line source. This section is $4.7 \mathrm{~m}(15.4 \mathrm{ft})$ long and $2 \mathrm{~m}(6.6$ $\mathrm{ft}$ ) deep and encompasses the dike and surrounding host matrix (Figure 3.1). Simulations will be performed under Neumann conditions at the upper boundary: no flow conditions on the east and west and a unit gradient condition at the lower boundary. The surface flux will be chosen to match those used in the FY 2002 field experiments. The resulting 2-D distributions of water content and node-centered porewater velocities will be coupled with 2-D distributions of CEC and selectivity coefficients to generate the input for CRUNCH. CRUNCH will then be used to simulate the behavior of $\mathrm{Sr}^{++}$and the exchangeable 


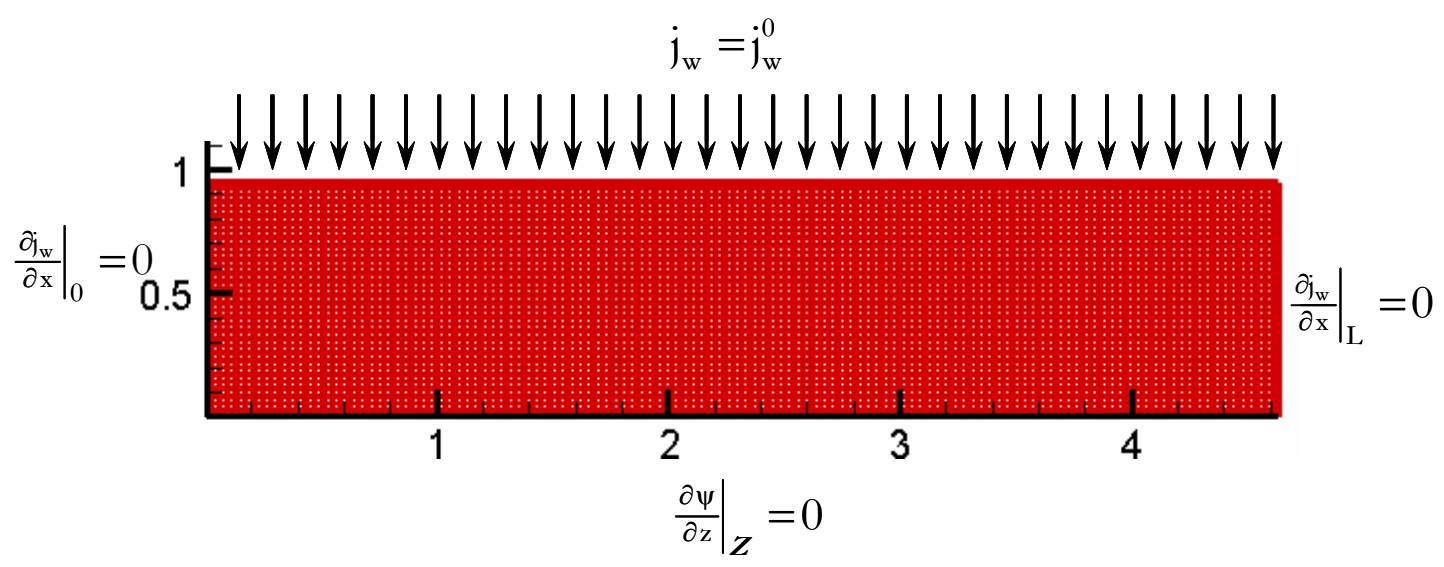

Figure 3.1. Flow Domain with Boundary Conditions

cations along the transect during steady-state infiltration. The simulation will provide insight into the variability in transport behavior along the transect and support the design of an intensive sampling strategy.

The strategy will be to be to select a subsection of the transect to be ultimately excavated for intensive sampling. This area will have to be one that maximizes the range of heterogeneities controlling flow and transport that are captured while minimizing the cost of excavation and the number of samples to be analyzed. Results of these simulations will be analyzed in concert with the GPR data to identify the most appropriate region for sampling.

In the second phase of this task, water flow was simulated on a 2-D vertical outcrop, perpendicular to the line source (Figure 3.2). Two separate sections, $2 \mathrm{~m}(6.6 \mathrm{ft})$ wide by $2 \mathrm{~m}(6.6 \mathrm{ft})$ deep, will compare the response of the dike and host matrix. Simulations will be performed under Neumann conditions at the upper boundary: no flow conditions on the east and west and a unit gradient condition at the lower boundary. As in phase one, the surface flux will be chosen to match those used in the FY 2002 field experiments. The resulting 2-D distributions of water content and node-centered pore-water velocities will be coupled with 2-D distributions of CEC and selectivity coefficients to generate the input for CRUNCH. The results of the simulation will provide insight into the variability in transport behavior away from the line source, which will allow optimization of the sampling strategy perpendicular to the line source.

\subsection{Measurements of Cation Exchange Capacity}

Cation exchange is a special case of competitive sorption and is gaining acceptance for modeling reactive transport onsite. The accuracy of the classical cation exchange models is extremely sensitive to the accuracy of description of sorption equilibrium, especially if several competing cations are present simultaneously (Cernik et al. 1994). Reviews of existing data suggest a need for new batch and column experiments at higher salt concentrations as well as a correlation with lithofacies information. The CEC data reported by McHenry (1957) were determined with a modified version of the Bower's procedure (Bower et al. 1952; Richards 1954). The CEC data reported by Rouston and Fecht (1979) were 


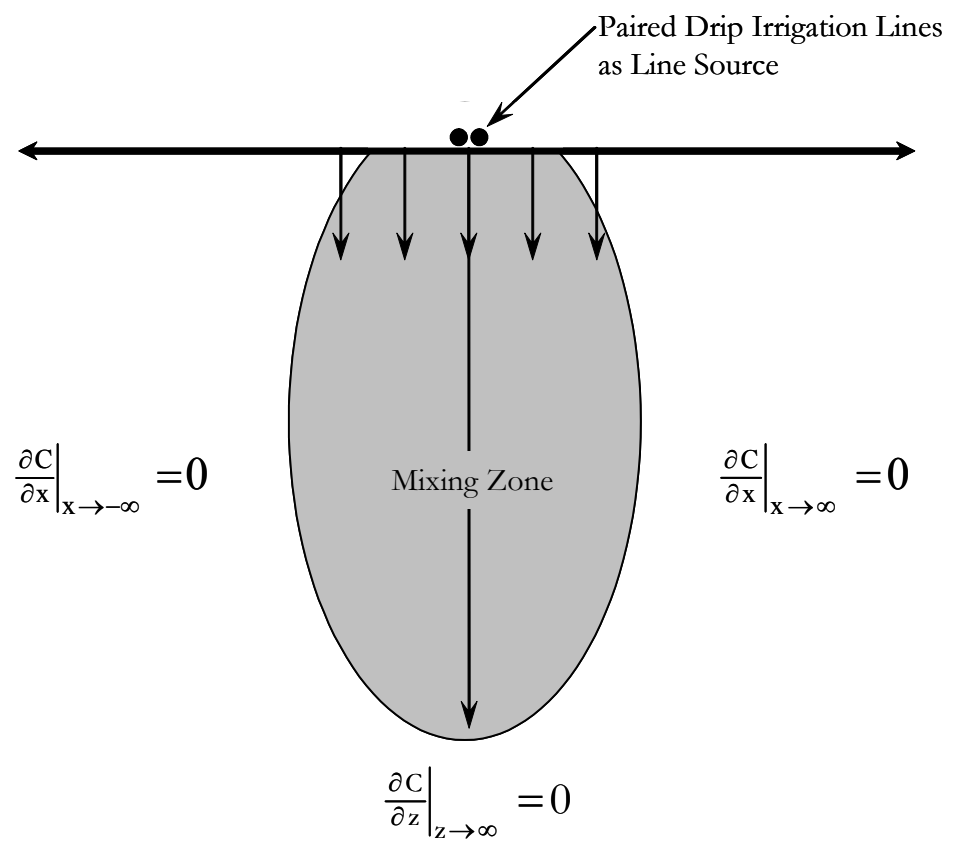

Figure 3.2. Schematic of 1-D Advection and 2-D Dispersion in a Half Plane of a Porous Medium

determined using a procedure developed by Rouston et al. (1973). While these data are useful for exploring relationships between CEC and grain-size characteristics, they are not compatible with data requirements of the multi-site cation exchange models. There are three objectives to this task. The first objective is to measure CEC on a set of samples representative of the main lithofacies at the site. Sediment CECs will be determined by the sequential extraction method of Zachara et al. (2002) on the $<2$-mm $\left(<0.08\right.$-in.) size fraction. Measurements will be made with $\mathrm{NaNO}_{3}$ concentrations of $0.01,0.1$, 1 , and $5 \mathrm{M}$. These measurements will be made in conjunction with similar measurements on $100-\mathrm{N}$ samples. Since these measurements are performed on the $<2-\mathrm{mm}(<0.08$-in.) size fraction, the results will be corrected for the $>2$-mm $(<0.08$-in.) fraction to allow determination of CEC for the bulk sediment (Kaplan and Serne 1999). Preliminary analysis shows a possible exponential relationship between CEC and geometric mean grain size diameter. The second objective of this task is to determine the mean particle-size distribution of the samples on which CECs are measured. In addition to cation exchange capacity, all samples will be characterized in terms of particle-size distribution, mineralogy, and exchangeable bases. The data resulting from this analysis will support the development of a more robust relationship between CEC and soil physical properties for an applicable range of textures. The final goal of this task is to identify the relationship between CECs determined by the cation elution method of Zachara et al. (2002) and the methods used in the earlier measurements by McHenry (1957) and Rouston and Fecht (1979). The identification of a relationship between the different methods would permit use of a relatively large database of CECs and grain-size data.

\subsection{Measurements of Particle-Size Distributions}

Particle-size distributions will be determined by a combination of dry sieving, wet sieving/hydrometer methods. The PSD test will be performed on the $<2-\mathrm{mm}(<0.08$-in. $)$ size fraction using the methods described by Gee and Bauder (1986). To determine fractions of gravel, very coarse sand, coarse sand, 
medium sand, fine sand, and silt plus clay, the air-dried subsamples will be wet-sieved using deionized water to disperse the individual particles. The water-soil combinations will be shaken for 10 minutes at $150 \mathrm{rpm}$ in an orbit shaker. The total material will then be transferred to a 2 -mm $(0.08$-in.) sieve (No. 10 mesh) and wet-sieved to separate materials larger than $2 \mathrm{~m}(6.6 \mathrm{ft})$. Material passing through the 2-mm (0.08-in.) sieve will be further wet-sieved sequentially through $1.00-\mathrm{mm}(0.04-$ in.) (No. 18), 0.5 -mm (0.02-in.) (No. 35), 0.25-mm (0.01-in.) (No.60), 0.106-mm (0.004-in.) (No.140), and 0.053-mm (0.002-in.) (No. 270) sieves. Soil passing through the $0.053-\mathrm{mm}(0.002$-in.) sieve is collected in the pans. All fractions smaller than $2 \mathrm{~mm}\left(0.08 \mathrm{in}\right.$.) will be oven dried at $110^{\circ} \mathrm{C}$. After oven-dried material weights are obtained, the samples will be dry sieved until not more than 1 mass percent of the residue on the sieve passed through the sieve during 1 min of sieving. Material remaining on the 2-mm (0.08-in.) sieve will be allowed to air dry and then weighed. Subsamples with high silt or clay content will be wet-sieved multiple times to assure that all of the clay-size particles are separated from the larger particles. The mass of each size fraction will be determined using a calibrated balance. In the hydrometer analysis, the fraction of interest in the fraction passing through the $0.053-\mathrm{mm}(0.002-\mathrm{in}$.) sieve. This fraction will be dispersed with sodium hexametaphosphate. Hydrometer readings are used to determine the soil sedimentation rates. The rates for each sample are the used to calculate the distribution of materials smaller than $0.053 \mathrm{~mm}$ (0.002 in.). Particle density is a needed input for the hydrometer-method calculation of particle size and will be determined using the pychnometer method (Blake and Hartge 1986, pp. 363-375). Bulk-density measurements will be conducted on undisturbed samples. The porosity of the samples will be estimated using the bulk density of undisturbed samples and the average particle density as $\phi=1-\rho_{\mathrm{b}} / \rho_{\mathrm{s}}$.

\subsection{Determination of Selectivity Coefficients}

A critical step in the development of a reactive transport model for strontium is the determination of parameters for a multicomponent ion exchange model for $\mathrm{Sr}^{2+}$. These parameters are required to allow the calculation of $\left[\mathrm{Sr}^{2+}\right]$ and $\left[\mathrm{SrX}_{2}\right]$, and hence $\mathrm{K}_{\mathrm{d}}-\mathrm{Sr}$, as a function of the controlling system parameters, i.e., CEC, selectivity coefficients, aqueous concentration, and adsorbed concentration of the primary competitive cations. The objective of this task is to parameterize a multicomponent exchange model for $\mathrm{Sr}^{2+}$ on the major lithofacies of the Hanford formation sediment identified at the experimental site that will allow site-specific calculations when site-specific values of $\mathrm{CEC}, \mathrm{Ca}_{\text {total }}$, and $\mathrm{Sr}_{\text {total }}$, are available. Initial analyses will be performed using the data developed in the B-BX-BY FIR. The exchange complex in Hanford sediment is saturated with the following cations in order of decreasing concentration of $\mathrm{Ca}^{2+}>\mathrm{Mg}^{2+}>\mathrm{Na}^{+}>\mathrm{K}^{+}>\mathrm{Sr}^{2+}$, but the functional relationships between surface and aqueous cation distributions have not been quantitatively established (Zachara et al. 2002). Therefore, it will be necessary to determine selectivity coefficients for the lithofacies of interest. Ultimately, $\mathrm{K}_{\mathrm{c}}$ will be determined for the chemically heterogeneous flow domain of the field experiment using inverse modeling.

\subsection{Permeability Characterization}

Even at a site as well instrumented as this, the data resulting from the traditional vadose-zone characterization tools will be insufficient to predict the detailed transport of reactive solutes. In this task, we will combine hydraulic, geophysical, hydrogeochemical, and sedimentological methods to yield 2-D and 3-D high-resolution multi-parameter data sets. The proposed approach is analogous to the aquifer analogue concept that has been used extensively in large-scale reservoir analysis (Flint and Bryant 1993) 
and more recently in the study of smaller outcrops of unconsolidated sediments (Jussel et al. 1994; Huggenberger et al. 1994). In this task, the infiltration zone will be excavated following completion of the infiltration tests. The vertical cut face will be photographed using high-resolution visible and infrared techniques to identify the spatial distribution of the different lithofacies within the cut face. In the next step, air permeability, hydraulic conductivity, and electrical property (electrical conductivity and permittivity) measurements will be made on representative lithofacies. In the next step, the samples will be taken for granulometric analysis. Granulometric data will be coupled with the permeability measurements to delineate the hydrogeological facies (Ward et al. 2003; Murray et al. 2003). Samples will be taken from the different lithofacies types and characterized hydraulically, based on laboratory measurements. These samples will also be characterized chemically to determine the sorption parameters. The analyses described above will provide 2-D distributions of permeability, mean grain diameter, and CEC, based on relationships developed in the laboratory. These results will be extended to 3-D using ground-penetrating radar profiles derived from surface measurements along the length of the transect.

\subsection{3-D Ground Penetrating Radar Facies}

There is a gap between the typical local-scale measurement and a scale of practical interest, which is often much larger. GPR has the potential to fill this gap by providing information over multiple scales. Figure 3.3 shows a plot of 3-D GPR data collected from the S-16 Pond Dike (Clement 2000). The continuity and 3-D geometry of these data show the changing shape and depth of the reflections. The data quality suffered from linear noise throughout the sections was probably the result of relatively high conductance soils at the surface. However, removal of the top $1.5 \mathrm{~m}(5 \mathrm{ft})$ at the test site should eliminate this problem. The $100-\mathrm{MHz}$ data produced the best results with reflections from depths as great as $12 \mathrm{~m}$ (39 ft). Diffractions and disrupted zones indicate the possible presence of clastic dikes. Coherent reflections were clearly present in the upper few meters, suggesting the presence of near-surface heterogeneity. In FY 2002, CMP data were collected at two locations along the profiles during each field campaign, and this proved to be insufficient. One was located directly above the clastic dike $(\sim 50 \mathrm{~m}[\sim$ $164 \mathrm{ft}$ ] from the starting point) and the other at $\sim 40 \mathrm{~m}(130 \mathrm{ft})$ from the starting point. Measurements with the $450-\mathrm{MHz}$ antennas started with an antenna separation of $26 \mathrm{~cm}$ (10 in.) and were moved away from one another in steps of $2 \mathrm{~cm}(0.8 \mathrm{in}$.) (i.e., the transmitting antenna and receiving antenna each moved $1 \mathrm{~cm}[0.4 \mathrm{in}]$.$) . The 225-\mathrm{MHz}$ antennas started with an antenna separation of $26 \mathrm{~cm}$ (10 in.), and they were moved away from one another in steps of $4 \mathrm{~cm}(1.6 \mathrm{in}$.$) .$

In the FY 2003 test, two surface GPR surveys will be conducted at the site, one before the infiltration tests and one after excavation of the transect to allow development of 3-D maps of heterogeneity. The goal is to generate a 3-D map of radar facies of the test site. The radar facies map will then be coupled with observed lithofacies and measurements of hydraulic properties in order to generate a 3-D map of hydrofacies for use in a numerical model of the experiment. TO generate the radar facies map, a series of common-offset GPR profiles will be collected parallel to the transect using the PulseEKKO IV system with a transmitter voltage of $1000 \mathrm{~V}$. Antenna frequencies of 100,200 , and $450 \mathrm{MHz}$ will be used to collect these profiles. As shown by Szerbiak et al (2001), the 100-MHz antenna provides a good compromise of vertical resolution $(\sim 0.5 \mathrm{~m})$ and penetration depth $(\sim 15 \mathrm{~m})$. The $200-\mathrm{MHz}$ antenna has a higher resolution at $(\sim 0.3 \mathrm{~m}[\sim 1 \mathrm{ft}])$, but a penetration depth of $<10 \mathrm{~m}(<33 \mathrm{ft})$ is ideal for getting a detailed description of the upper $5 \mathrm{~m}(16.4 \mathrm{ft})$ of the transect, which is equivalent to the depth of penetration of most plumes beneath leaking tanks. First CMP gathers will be recorded at predetermined 


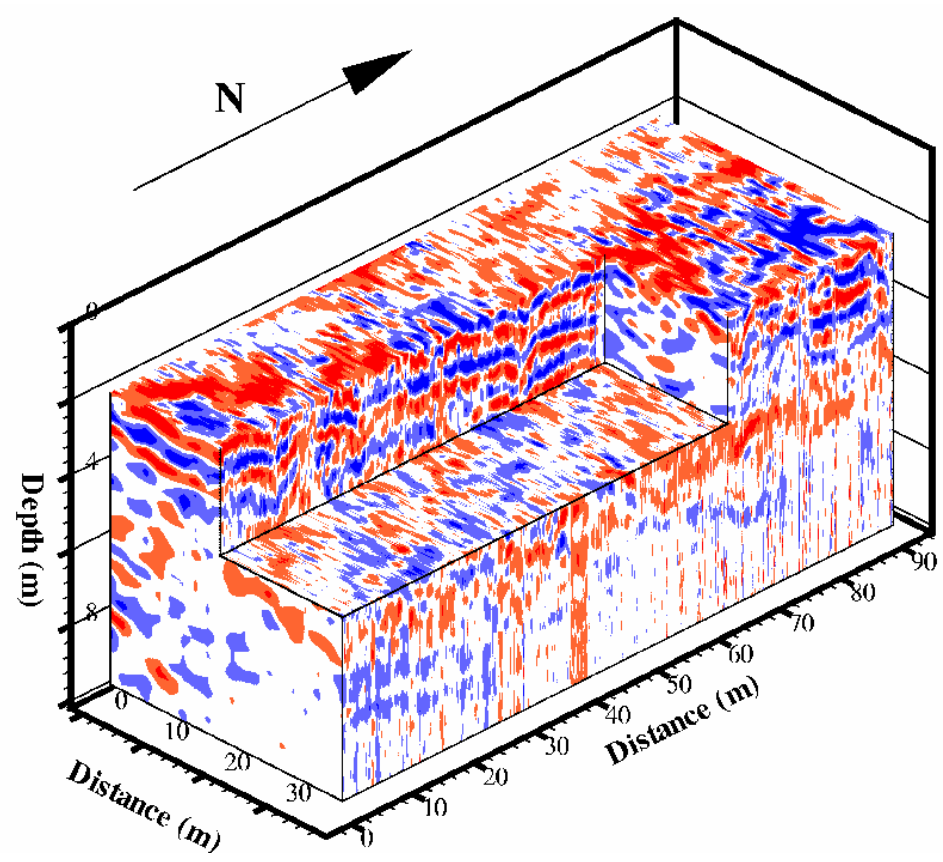

Figure 3.3. Three Dimensional Chair Diagram of the 216-S-16 Pond Data. The upper $2 \mathrm{~m}$ of data are removed to show the structure at depth.

locations along the transect to permit velocity calculations and to optimize the source-receiver spacing for use in the common-offset profiles. The profiles will be collected on a rectangular grid of 20 east-west oriented lines, parallel to the line source, with a spacing of $0.5 \mathrm{~m}(1.6 \mathrm{ft})$ between adjacent lines. Owing to the depositional environment, lithofacies can be expected to have some spatial continuity, at least in the host matrix, that is correlated over some distance. Using an approach similar to that of Rea and Knight (1998), 3-D variogram modeling will be used to determine the correlation lengths of radar reflections and to obtain maps of subsurface heterogeneity. Given the relationship between lithology and electrical properties, the correlation structures derived from electrical properties will be used as indicators of the underlying heterogeneity and will be coupled with local lithofacies map and measured hydraulic properties to generate a 3-D hydrofacies map of the site.

\subsection{Multi-region Flow Parameters}

While the hydraulic conductivity and water-holding capacity of a soil can greatly influence water and solute transport, much of the chemical transport to groundwater can occur through preferential flow pathways. Simplified, preferential flow, mobile-immobile models partition the water content, $\theta$, into mobile $\left(\theta_{\mathrm{m}}\right)$ and immobile $\left(\theta_{\text {im }}\right)$ domains, with solute exchange between the domains characterized by a mass-exchange coefficient $(\alpha)$. However, before such models can be routinely used, their applicability must first be evaluated and the necessary parameters obtained. Successful application at the field scale will also require information about spatial trends and the relationship between these parameters and surface boundary conditions, particularly the water flux density, $\mathrm{J}_{\mathrm{w}}$. 
In the FY 2003 tests, an in situ method will be used to determine the mobile-immobile model parameters, $\theta_{\mathrm{m}}$ and $\theta_{\mathrm{im}}$, along the main transect (A-B) after the site has been surveyed by GPR and before the injection test. This method is based on a sequential tracer application technique and uses a tension infiltrometer to apply a series of four fluorobenzoate tracers at different pressure heads (Clothier et al. 1995). In this test, pressure heads of $10,-30,-60$, and $-150 \mathrm{~mm}(0.4,-1.2,-2.36$, and $-5.9 \mathrm{in}$.) will be used. The statistics (mean and variance, correlation length) of the flow-and-transport properties will be determined for the sequence of $\psi$ starting at the highest value and decreasing. Saturated hydraulic conductivities will also be measured along the transect using the Guelph permeameter. Relationships between the parameters will be identified and correlated to pore-water velocities and reactivity parameters determined later in the infiltration tests.

\subsection{Infiltration Tests}

The experiments will be conducted along a 60-m (197-ft) long transect at the clastic dike site using the infrastructure and design used in the FY 20902 tests. In addition to the existing instrumentation, the remaining TDR probes on the $0.5-\mathrm{m}$ (1.6-ft) spacing will be connected for monitoring. Probes will be multiplexed to a Tektronix 1502B reflectometer using Dynamax multiplexers. Data acquisition will be controlled by computer. Minor modifications will be made in the system wiring to reduce the effects of stray voltages, and the monitoring protocol will be changed to improve data-collection efficiencies. Additional stainless steel solution samplers/tensiometers will be added for sampling the $20 \mathrm{~cm}$ (7.9 in.) depth while the 40-cm (15.7-in.) and 80-cm (31.5-in.) samplers will be extended to the entire length of the transect.

Modifications in the tensiometer design are planned to reduce the effect of temperature on the pressure transducer measurements. Changes are also planned to simplify the conversion of the solution samplers to tensiometers and vice versa and to improve data quality. Each lysimeter will be fitted with a temperature-compensated pressure transducer and multiplexed using Cambell Scientific's AM416 multiplexers. Data acquisition will be controlled by a CR10 datalogger. Net infiltration rates will be determined from flux measurements using a water flux meter.

As in FY 2002, water will be applied from a surface-line source centered over the 1.0-m (3.3-ft) deep probe (Figure 3.1). Water will be applied at rates equivalent to $10^{2}, 10^{3}$, and $10^{4} \mathrm{~mm}(4,39$, and $394 \mathrm{in}$.) per $\mathrm{yr}^{-1}$ to confirm the existence of complementary flow domains identified in the modeling (Ward et al. 2003).

Application will start with the lowest rate and will proceed until steady state has been attained. Measurements of $\theta, \psi$, and water storage, $\mathrm{W}$, will be measured at frequencies varying from 30 min to $2 \mathrm{hr}$, depending on the probe depth and the stage of the infiltration. During wetting, the soil profile will be monitored for $\theta, \psi$, and W. At each flux, a direct measure of a $K(\theta)$ and $\psi(\theta)$ point on the wetting curve will be obtained. At steady state, a conservative tracer will be applied and a solute mass flux measured, from which the spatial distribution of the mean and variance of solute travel-time $(t)$ will be determined. The solute front was tracked using pore-water samples and TDR measurements of conductivity. Measurements made during subsequent drainage will provide the drainage branch of $\psi(\theta)$. The flux will be incremented once the tracer has been leached from the profile. Water and tracer fronts 


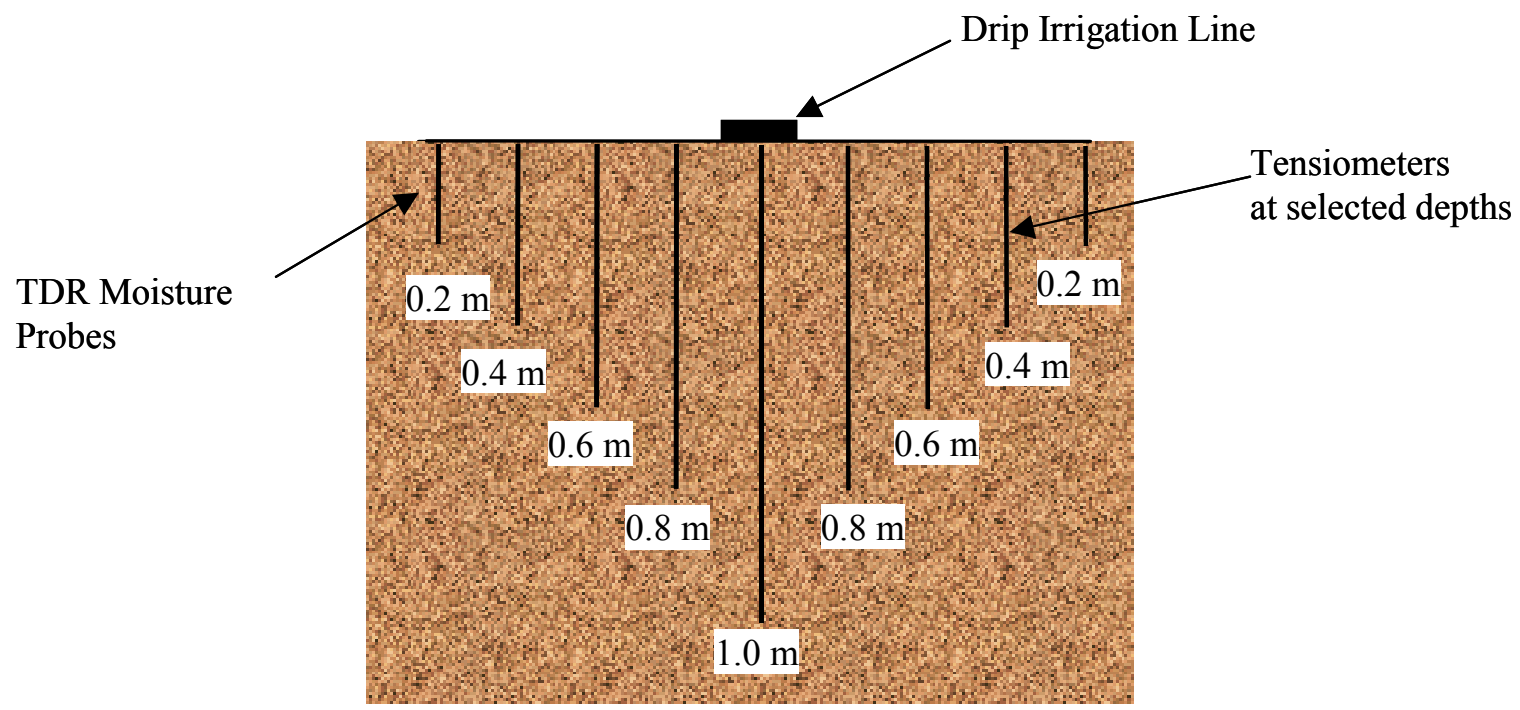

Figure 3.4. Schematic of Experimental Layout

will be monitored using neutron probe. Measurements of $\theta$, $\psi$, water storage (W), water and solute mass flux, transport volume $\left(\theta_{t}\right)$, and wetted surface area, $\mathrm{A}(\theta)$, that govern capillary and adsorption phenomena can be obtained at the local scale under 1-D, 2-D, or 3-D flow conditions. Permeameters and infiltrometers allow measurement of constitutive properties in 3-D space while changing the size of the volume of interrogation. Thus, coupling these techniques with non-invasive electromagnetic techniques (such as electromagnetic induction and ground-penetrating radar) for use in the Hanford vadose zone will be used to answer questions on 1) the effects of heterogeneity on unsaturated flow and transport, 2) the scale of heterogeneity definition required for predicting these processes, and 3) the relationship between constitutive properties measured at different support scales or in different volumes of investigation. At the same time, a unique data set to support the development of scaling laws applicable to unsaturated, heterogeneous soils would be obtained.

The steady-state measurements of $\psi, \mathrm{W}$, and $t$ will also be used to determine the constitutive properties through inverse methods. Relating each flux to the resulting equilibrium water content provides a direct measure of the unsaturated conductivity function. The water content and matric potential data provide a direct in situ measurement of the $\theta(\psi)$ function. Steady-state distributions of $\theta, \psi$, and $\mathrm{W}$ will also be analyzed by inverse methods to determine the macroscopic capillary length, $\alpha$, and the saturated hydraulic conductivity, $\mathrm{k}_{\mathrm{s}}$ using the method described Zhang et al. (2000). This method is based on an analytical solution for steady flow from a surface line source and is discussed in more detail in Section 6.

Solute breakthrough curves derived from electrical-conductivity measurements and pore-water analysis will be used to determine the longitudinal $\left(\mathrm{D}_{\mathrm{L}}\right)$ and transverse $\left(\mathrm{D}_{\mathrm{T}}\right)$ dispersion coefficients as well as their spatial-scale dependence. Data analysis will take advantage of the analytical solutions to the CDE presented by Leij et al (1991). This method assumes that solute transport is adequately described by the $\mathrm{CDE}$ at the local scale and that flow is steady with 1-D advection and 2-D or 3-D dispersion (Figure 3.2). Steady-state profiles of $\mathrm{C}=\mathrm{C}(\mathrm{x}, \mathrm{z}, \infty)$ will be used to determine $\mathrm{D}_{T}$, after which values of $\mathrm{D}_{\mathrm{L}}$ are determined by an iterative procedure. Details of this method are summarized by Ward and Gee (2002). 
Field-scale parameters will be determined by simultaneous inversion of the complete data set. The STOMP-UCODE procedures developed by Zhang et al. (2002c) will be extended to handle the analysis of transport measurements.

The resulting data will describe the local-scale flow-and-transport properties from which the spatial distribution of the mean and variance can be determined for evolving scales. The relationship between the volume of measurement and the constitutive properties will be established by quantifying the evolution of properties under the different flow conditions. These results will be compared with the sediment core data to establish the criteria to be satisfied by the scaled properties. To validate the scaling criteria, the infiltration experiment will be concluded by injecting a water-methanol mixture with a depressed surface tension $(\gamma)$, and the parameters will be reanalyzed. Changing $\gamma$ will change the $\psi(\theta)$ relationship of the soil in a predictable fashion without changing or deforming the existing pore structure and will allow validation of scaling methods developed.

The data derived from this study will be used to develop scaling theory applicable to unsaturated flow and transport in heterogeneous soils. The product will be an improved understanding of the relationships between the spatial variations in constitutive properties, observed flow-and-transport phenomena, and their scale dependence. This will improve our ability to develop representative conceptual and numerical models of vadose-zone transport. This result, in turn, will overcome a major hindrance to the evaluation of remediation and disposal options at different waste sites.

Data will be managed as described in Section 6.0. Data will be processed for display on a secure web site on which injection patterns, water-content changes, and pressure-profile responses can be observed in near-real time by collaborators and interested parties. An example of display capabilities for observing vadose-zone water-content changes, pressure-profile variations, and drainage responses to both natural and controlled boundary conditions is found by viewing the current Vadose Zone Transport web site where a Hanford test site (the Buried Waste Test Facility) near the 300 Area has been instrumented with water content, pressure, precipitation, and drainage sensors and is remotely monitored daily. These data can be found at http://etd.pnl.gov:2080/vadose/tensiometer.htm.

\subsection{Tracer Tests}

Apart from technetium-99 and tritium, strontium-90 and uranium are the two primary radionuclides measured in Hanford Tank farm characterization. Both radionuclides have migrated an appreciable distance from the sources in WMA B-BX-BY, suggesting enhanced mobility in the vadose zone at the time of the release events. The T, TX, and TY tank farms have waste streams similar to those in the B, $\mathrm{BX}$, and BY tank farms; thus, information on the field-scale transport of $\mathrm{Sr}^{++}$is critical. Strontium exists almost exclusively as the $\mathrm{Sr}^{2+}$ species between $\mathrm{pH} 3$ to 9.5, and it sorbs to sediments almost exclusively by cation exchange (Kaplan et al. 1998). The primary attenuation mechanism for strontium-90 in Hanford sediments is isotopic exchange with the labile, indigenous, stable isotopic pool. Most of the labile strontium repository exists on the cation exchange complex in the sediment. Data from B tank farm sediments show 20 to $60 \mu \mathrm{eq} / \mathrm{g}$ on the cation exchange complex indigenous strontium occupying 5 to $10 \%$ of the exchange complex (Zachara et al. 2002). With the recent success in the multi-component modeling of strontium sorption and desorption, it is anticipated that the relative simplicity of $\mathrm{Sr}^{++}$ geochemistry would ease data interpretation. With our improved understanding of the subsurface flow fields in heterogeneous media gained for the FY 2002 experiments coupled with the reactive modeling 
capabilities developed by the S\&T modeling team for $\mathrm{Sr}^{++}$, stable strontium is the ideal tracer for a fieldscale study.

For the FY 2003 field tests, two tracer studies using stable Sr++ will be performed. These tests will be designed to allow investigation of the dependence of the cation exchange on ionic strength and the presence of competing cations. Although information on the dependence of the divalent-monovalent cation exchange on ionic strength is of greatest importance, it will not be possible to use $\mathrm{NaNO}_{3}$, the obvious source for the monovalent $\mathrm{Na}^{+}$competitor, simply because the required concentrations will exceed regulatory limits. Sodium thiosulphate, which has been used in the past, has the capability to change the redox environment and the $\mathrm{pH}$, which could confound interpretation of the experimental results. Although lithium could be used in very small quantities, selectivity coefficients have not been measured in sediments onsite. Thus, in the first experiment, a tracer cocktail containing $0.5 \% \mathrm{SrCl}_{2} \cdot 6 \mathrm{H}_{2} \mathrm{O}$ $\left(2670 \mathrm{ppm} \mathrm{Sr}{ }^{++}\right.$) amended with a $1 \mathrm{~m} \mathrm{~mol} / \mathrm{L}$ solution of $\mathrm{Mg}^{++}$will be prepared. The addition of $\mathrm{Mg}^{++}$is to increase the competition for sorption sites and increase the mobility of $\mathrm{Sr}^{++}$. Calcium, while a good competitor, is present in already high concentrations, and the addition of calcium to enhance mobility might lead to precipitation reactions. Household bleach will be added to control the algal growth and prevent plugging of the irrigation system. A tracer will be applied after the plot has been brought to steady-state flow conditions at an input flux of $1000 \mathrm{~mm} \mathrm{yr}^{-1}$. In the second experiment, the same tracer cocktail will be used except that no magnesium will be added. This will have the effect of reducing the competition for reactive sites and increase the sorption of $\mathrm{Sr}^{++}$. Tracer migration will be tracked using solution samples and TDR conductivity measurements. The chloride ion, $\mathrm{Cl}^{-}$, will be tracked as the conservative tracer. Pore-water samples and soil extracts will be analyzed for anions using an ion chromatograph while cations will be determined by inductively coupled plasma techniques.

\subsection{Inverse Reactive Transport Modeling}

Natural soils contain a variety of different minerals and materials of varying texture. Because different minerals can have different types of cation exchange sites exhibiting different exchange selectivities, they are chemically heterogeneous (McBride 1994). This surface heterogeneity may explain the commonly observed "non-ideal" behavior of cation exchange in soils where exchange selectivities or exchange capacities may vary with solution conditions and spatial location. The objective of this task is to extend the STOMP-UCODE combination to include the CRUNCH multicomponent transport model simultaneously to determine hydraulic, transport, and ion exchange parameters from the field-scale observations of reactive transport. The latter include dispersivity, CEC, selectivity coefficients, and possibly initial concentrations of $\mathrm{Na}^{+}, \mathrm{K}^{+}, \mathrm{Ca}^{2+}, \mathrm{Mg}^{2+}, \mathrm{Sr}^{2+}$, and boundary concentrations of these cations. Because STOMP and CRUNCH are not fully coupled, optimum parameter estimates will determined by solving the inverse problem of water flow and reactive solute transport in a two-step procedure. In the first step, steady-state observations of water content and matric potential will be inverted to determine the distribution of hydraulic properties. In the next step, the best-fit transport parameters will be determined by minimizing the weighted sum of squares, which is a function of the differences between the experimental, calculated adsorbed amounts, and the sequential breakthrough of the porewater cations.

The parameters to be estimated are dispersivities, CECs, and selectivity coefficients. For a small number of sites, it is expected that the classical least-squares schemes will suffice to find the optimum set of parameters. However, as the number of sites entering the model increases, classical optimization schemes may become unstable, and fitted parameters may be nonunique and unidentifiable. To overcome 
this problem, techniques developed under the reactive transport scaling task will be used to extend the hydraulic-parameter scaling technique to reduce the number of reactive transport parameters to be fitted. In the second step, the flow solution and chemical reactions will be will be revised, and the sums of squares residual evaluated to determine if the fit has improved. On completion, it is expected that this resulting tool will have the capability to determine reactive transport parameters as well as initial cation concentrations and boundary concentrations. 


\subsection{Monitoring Technologies}

In FY 2003, we will use the same techniques that were used in FY 2002 (Ward and Gee 2002; Ward et al. 2002). In addition to those techniques, we will employ digital infrared and visible photography, small-scale air permeability measurements, mini disk infiltrometer measurements for hydraulic conductivity, and tension infiltrometer measurements to characterize the mobile-immobile transport parameters. The combination of high-resolution photography and permeability measurements will allow characterization of the site on the scale of millimeters (Figure 4.1) and allow the prediction of hydraulic properties over larger spatial scales based on GPR measurements. During the infiltration tests, the method used last year, namely, neutron-probe and time-domain reflectometry, will be used to monitor the movement of the infiltration front while TDR will also monitor the solute front. Tensiometers fitted with pressure transducers will be used to monitor matric potential up to steady-state flow conditions. At steady state, tensiometers will be converted to solution samples for collection pore-water samples.

These tools were evaluated in FY 2002 and shown to be useful at the Vadose Zone Test Facility (see Table 1.1, Project 30998, and the associated web site http://etd.pnl.gov:2080/vadose/). The boreholes emplaced for neutron logging and cross-borehole radar will also be used to establish a local datum to which all other measurements can be related spatially. A discussion of the different monitoring technologies, as well as their resolution and spatial sensitivity, is presented by Ward and Gee (2002).

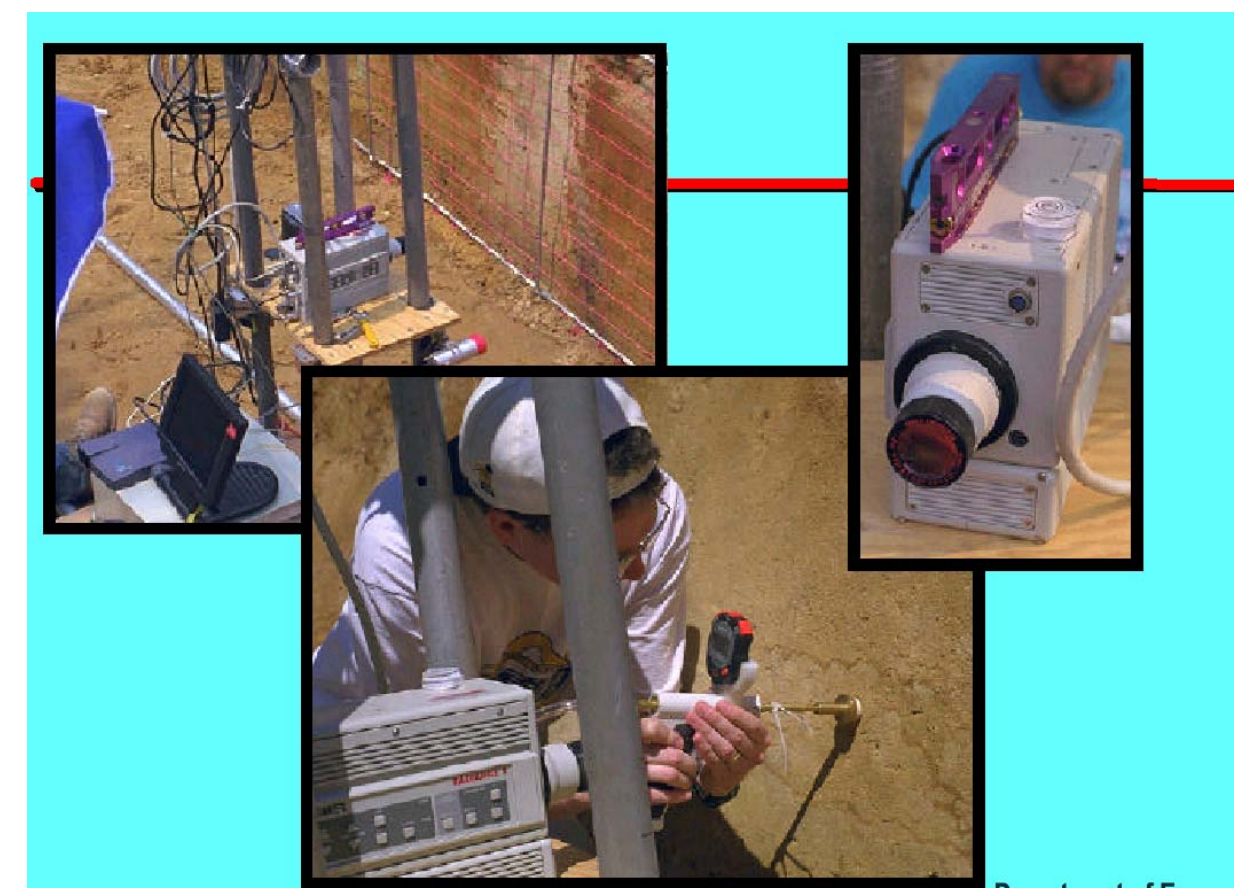

Figure 4.1. Field Setup for High-Resolution Digital Photography and Small-Scale Permeability Measurements 


\subsection{Sampling and Analysis}

As in previous tests, the entire site will be logged by neutron probe, TDR, and ground-penetrating radar to determine moisture distributions before water and tracer injection. Existing cone penetrometer (CPT)-pushed boreholes will provide access for the geophysical instrumentation.

Periodically during the course of the experiment, water content, matric potential, resistivity, and tracer concentrations will be monitored. Tensiometers will serve the dual purpose of monitoring matric potential and collecting pore-water samples. Similar determinations will be made on pore-water samples. On completion of the transport tests, the site will be excavated and the cut face characterized using ground-penetrating radar, visible and infrared photography, air permeameter measurements, and mini disk infiltrometer. Samples will be taken for granulometric analysis. The resulting time and depth history of tracer movement will be used to characterize transport properties using spatial and time-moment analyses as well as vadose-zone transport models.

\subsection{Hydraulic Properties}

Sampling will include 5-cm-OD (2-in.-OD) undisturbed cores to allow measurements of particle-size distributions, water retention, $\theta(\psi)$, saturated hydraulic conductivity, $\mathrm{k}_{\mathrm{s}}$, and bulk density, $\rho_{\mathrm{b}}$. The $\theta(\psi)$ will be measured for drainage conditions by equilibrating samples on pressure plates at matric potentials $\psi$ of $-0.5,-1,-3.3$, and $150 \mathrm{~m}(-1.6,-3.3,-10.8$, and $492 \mathrm{ft})$ with water content, $\mathrm{q}$, being determined by gravimetry after each equilibration. These cores will be taken at increments of $1 \mathrm{~m}(3.3 \mathrm{ft})$ along the horizontal and at depths of $0.25,0.5,1.0$, and $2.0 \mathrm{~m}(0.8,1.6,3.3$, and $6.6 \mathrm{ft})$ with more detailed sampling near interesting subsurface features. Larger undisturbed cores will be taken at selected locations for determining unsaturated hydraulic conductivity. Saturated hydraulic conductivity, $\mathrm{k}_{\mathrm{s}}$, will be measured using constant head techniques (Klute and Dirksen 1986, pp 687-734), and the unsaturated hydraulic conductivity, $\mathrm{K}(\psi)$, will be determined using an instantaneous profile method (Wessolek et al. 1994).

\subsection{Tracer Concentrations}

Tracer concentrations will be measured on soil-water extracts using ion chromatography. Samples for analysis of $\mathrm{Cl}^{-}$will be prepared using leaching methods described in the Sampling and Analysis Plan (Appendix B). PNNL will analyze pore-water extracts and solution samples to determine tracer depth and time-breakthrough curves. Tracer distributions will be analyzed to locate the center of mass (time or depth) and the variance about the mean for each cutface. Tracer concentrations will be fit to various models to quantify the transport velocity and the transverse and longitudinal dispersion coefficients for both conservative and reactive tracers. Pore water and soil-core data will be used to resolve mass balance.

Tracer analysis will also be conducted on solution extracts taken during the course of the experiment. These samples will be collected periodically by applying a vacuum to the array of solution samplers. The sampling schedule will be determined by premodeling the injection. However, the goal will be to obtain at least 15 samples per location to adequately describe the breakthrough curve. 
Pore-water samples will be analyzed for anions using an ion chromatograph while cations will be determined by inductively coupled plasma techniques. Fluoride, chloride, nitrite, nitrate phosphate, sulfate, and oxalate were separated on a Dionex AS4A column with an eluent of $1.75 \mathrm{mM}$

$\mathrm{NaHCO}_{3} / 1.85 \mathrm{mM} \mathrm{Na}_{2} \mathrm{CO}_{3}$ and measured using a conductivity detector following PNL-ALO-212, Rev. 1, which is based on U.S. Environmental Protection Agency (EPA) Method 9056, "Determination of Inorganic Anions by Ion Chromatography" found in SW-846 "Test Methods for Evaluating Solid Waste, Physical/Chemical Methods" that can be accessed online at http://www.epa.gov/epaoswer/hazwaste/test/sw846.htm (EPA 1994).

Cation analysis will be performed using an inductively coupled plasma unit. High-purity calibration standards will be used to generate calibration curves and to verify continuing calibration during the analysis run. If necessary, dilutions will be made of each to assure that the analysis falls within the linear calibration range of the instrument. Details are found in EPA Method 6010B, "Inductively Coupled Plasma-Atomic Emission Spectrometry" in the aforementioned online version of SW-846 (EPA 1996). Samples will be analyzed for $\mathrm{Na}^{+}, \mathrm{K}^{+}, \mathrm{Ca}^{2+}, \mathrm{Mg}^{2+}$, and $\mathrm{Sr}^{2+}$. 


\subsection{Equipment and Materials}

This section describes the equipment and materials (laboratory and field) required to conduct the field tests. The layout of the field site, including the new sampling locations, is shown in Figure 2.4. Details on the instrumentation have been described by Ward and Gee (2002). Most of the infrastructure needed for the FY 2003 is already in place. The following items will be required for infiltration and tracer testing for FY 2003:

- Holding tank (15,142 L [4000 gal]

- Two mixing tanks (757 L [200 gal])

- Delivery metering system capable of delivering approximately $700 \mathrm{~L}$ (185 gal)/hr (3 gpm)

- Ion specific probe for chloride

- Sample vials

- Extraction (vacuum) pump-for moving samples from solution samples

- Site trailer

- Refrigerator for samples

- Portable computers for sampling and data collection with Excel. 


\subsection{Data Management}

A project database has been established for storing and managing laboratory and field data. A project-data custodian will be designated to control and maintain the data and to make them available on a secure project web site. The data will be stored electronically in a mutually agreeable format or software package, and task leaders will provide hard copies to the data custodian for storage in the project files. During the course of the experiment, data access will be vital to the success of each test, and data sharing and their interpretation are encouraged. The following information must be included, as a minimum, in the database:

- Sample identifier

- Sample spatial location

- Sampling time

- Sampling date

- Analysis date

- Laboratory name

- Variable measured and value

- Measurement unit.

Processed data from the FY 2000 and FY 2001 tests have been posted on the VZTFS web site, and raw data are available on CD ROM. Papers representative of the FY 2000 field test were presented in a special session at the annual fall meeting of the American Geophysical Union (AGU) in December 2000. Results will be publicized in peer-reviewed journals. 


\subsection{Data Analysis and Interpretation}

As the research proceeds, the scale at which one needs to understand and characterize the vadose zone may also change, which would imply that the resolution of the geophysics must change (either up or down). Through the series of planned tests, we can identify the scale at which characterization must be done to characterize contaminant plumes at the waste-site scale. Analysis of the experimental data to determine parameters and properties and their spatial representation will follow techniques started in FY 2001 and will continue through this year. The analysis of data from the field tests will be completed for inclusion in draft reports due in December 2003.

\subsection{Hydraulic Properties}

The physics that define the GPR method as specified in Topp et al. (1980) state that the dielectric constant of a soil is directly related to the water content of the soil. The electromagnetic wave propagation in the soil is related to the dielectric constant by the equation

$$
V=\frac{C}{\sqrt{\varepsilon}}
$$

where,

$$
\begin{aligned}
\mathrm{V} & =\text { radar-wave-propagation velocity } \\
\mathrm{C} & =\text { the speed of light in a vacuum } \\
\varepsilon & =\text { the relative dielectric permittivity. }
\end{aligned}
$$

Topp et al. (1980) then fit a third-degree polynomial equation, which relates the dielectric constant to volumetric water content $(\theta)$, to the soil data for a broad textural variety of soils. This is given by

$$
\varepsilon=3.03+9.3 \theta+1460 \theta^{2}-76.7 \theta^{3}
$$

This method is particularly useful because the dielectric constant of most soil particles is about 3 to 5 while the dielectric constant of water is about 81 , which means that water dominates the electromagnetic signature. The final product of the GPR survey is to develop soil-water distribution for a volume of porous material. Steady-state distributions of water content, pressure head, and water storage will be used with the solution of Zhang et al. (2000) to estimate the hydraulic properties by inverse methods. In situ measures of water content and pressure head at different fluxes will provide direct measurements of the water retention as a function of spatial scale.

\subsection{Transport Properties}

To describe 2-D and 3-D solute transport, both the longitudinal and transverse dispersion coefficients are needed. Zhang et al. (2000) extended existing steady-state solutions for constant-flux infiltration to obtain expressions for distributions of $\psi$, water storage, $\mathrm{W}$, and solute travel time, $\mathrm{T}$, for constant flux below a surface line source. The solution of Zhang et al. (2000) will be used to estimate the hydraulic 
properties by inverse methods. Leij et al. (1991) presented an analytical solution for the 2-D CDE for semi-infinite media with 1-D flow using a double integral transform. This solution will be used to determine values of $\mathrm{D}_{\mathrm{L}}$ during transient conditions and $\mathrm{D}_{\mathrm{T}}$ during steady-state flow, provided the flow field is known or can be measured. The inverse reactive transport model will be used to estimate dispersivities, CECs, and selectivity coefficients. For a small number of sites, it is expected that the classical least-squares schemes will suffice to find the optimum set of parameters.

\subsection{Geostatistical Determination of Spatial Correlation}

Although sedimentary units typically show a great degree of spatial variability, they also tend to show a distinct, directional correlation, which is thought to be related to depositional processes. This variability has been shown to affect transport processes. Analysis of the degree of spatial variability and identification of spatial correlation length scales will be based on the theory of regionalized variables. In this approach, a value of a parameter $Z($ e.g., $\theta, \psi)$ measured at a given location is considered a single realization taken from a probability distribution. The set of such values measured at different locations is then treated as a spatial array of random values. Application of the theory is based on the assumption that $Z$ is spatially stationary so that 1 ) each location is described by the same probability distribution, $\mathrm{f}(\mathrm{Z} ; \mathrm{x}, \mathrm{y})$, and 2) spatial covariance depends only on the separation between the measurements and not on the absolute location. To calculate the properties of $\mathrm{Z}$ without knowing $\mathrm{f}$, we require two assumptions: 1) staionarity and 2) ergodicity. Discrete measurements will be obtained at different times along the sampling transects and will be used to construct semivariograms. Experimental semivariograms will be calculated from the pre-injection GPR data as well as the water contents, pressure heads, water storage, and tracer travel times measured during the experiment. Semivariograms will be used to identify the spatial correlation structure and the correlation lengths (the distance at which a plateau in variance is reached) for each principle direction. The equation used to relate the directional correlation length for properties measured over an increasing spatial scale is

$$
\gamma(h)=\left(\frac{1}{2 N(h)}\right)_{j=1}^{N(h)}\left[Z_{j}(x+h)-Z_{j}(x)\right]^{2}
$$

where the sum is taken over the set of all measured pairs of values a distance $h$ apart; $h$ is the separation distance, $\mathrm{N}(\mathrm{h})$ is the number of measurement pairs separated by distance $\mathrm{h}$, and $Z(\mathrm{x})$ is the value at position $\mathrm{x}$. As the separation distance becomes greater along a given direction $s, \gamma(\mathrm{h})$ approaches an asymptotic value known as the correlation length, $\lambda_{\mathrm{s}}$, which represents the distance beyond which measurements of $Z$ are statistically independent. In some formations, $\gamma(\mathrm{h})$ may oscillate, an indication of a cyclical property. This might be expected at locations of fine-textured layers in a coarse host matrix such as silt lenses or polygon boundaries of a dike. In such instances, a model, such as the hole effect model, that takes this phenomenon would have to be considered. Methods such as those outlined above will be used to quantify the spatial correlation structure at the test site. 


\subsection{Schedule}

The project schedule is shown in Table 9.1.

Table 9.1. Preliminary Schedule for FY 2003 Experiment

\begin{tabular}{|c|c|c|c|c|}
\hline Date 2003 & Activity & NProbe & GPR & Solution Samples \\
\hline 30-Apr & Site walk down & & & \\
\hline 5-May & Baseline logging & $\mathrm{X}$ & $\mathrm{X}$ & \\
\hline 12-May & Instrumentation tests & & & \\
\hline 19-May & Instrumentation placed & & & \\
\hline 20-May & Drip lines installed & & & \\
\hline 22-May & Start water injection & & & \\
\hline 23-May & Monitor profile & $\mathrm{X}$ & & \\
\hline 23-May & Monitor profile & $\mathrm{X}$ & & \\
\hline 27-May & Monitor profile & $\mathrm{X}$ & & \\
\hline 28-May & Monitor profile & $\mathrm{X}$ & & \\
\hline 29-May & Collect samples & $\mathrm{X}$ & & $\mathrm{X}$ \\
\hline 2-Jun & Collect samples & $\mathrm{X}$ & & $\mathrm{X}$ \\
\hline 5-Jun & Inject tracers & $\mathrm{X}$ & & $\mathrm{X}$ \\
\hline 6-Jun & Collect samples & $\mathrm{X}$ & $\mathrm{X}$ & $\mathrm{X}$ \\
\hline 9-Jun & Collect samples & & & $\mathrm{X}$ \\
\hline 11-Jun & Collect samples & $\mathrm{X}$ & & $\mathrm{X}$ \\
\hline 13-Jun & Collect samples & & & $\mathrm{X}$ \\
\hline 16-Jun & Collect samples & & & $\mathrm{X}$ \\
\hline 19-Jun & Collect samples & $\mathrm{X}$ & & $\mathrm{X}$ \\
\hline 23-Jun & Collect samples & & & $\mathrm{X}$ \\
\hline 26-Jun & Collect samples & & & $\mathrm{X}$ \\
\hline 30-Jun & Collect samples & $\mathrm{X}$ & & $\mathrm{X}$ \\
\hline 2-Jul & Collect samples & & & $\mathrm{X}$ \\
\hline 7-Jul & Collect samples & & $\mathrm{X}$ & $\mathrm{X}$ \\
\hline 9-Jul & Increase flowrate & & & $\mathrm{X}$ \\
\hline 14-Jul & Introduce $2^{\text {nd }}$ Tracers & $\mathrm{X}$ & & $\mathrm{X}$ \\
\hline 17-Jul & Collect samples & & & $\mathrm{X}$ \\
\hline 21-Jul & Collect samples & & & $\mathrm{X}$ \\
\hline 24-July & Collect samples & & & $\mathrm{X}$ \\
\hline 28-Jul & Collect samples & & & $\mathrm{X}$ \\
\hline 31-Jul & Collect samples & & & $\mathrm{X}$ \\
\hline 4-Aug & Collect samples & & & $\bar{X}$ \\
\hline 7-Aug & Collect samples & & & $\mathrm{X}$ \\
\hline 11-Aug & Collect samples & & & $\mathrm{X}$ \\
\hline 14-Aug & Collect samples & & & $\mathrm{X}$ \\
\hline 25-Aug & Shut off irrigation & $\mathrm{X}$ & $\mathrm{X}$ & $\mathrm{X}$ \\
\hline 25-Aug & Excavate transect & $\mathrm{X}$ & & $\mathrm{X}$ \\
\hline 29-Aug & Terminate test & & & $\mathrm{X}$ \\
\hline
\end{tabular}




\subsection{Health and Safety}

An excavation permit (No. DAN-1737) was obtained for work at this site in FY 2001 and will be revised to accommodate the proposed work. The work will be conducted in an environmentally compliant manner that includes radiation protection to workers. Safety and health issues relating to the VZTFS are addressed in site-specific safety documents (Appendix D) that identify radiological and industrial safety health hazards as well as other measures to protect against these hazards. Safety documents include specific training requirements that must be met by all site workers and visitors. Jobspecific Health and Safety Plans for drilling, instrument installation activities, and sampling activities are also specified in Appendix D. Briefings will be conducted with all site visitors to assure that health and safety issues are understood and that safe practices will be followed during the course of the experiments. All VZTFS participants are required to read and sign the Health and Safety Plan before entering the field site. 


\subsection{Waste and Residuals Management}

\subsection{Management Activity A - Solid Waste Management Plan for Cone Penetrometer/Tensiometer Installation}

Scope: This plan covers waste disposition for the waste generated from cone penetrometer installations for the Vadose Zone Transport Field Study.

Anticipated Waste Streams: Based on the project test plan, the only anticipated waste streams from the above activities are nonregulated, nonhazardous solid wastes, which may include paper, plastic, rags, etc. These materials have been designated as nonhazardous. The determination has also been made that the test site is a nonradiological area, and therefore, none of the waste would be classified as radiological low-level waste.

Waste Management: The waste stream described above will be disposed of to a normal "trash" receptacle. The management of any other unanticipated solid waste will be in accordance with PNNL internal waste-management procedures.

Contingency Plan: In the event of a spill or accidental release of a material to the environment, the procedure for spill response (http://sbms.pnl.gov/standard/0e/0e00t010.htm) will be in effect.

If a spill occurs, call 375-2400.

\subsection{Management Activity B - Soil Management Plan}

Scope: This plan covers the disposition of the soil generated from drilling activities for the Vadose Zone Transport Field Study Clastic Dike study site.

Anticipated Waste Streams: Based on the project test plan, there are no anticipated waste streams from the drilling activities, including drilling the injection well and drilling to install tensiometers and other instrumentation.

The soil from the drilling activity is environmental media and, other than soil samples to be taken for characterization and analysis, the soil will all be returned to the cores from which it came.

If solid waste is produced during these activities, it is anticipated that it would be nonregulated, nonhazardous solid wastes, which may include paper, plastic, rags, etc. These materials have been designated as nonhazardous. The determination has also been made that the test site is a nonradiological area, and therefore, none of the waste would be classified as radiological low-level waste.

Waste Management: The waste stream described above (paper, plastic, etc.) will be disposed of to a normal "trash" receptacle. 
The management of any other unanticipated solid waste will be in accordance with PNNL internal waste-management procedures.

Contingency Plan: In the event of a spill or accidental release of a material to the environment, the procedure for spill response (http://sbms.pnl.gov/standard/0e/0e00t010.htm) will be in effect.

If a spill occurs, call 375-2400. 


\subsection{Quality Assurance}

All work conducted by PNNL shall be performed in accordance with appropriate standards of quality, reliability, environmental compliance, and safety based on client requirements, cost and program objectives, and potential consequences of malfunction or error. To provide clients with quality products and services, PNNL has established and implemented a formal Quality Assurance (QA) Program. These management controls are documented in the PNNL Standards-Based management System (SBMS). Staff at PNNL, Bechtel Hanford Incorporated (BHI), and U.S. Department of Energy-Richland Operations (DOE-RL) can access the SBMS menu. PNNL staff can go to PNNL's internal home page at http://labweb.pnl.gov/ and select "Policies \& Procedures (SBMS)." Offsite users can access SBMS by going to http://sbms.pnl.gov/. This QA Plan also complies with the format requirements of QAMS005/80 (Interim Guidelines and Specifications for Preparing Quality Assurance Project Plans). If other quality-related activities are later performed, the appropriate SBMS requirements and procedures shall be applied unless specifically excluded. 


\subsection{References}

Alexander DJ, and VG Johnson. 1993. Groundwater Impact Assessment Report for the 1325-N Liquid Waste Disposal Facility. WHC-EP-0675, U.S. Department of Energy, Office of Environmental Restoration and Waste Management, Richland, WA.

Arya LM, FJ Leij, PJ Shouse, and MTh van Genuchten. 1999. "Relationship between the hydraulic function and the particle size distribution." Soil Sci. Soc. Am. J. 63:1063-1070.

Blake GR, and KH Hartge. 1986. "Bulk Density." In Methods of Soil Analysis, Part I. Physical and Mineralogical Methods: Agronomy Monograph no. 9 ( $2^{\text {nd }}$ ed.). In A. Klute (ed.) Methods of Soil Analysis, Part 1. Physical and Mineralogical Methods, Agronomy Monograph 9, American Society of Agronomy, Madison, WI.

Boekhold AE, SEATM van der Zee, and FAM de Haan. 1991. "Spatial patterns of cadmium contents related to soil heterogeneity." Water, Air and Soil Pollution. 57-58:479-488.

Bond WJ, and PJ Wierenga. 1990. "Immobile Water During Solute Transport in Unsaturated Sand Columns." Water Resour. Res. 26:2475-2481.

Bosma WJP, and SEATM van der Zee. 1993. "Transport Of Reacting Solute In A One-Dimensional, Chemically Heterogeneous Porous Medium.” Water Resour. Res. 29 (1):117-131.

Bottcher J. 1997. “Use of Scaling To Quantify Variability of Heavy Metal Sorption Isotherms.” Eur. J. Soil Sci. 48(3):379-386.

Bower CA, RF Reitemeier, and M Fireman. 1952. "Exchangeable Cation Analysis of saline and alka; I soils." Soil Sci. 73:252-261.

Brooks RH, and AT Corey. 1964. "Hydraulic properties of porous media." Hydrol. Pap. 3, Colorado State University, Fort Collins, CO.

Burdine NT. 1953. "Relative permeability calculations from pore-size distribution data." Trans. AIME, 198:71-77.

Burr DT, EA Sudicky, and RL Naff. 1994. "Nonreactive And Reactive Solute Transport in 3Dimensional Heterogeneous Porous-Media - Mean Displacement, Plume Spreading, and Uncertainty." Water Resour. Res. 30:791-815.

Campbell GS. 1974. "A simple method for determining unsaturated conductivity from moisture retention data." Soil Sci. 117:311-314.

Cernik M, K Barmettler, D Grolimund, W Rohr, M Borkovec, and H Sticher. 1994. "Cation-Transport In Natural Porous-Media on Laboratory-Scale - Multicomponent Effects." J. Contam. Hydrol. 16(4):319337. 
CH2M HILL. 2002. Field Investigation Report for Waste Management Area S-SX. RPP-7884, Rev. 0. CH2M HILL Hanford Group, Inc., Richland, WA.

Clement WP. 2000. GPR Data Acquired to Image Clastic Dikes at the Hanford Site, Hanford,

Washington. Technical Report BSU CGISS 00-07, Center for Geophysical Investigation of the Shallow Subsurface, Boise State University, Boise, ID.

Clothier BE, L Heng, GN Magesan, and I Vogeler. 1995. "The Measured Mobile-Water Content of an Unsaturated Soil as a Function of Hydraulic Regime.” Aust. J. of Soil Res. 33 (3):397-414.

Cvetkovic V, and G Dagan. 1994. "Transport of Kinetically Sorbing Solute By Steady Random Velocity In Heterogeneous Porous Formations.” J. Fluid Mech. 265:189-215.

DOE, see U.S. Department of Energy.

EPA, see U.S. Environmental Protection Agency.

Fayer, MJ, and TB Walters. 1995. Estimated Recharge Rates at the Hanford Site. PNL-10285, Pacific Northwest Laboratory, Richland, WA.

Fecht KR, KA Lindsey, BN Bjornstad, DG. Horton, GV Last, and SP Reidel. 1998. Clastic Injection Dikes of the Pasco Basin and Vicinity. BHI-01003, Draft A, Bechtel Hanford Inc., Richland, WA.

Flint SS, and ID Bryant. 1993. The Geological Modeling of Hydrocarbon Reservoirs and Outcrop Analogues. Blackwell Scientific Publications, Spec. Publ. Int. Assoc. of Sedimentologists No. 15.

Gee GW, and JW Bauder. 1986. "Particle Size Analysis.” In Methods of Soil Analysis, Part 1, ed. A. Klute, pp. 383-409. American Society of Agronomy, Madison, WI.

Gephart RE. 2001. A Short History of Hanford Waste Generation, Storage and Release. PNNL-13605, Rev. 1, Pacific Northwest National Laboratory, Richland, WA.

Gephart RE, and RE Lundgren. 1998. Hanford Tank Cleanup: A Guide to Understand the Technical Issues. Battelle Press, Richland, WA.

Hartman MJ, LF Morasch, and WD Webber. 2002. Hanford Site Groundwater Monitoring for Fiscal Year 2001. PNNL-13788. Pacific Northwest National Laboratory, Richland, WA.

Huggenberger P, M Rauber, and F Stauffer. 1994. "Integration of geophysical and sedimentological information in the stochastic description of inhomogeneities in fluvial gravel deposits." In: Transport and Reactive Processes in Aquifers (ed. by T. Dracos and F. Stauffer), IAHR Symp. Zürich, Switzerland, April 1994, 177-181, Balkema, Rotterdam.

Jacobs Engineering Group Inc. 1997. Engineering Calculations for the Supplement Analysis for the Tank Waste Remediation System Decision Assessment. Richland, WA.

Jacobs Engineering Group Inc. 1998a. Final AX Tank Farm Vadose Zone Screening Analysis for the Retrieval Performance Evaluation Criteria Assessment. Richland, WA. 
Jacobs Engineering Group Inc. 1998b. Final SX Tank Farm Vadose Zone Screening Analysis for the Retrieval Performance Evaluation Criteria Assessment. Richland, WA.

Jussel P, F Stauffer, and T Dracos. 1994. "Transport modeling in heterogeneous aquifers: 1. Statistical description and numerical generation of gravel deposits." Water Resour. Res. 30:1803-1817.

Kabala ZK., and G Sposito. 1991. "A Stochastic Model of Reactive Solute Transport with Time-Varying Velocity in a Heterogeneous Aquifer." Water Resour. Res. 27:241-350.

Kaplan DI, KE Parker, and IV Kutynakov. 1998. Radionuclide Distribution Coefficients for Sediments Collected from Borehole 299-E17-21: Final Report for Subtask 1a. PNNL-11996, Pacific Northwest National Laboratory, Richland, WA.

Kaplan DI, and RJ Serne. 1999. Geochemical Data Package for the Hanford Immobilized Low-Activity Tank Waste Performance Assessment (ILAW-PA). PNNL-13037, Pacific Northwest National Laboratory, Richland, WA.

Khaleel R. 1999. Far-Field Hydrology Data Package for Immobilized Low-Activity Tank Waste Performance Assessment. HNF-4769, Rev. 1, Fluor Daniel Northwest, Inc., Richland, WA.

Klute A, and C Dirksen. 1986. "Hydraulic conductivity and diffusivity: Laboratory methods." In Methods of soil Analysis, Part 1, by Klute (ed.), ASA, Madison, WI.

Knepp AJ. 2002. Field Investigation Report for Waste Management Area B-BX-BY. RPP-10098. Rev. 0. CH2MHILL Hanford Group, Inc., Richland, WA.

Leij FJ, TH Skaggs, and MTh van Genuchten. 1991. "Analytical Solutions For Solute Transport In 3Dimensional Semi-Infinite Porous-Media.” Water Resour. Res. 27:2719-2733.

Lichtner PC, and JM Zachara. 2002. "Modeling Batch Reactor Ion Exchange Experiments of StrontiumCalcium-Magnesium-Potassium-Sodium on Hanford Sediments." Appendix D.2.3. In AJ Knepp. 2002. Field Investigation Report for Waste Management Area B-BX-BY. RPP-10098, Rev. 0., CH2MHILL Hanford Group, Inc., Richland, WA.

Mann FM, RJ Puigh II, PD Rittmann, NW Kline, JA Voogd, Y Chen, CR Eiholzer, CT Kincaid, BP McGrail, AH Lu, GF Williamson, NR Brown, and PE LaMont. 1998. Hanford Immobilized Low-Activity Tank Waste Performance Assessment. DOE/RL-97-69, U. S. Department of Energy, Richland, WA.

McBride MB. 1994. Environmental Chemistry of Soils. Oxford University Press, NY.

McHenry JR. 1957. Properties of soils of the Hanford Project. HW-53218, Hanford Atomic Products Operation, Richland, WA.

Meyer PD, ML Rockhold, CJ Murray, and Y-J Chien. 2002. "Uncertainty Assessment of a Parameterization Method for Vadose Zone Modeling," Eos Trans. AGU, 83(47), Fall Meet. Suppl., Abstract H22F-01. (Presentation at the 2002 Fall Meeting of the American Geophysical Union, San Francisco, CA). 
Miller EE, and RD Miller. 1956. "Physical theory for capillary flow phenomena." J. Appl. Phys., 27:324-332.

Mualem Y. 1976. "A new model for predicting the hydraulic conductivity of unsaturated porous media." Water Resour. Res. 12:513-522.

Murray CJ, AL Ward, JL Wilson, PE Long, BJ Lechler, WP Clement, PK Kannberg, and GW Gee. 2001. "The Effects of Clastic Dikes on Vadose Zone Transport at the Hanford Site, Southcentral Washington." In: Eos Trans. AGU, 82(47), Fall Meet. Suppl., Abstract H52A-0370.

Murray CJ, AL Ward, and JL Wilson. 2003. Influence of Clastic Dikes on Vertical Migration of Contaminants in the Vadose Zone at Hanford. Final Report EMSP. Project Number: 70193, Pacific Northwest National Laboratory, Richland, WA.

National Academy of Science. 2000. Research Needs in Subsurface Science. National Academy Press, Washington, D.C.

Petersen LW, P Moldrup, OH Jacobsen, and DE Rolston. 1996. "Relations between specific surface area and soil physical and chemical properties." Soil Sci. 161(1):9-21.

Rabideau AJ, and CT Miller. 1994. "Two-Dimensional Modeling of Aquifer Remediation Influenced b Sorption Nonequilibrium and Hydraulic Conductivity Heterogeneity." Water Resour. Res. 30:1457-1470.

Rea J, and R Knight. 1998. "Geostatistical analysis of ground penetrating radar data: a means of describing spatial variation in the subsurface.” Water Resour. Res. 34:329-339.

Reidel, S. P. and D. G. Horton. 1999. Geologic data package for immobilized low-activity waste 2001 performance assessment. PNNL-12257. Pacific Northwest National Laboratory, Richland, Washington.

Reynolds WD, and DE Elrick. 1985. "In situ measurement of field-saturated hydraulic conductivity, sorptivity, and the $\alpha$-parameter using the Guelph permeameter." Soil Sci., 140 (4):292-302.

Richards LA. 1954. Diagnosis and improvement of saline and alkali soils. U.S. Dept. of Agric., Agricultural Handbook No. 60.

Robin MJL, EA Sudicky, RW Gillham, and RG Kachanoski. 1991. "Spatial Variability of Strontium Distribution Coefficients and their Correlation with Hydraulic Conductivity in the Canadian Forces Base Borden Aquifer." Water Resour. Res. 27:2619-2632.

Rockhold ML, PD Meyer, Y-J Chien, and CJ Murray. 2002. "Effects of Model Grid Resolution and Parameter Upscaling on Predictions of Water Flow in Heterogeneous, Unsaturated Porous Media." In: Eos Trans. AGU, 83(47), Fall Meet. Suppl., Abstract H62B-0863. (Presentation at the 2002 Fall Meeting of the American Geophysical Union, San Francisco, CA.)

Rouston RC, RE Wildung, and RJ Serne. 1973. "A column cation-exchange capacity procedure for lowexchange capacity sands." Soil Sci. 115:107-112. 
Rouston RC, and KR Fecht. 1979. "Soil (sediment) properties of twelve Hanford wells with geologic interpretation.” RHO-LD-82 Rockwell Hanford Operations, Richland, WA.

Schulte A. 1995. Influence of Soil Sample Preparation on $\mathrm{Cd}$ and $\mathrm{Cu}$ Adsorption in Acid Forest Soils, Pflanz Bodenkunde 158 (5):465-467.

Serne RJ, GV Last HT Schaef, DC Lanigan, CW Lindenmeier, CC Ainsworth, RE Clayton, VL LeGore, MJ O'Hara, CF Brown, RD Orr, IV Kutnyakov, TC Wilson, KB Wagnon, BA Williams, and DS Burke. 2002. Characterization of Vadose Zone Sediment: Borehole 41-09-39 in the S-SX Waste Management Area. PNNL-13757-3, Pacific Northwest National Laboratory, Richland, WA.

Serne RJ, and VL LeGore. 1996. Strontium-90 Adsorption-Desorption Properties and Sediment Characterization at the 100 N-Area. PNL-10899, Pacific Northwest National Laboratory, Richland, WA.

Steefel CI, and KTB MacQuarrie. 1996. “Approaches to Modeling Reactive Transport in Porous Media." In: Reactive Transport in Porous Media, PC Lichtner, CI Steefel, and EH Oelkers (Eds), Reviews in Mineralogy, 34:83-125.

Steefel CI, and SB Yabusaki. 1996. OS3D/GIMRT, Software for Multicomponent-Multidimensional Reactive Transport: User's Manual and Programmer's Guide. PNL-11166, Pacific Northwest National Laboratory, Richland, WA.

Steefel CI, S Carroll, and S Roberts. 2002. "Strontium Migration In Hanford Sediment From The B-BXBY Tank Farm: A Cation Exchange Model Based On Laboratory Transport Experiments." Appendix D.2.5. In: Knepp AJ. 2002. Field Investigation Report for Waste Management Area B-BX-BY. RPP10098. Rev. 0. CH2MHILL Hanford Group, Inc., Richland, WA

Sugita F, and RW Gillham. 1995a. "Pore Scale Variation in Retardation Factor as a Cause of Nonideal Reactive Breakthrough Curves .3. Column Investigations. Water Resour. Res. 31 (1):121-128.

Sugita F, and RW Gillham. 1995b. "Pore Scale Variation in Retardation Factor as a Cause of Nonideal Reactive Breakthrough Curves .1. Conceptual-Model and Its Evaluation.” Water Resour. Res. 31(1):103112.

Sugita F, RW Gillham, and C. Mase. 1995. "Pore Scale Variation in Retardation Factor as a Cause of Nonideal Reactive Breakthrough Curves .2. Pore Network Analysis.” Water Resour. Res. 31 (1):113-119.

Szerbiak,R.B., G.A. McMechan, R.M. Corbeanu, C.Forster, and S.H. Snelgrove. 2001. "3-D characterization of a clastic reservoir analog: From 3-D GPR to a 3-D fluid permeability model." Geophysics 66(4): 1026-1037.

Tidwell VC, and JL Wilson. 1997. "Laboratory method for investigating permeability upscaling." Water Resour. Res. 33(7):1607-1616.

Todd ME. 2000. Data Quality Objectives Summary Report for the 200-TW-1 Scavenged Waste Group and 200-TW-2 Tank Waste Group Operable Units. BHI-01356, CH2M HILL Hanford Group, Inc., Richland, WA. 
Topp GC, JL Davis, and AP Annan. 1980. "Electromagnetic determination of soil water content: Measurements in coaxial transmission lines." Water Resour. Res. 16: 574-582.

United States Department of Energy (DOE). 1997. Waste Site Grouping for 200 Areas Soil Investigations. DOE/RL-96-81, Rev. 0, U.S. Department of Energy, Richland Operations Office, Richland, WA.

United States Department of Energy (DOE). 1998a. Groundwater/Vadose Zone Integration Project Specification. DOE/RL-98-48, U. S. Department of Energy, Richland, WA.

U.S. Department of Energy (DOE). 1998b. Removal Performance Evaluation for the AX Tank Farm. DOE/RL-98-72, Draft A, U.S. Department of Energy, Richland WA.

United States Department of Energy-Grand Junction Projects Office (DOE-GJPO). 1998. BX Tank Farm Report, GJO-98-40-TAR (GJPO-HAN-19), Grand Junction, CO.

U.S. Environmental Protection Agency (EPA). 1994. "Determination of Inorganic Anions by Ion Chromatography." Method 9056. In: Test Methods for Evaluating Solid Waste, Physical/Chemical Methods. SW-846. Available at: http://www.epa.gov/epaoswer/hazwaste/test/sw846.htm.

U.S. Environmental Protection Agency (EPA). 1996. "Inductively Coupled Plasma-Atomic Emission Spectrometry." Method 6010B. In: Test Methods for Evaluating Solid Waste, Physical/Chemical Methods. SW-846. Available at: http://www.epa.gov/epaoswer/hazwaste/test/sw846.htm.

Waite JL. 1991. Tank Wastes Discharged Directly to the Soil at the Hanford Site. WHC-MR-0227, U.S. Department of Energy, Office of Environmental Restoration and Waste Management, Richland, WA.

Ward, AL, GW Gee, and MD White. 1997. A Comprehensive Analysis of Contaminant Transport in the Vadose Zone Beneath Tank SX-109. PNNL-11463, UC-702. Pacific Northwest National Laboratory. Richland, WA.

Ward AL, and GW Gee. 2002. Vadose Transport Field Study: FY 2002 Test Plan. PNNL-13857, Pacific Northwest National Laboratory, Richland, WA.

Ward AL, GW Gee, ZF Zhang, and JM Keller. 2002. Vadose Zone Transport Field Study: FY 2002 Status Report. PNNL 14180, Pacific Northwest National Laboratory, Richland, WA.

Ward AL, CJ Murray, GW Gee, Y Xie, F Zhang, and GH Seedahmed. 2003. "Effects of Clastic Dikes on Flow in the Vadose Zone." (Submitted to Water Resources Research).

Wessolek G, R Plagge, FJ Liej, and MT van Genuchten. 1994. “Analyzing Problems in Describing Field and Laboratory Measured Soil Hydraulic Properties.” Geoderma, 64:93-110.

White MD, M Oostrom, MD Williams. 2001. Initial Assessments for S-SX Field Investigation Report FIR): Simulations of Contaminant Migration with Surface Barriers. PNWD-3111, Pacific Northwest National Laboratory, Richland, WA. 
Wood MI, R Khaleel, PD Rittmann, SH Finfrock, TH DeLorenzo, and DY Barbrick. 1996. Performance Assessment For The Disposal Of Low-Level Waste In The 200 West Area Burial Grounds. WHC-EP0645, Westinghouse Hanford Company, Richland, WA.

Zachara JM, SC Smith, and C Liu. 2002. "Ion Exchange Studies." RPP-10098, River Protection Project, Richland, WA. Appendix D.2.2. In: Knepp AJ. 2002. Field Investigation Report for Waste Management Area B-BX-BY. RPP-10098. Rev. 0. CH2MHILL Hanford Group, Inc., Richland, WA.

Zhang R. 1997. "Determination of soil sorptivity and hydraulic conductivity from the disk infiltrometer." Soil Sci. Soc. Am. J. 61:1024-1030.

Zhang ZF, RG Kachanoski, GW Parkin, and B Si. 2000. "Measuring hydraulic properties using a line source: II. Field test." Soil Sci. Soc. Am. J. 64:1563-4569.

Zhang ZF, AL Ward, and GW Gee. 2002a. "A Parameter Scaling Concept For Estimating Field-Scale Hydraulic Properties for Layered Soils." Vadose Zone J. (In Press)

Zhang ZF, AL Ward, GW Gee, and MD White. 2002b. "Parameter Estimation for Unsaturated Layered Soils Through a Combination of Non-similar Media Scaling and Inverse Flow Modeling." In: IAHR International Groundwater Symposium "Bridging the Gap between Measurement and Modeling in Heterogeneous Media, ” International Groundwater Symposium, Berkeley, CA, March 25-28 (In Press).

Zhang ZF, AL Ward and GW Gee. 2002c. Estimating Field-Scale Hydraulic Parameters of Heterogeneous Soils Using a Combination Parameter Scaling and Inverse Methods. PNNL-14109, Pacific Northwest National Laboratory, Richland, WA.

Zhang ZF, AL Ward, and GW Gee. 2003. "Describing the unsaturated hydraulic properties of anisotropic soils using a tensorial connectivity-tortuosity (TCT) concept.” Vadose Zone J. (In Press). 


\section{Appendix A}

\section{Excavation Permit (Dan 1737)}




\section{Appendix A: Excavation Permit (Dan 1737)}

Clastic Dike:

Antiaircraft Site H-42-Army Loop Road

\section{Strickland, Christopher E}

$\begin{array}{ll}\text { From: } & \text { Juracich, Samuel P } \\ \text { Sent: } & \text { Thursday, March 27, 2003 1:47 PM } \\ \text { To: } & \text { Gee, Glendon W; Stephenson, Michael J } \\ \text { Cc: } & \text { Clayton, Ray E; Keller, Jason M; Strickland, Christopher E } \\ \text { Subject: } & \text { RE: Water at the clastic dike }\end{array}$

Glendon - I have just finished reviewing the existing excavation permit (DAN-1946) and believe that you are still within the operating parameters. I will make a note-to-file indicating the enlargement of the original trench. Otherwise, please us DAN-1946.

Sam 


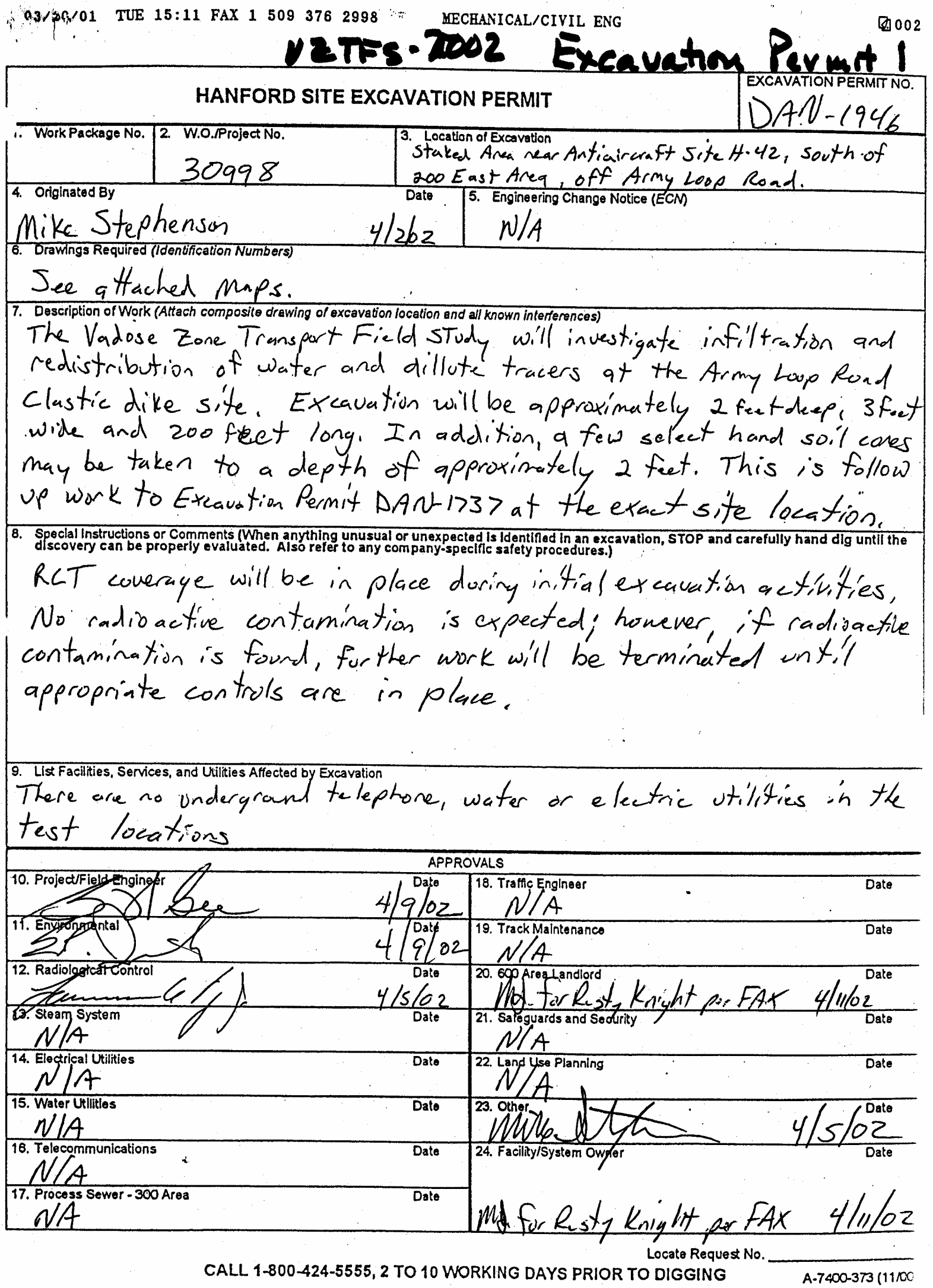




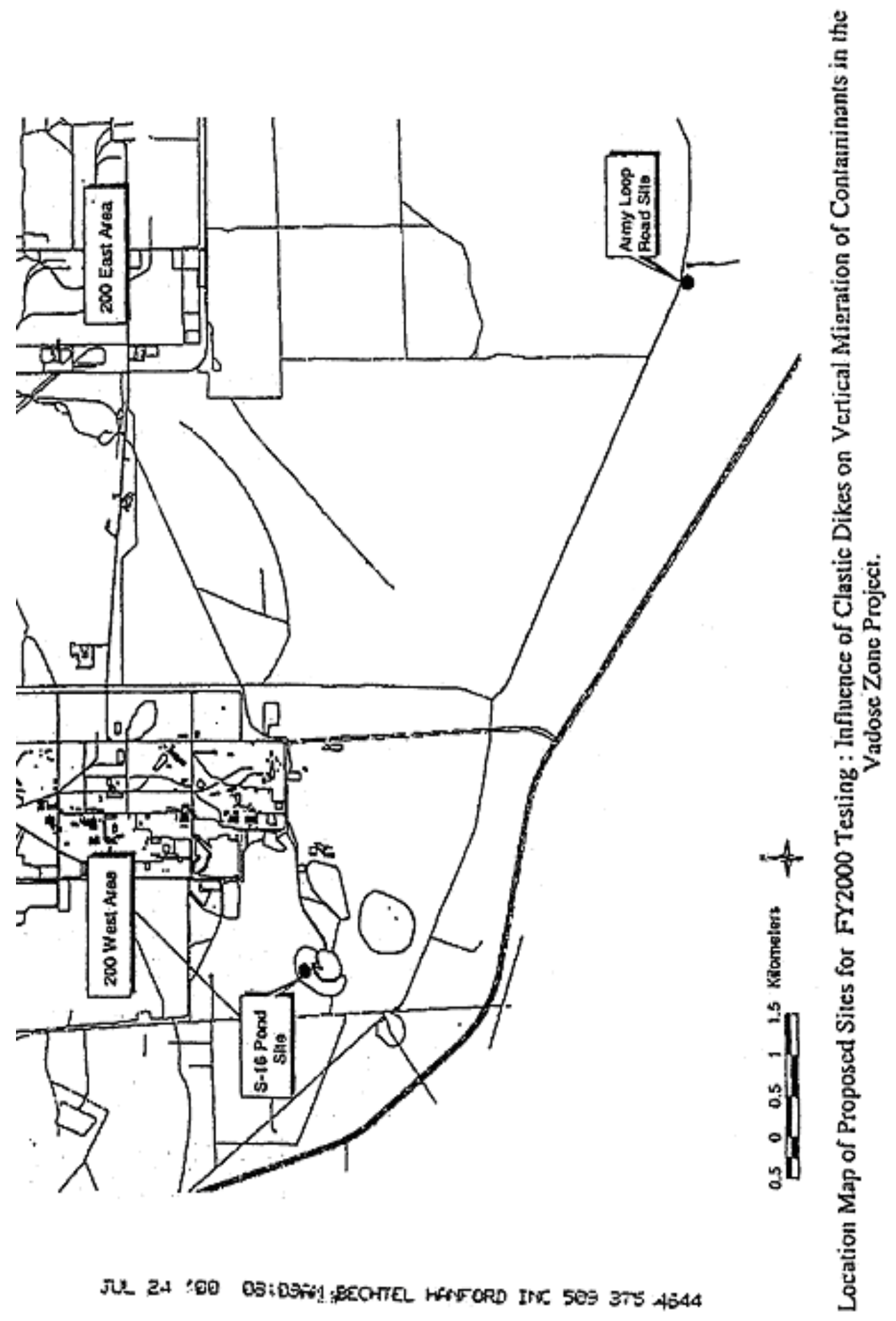




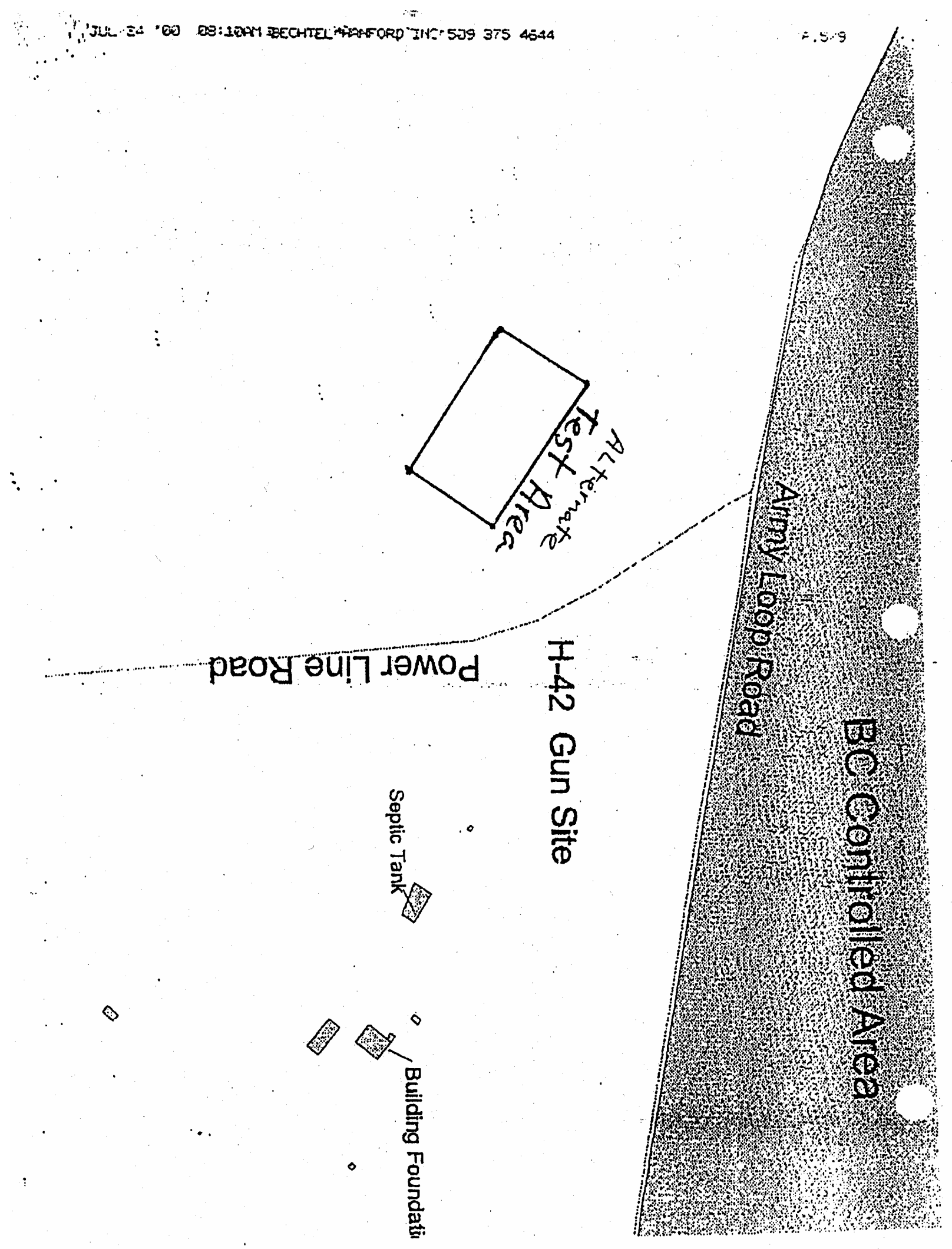


Stephenson, Michael J

From: Woody, Dave $M$

Sent: $\quad$ Tuesday, April 02, 2002 2:39 PM

To: Stephenson, Michael J

Subject: $\quad$ Vadose Zone Transport Field Study (HCRC\# 2002-600-018)

Mr. Stephenson,

Thank you for contacting our office regarding your project. This project is located south of the 200 East Area near Anti-Aircraft Site H-42 off of the Army Loop Road. The project will require excavation of a trench, 2 feet deep $\times 3$ feet wide $\times 200$ feet long, with several 2 feet deep hand excavated soil cores. All excavation will occur within the staked area near Anti-Aircraft Site H-42.

Per 36 CFR Part 800, Subpart B, 800.3.a, the DOE-RL Cultural Resources Program has concurred that this project is not the type of undertaking with potential to effect historic properties and no further actions are required. The finding is based on the following:

- The project is located in an area of low cultural sensitivity.

- A previous Cultural Resources Review and survey (HCRC 2000-600-032) conducted in June 2000 for Phase I of the same project determined that excavations at this locale would have no effect on historic properties.

All workers should be directed to watch for cultural materials (e.g. bones, artifacts) during all work activities. If any are encountered, work in the vicinity of the discovery must stop until and HCRL archaeologist has been notified, assessed the significance of the find, and, if necessary arranged for mitigation of the impacts to the find. The HCRL must be notified if any changes to project location or scope are anticipated.

We are tracking these kinds of projects, thus HCRC\# 2002-600-018 has been assigned to your request. This is your official notice of cultural resources review clearance.

Again, thank you for contacting us regarding your project.

Dave Woody, Archaeologist

Cultural Resources Project

PNNL 


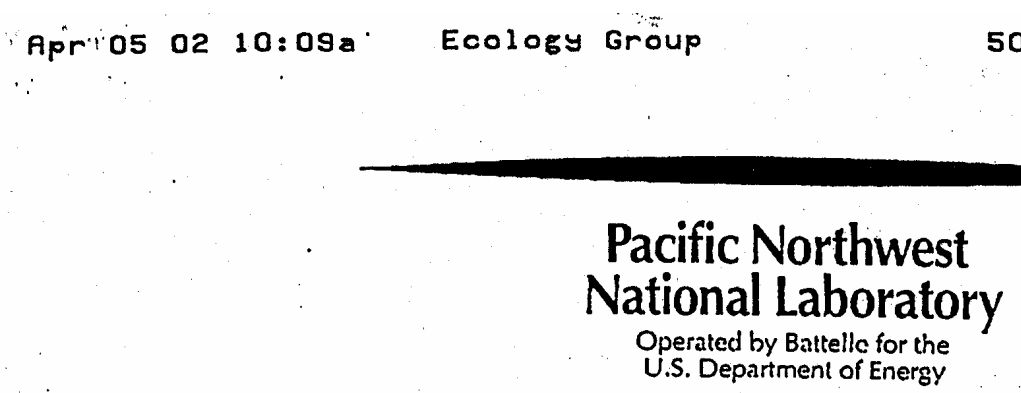

April 04, 2002

Mr. Glendon Gee'

Pacific Northwest National Laboratory

P. O. Box, MSIN K9-33

Richland, WA 99352

Dear Mr. Gee:

BIOLOGICAL REVIEW OF THE VADOSE ZONE TRANSPORT FIELD STUDY-ARMY

LOOP ROAD CLASTIC DIKE SITE, 600 Area, ECR \#2002 -600-018.

\section{Project Description:}

- Deployment of geophysical and soil physics techniques to investigate the infiltration and redistribution of water and dilute tracers in a controlled field experiment at the Army Loop Road clastic dike site. Activities are planned to begin in April and be completed by August, 2002. Activities include an excavation 2' deep, 3' wide, and 200' long.

- The Army Loop Road clastic dike site was previously reviewed under ECR \#2000-600032.

Survey Objectives:

- To determine the occurrence in the project area of plant and animal species protected under the Endangered Species Act (ESA), candidates for such protection, and species listed as threatened, endangered, candidate, sensitive, or monitor by the state of Washington, and species protected under the Migratory Bird Treaty Act.

- To evaluate and quantify the potential impacts of disturbance on priority habitats and protected plant and animal species identified in the survey.

Survey Methods:

- Pedestrian and ocular reconnaissance of the proposed project site were performed by J.M. Becker on April 3, 2002. The percent cover of dominant vegetation was visually estimated.

- Priority habitats and species of concern are documented as such in the following: Washington Department of Fish and Wildlife $(1994,1996)$, Washington State

90.2 Batlullu Bouluvard - 1?O. Box 999 - Kichland, WA Y9.352

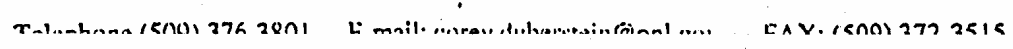




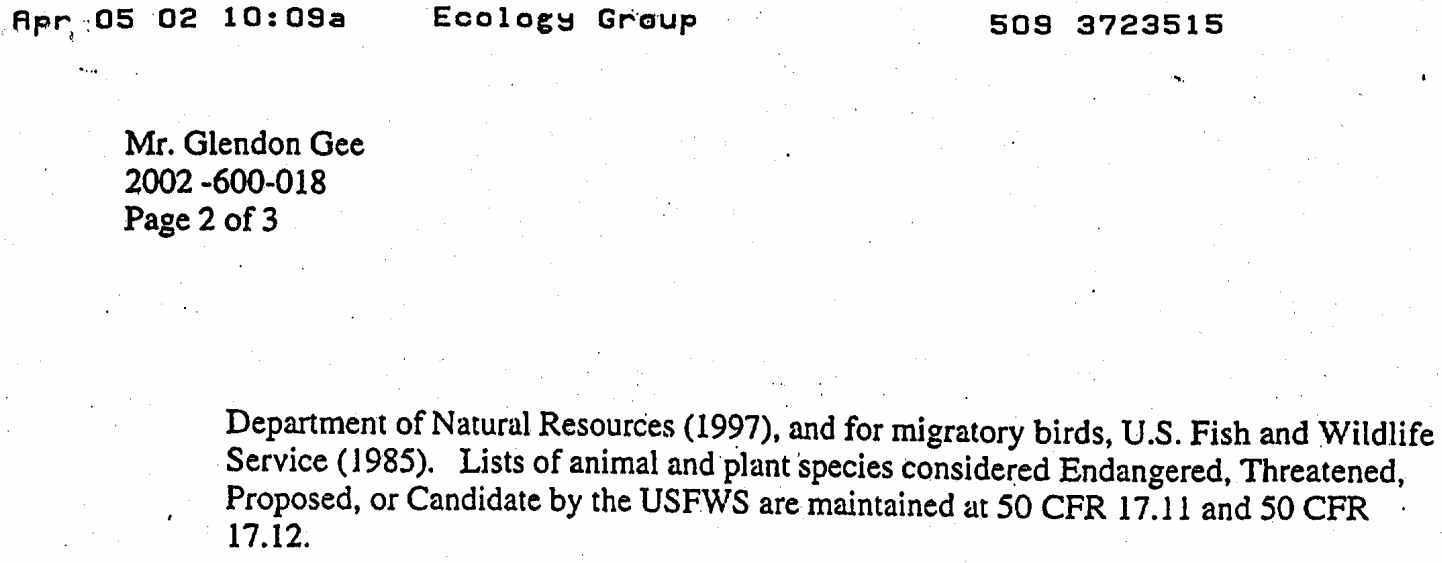

Mr. Glendon Gee

$2002-600-018$

Page 2 of 3

Department of Natural Resources (1997), and for migratory birds, U.S. Fish and Wildlife Service (1985). Lists of animal and plant species considered Endangered, Threatened, Proposed, or Candidate by the USFWS are maintained at 50 CFR 17.11 and 50 CFR 17.12.

\section{Survey Results:}

- The Army Loop Road clastic dike site was burned in the Hanford range fire of June, 2000 (Sackschewsky 2000). Much of the Army Loop Road clastic dike site has been previously excavated. There is very little vegetation on the excavated material. However, herbaceous species have begun to colonize the surrounding area. Herbaceous species consist largely of Sandberg's bluegrass (Poa sandbergii) and cheatgrass (Bromus teciorum), an alien annual weed.

- No migratory bird species were observed nesting in the vicinity of the proposed site.

\section{Considerations and Recommendations:}

- No plant or animal species protected under the ESA, candidates for such protection, or species listed by the Washington state government as threatened or endangered were observed in the vicinity of the proposed site.

- Although no migratory bird species were observed in the vicinity of the proposed site, the nesting season has just begun and ground-nesting species may yet elect to nest there. The duration of the nesting season is from approximately April 1 to July 31. Consequently, it is recommended that ground-disturbing activities be completed as soon as possible to minimize the possibility of encountering nesting birds. The nests, eggs, and young of migratory birds are protected under the Migratory Bird Treaty Act. If an active nest (birds or eggs in the nest) is encountered, we recommend contacting ECAP personnel for assistance.

- No adverse impacts to species, habitats, or other biological resources are expected to result from the proposed actions. 


$\because$ Apr 05 o2 10:09a Ecology Group $5093723515 \quad$ P.3

Mr. Glendon Gee

$2002-600-018$

Page 3 of 3

Sincerely,

Gamos M. Becker for:

Michael R. Sackschewsky

Project Manager

Ecological Compliance Assessment Project

MRS:cad

\section{REFERENCES}

Sackschewsky, M.R. 2000. Biological Review of the Clastic Dike Excavation Project, 600 Area, ECR \#2000-600-032. Letter Report to Chris Murray, Pacific Northwest National

Laboratory, Richland, Washington.

U. S. Fish and Wildlife Service. 1985. Revised List of Migratory Birds; Final Rule. 50 FR 13708 (April 5, 1985).

Washington Department of Fish and Wildlife. 1994. Species of Special Concern in Washington. (April 1994).

Washington Department of Fish and Wildlife. 1996. Priority Habitats and Species List. (January 1996).

Washington Department of Natural Resources. 1997. Endangered, Threatened \& Sensitive Vascular Plants of Washington (August 1997). 
HANFORD SITE EXCAVATION PERMIT

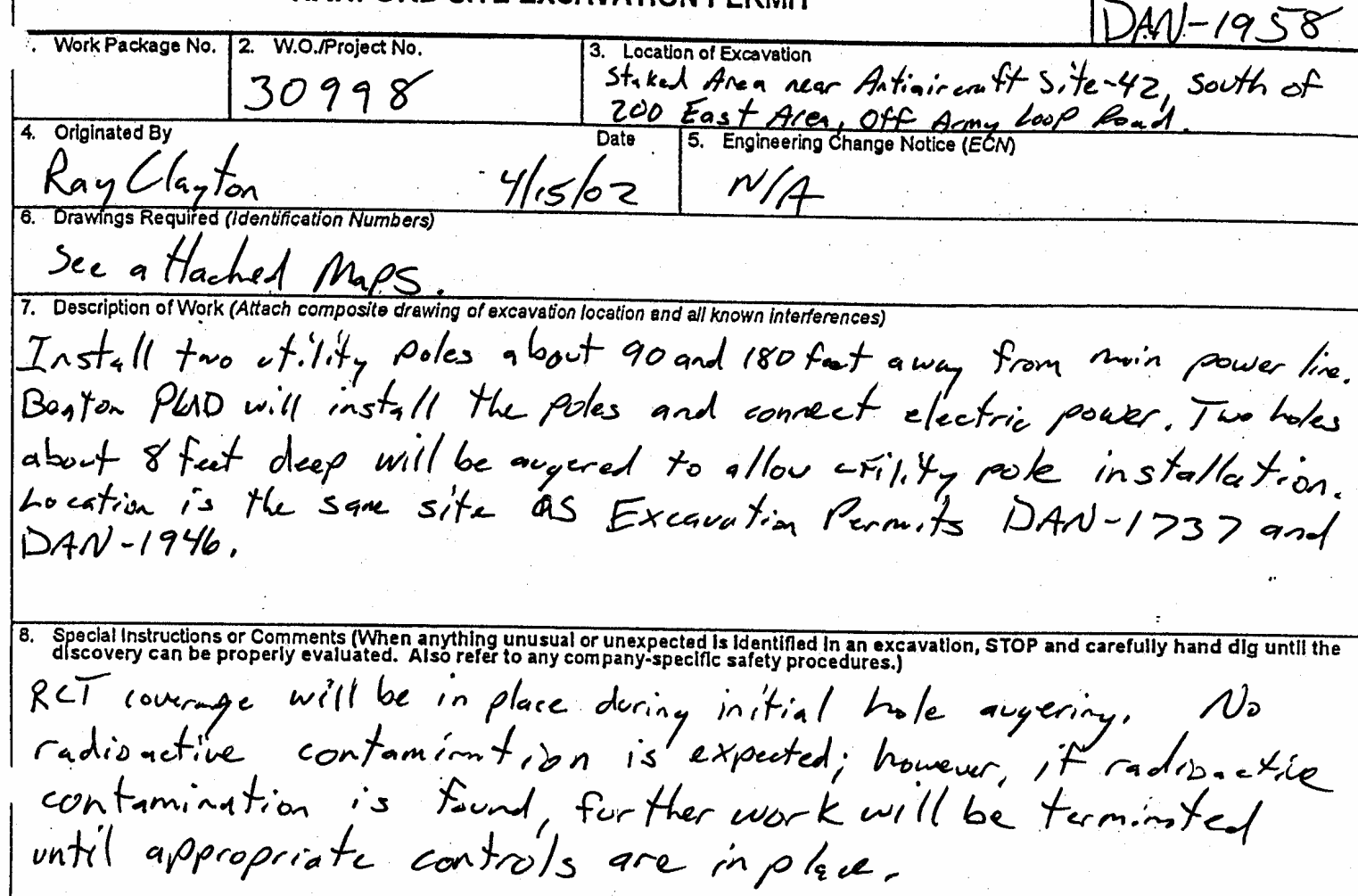
9. List Facillties, Services, and Utilities Affected by Excavation
There ane no undergrand telephove, water or electric t.l.t.ies in the test area.

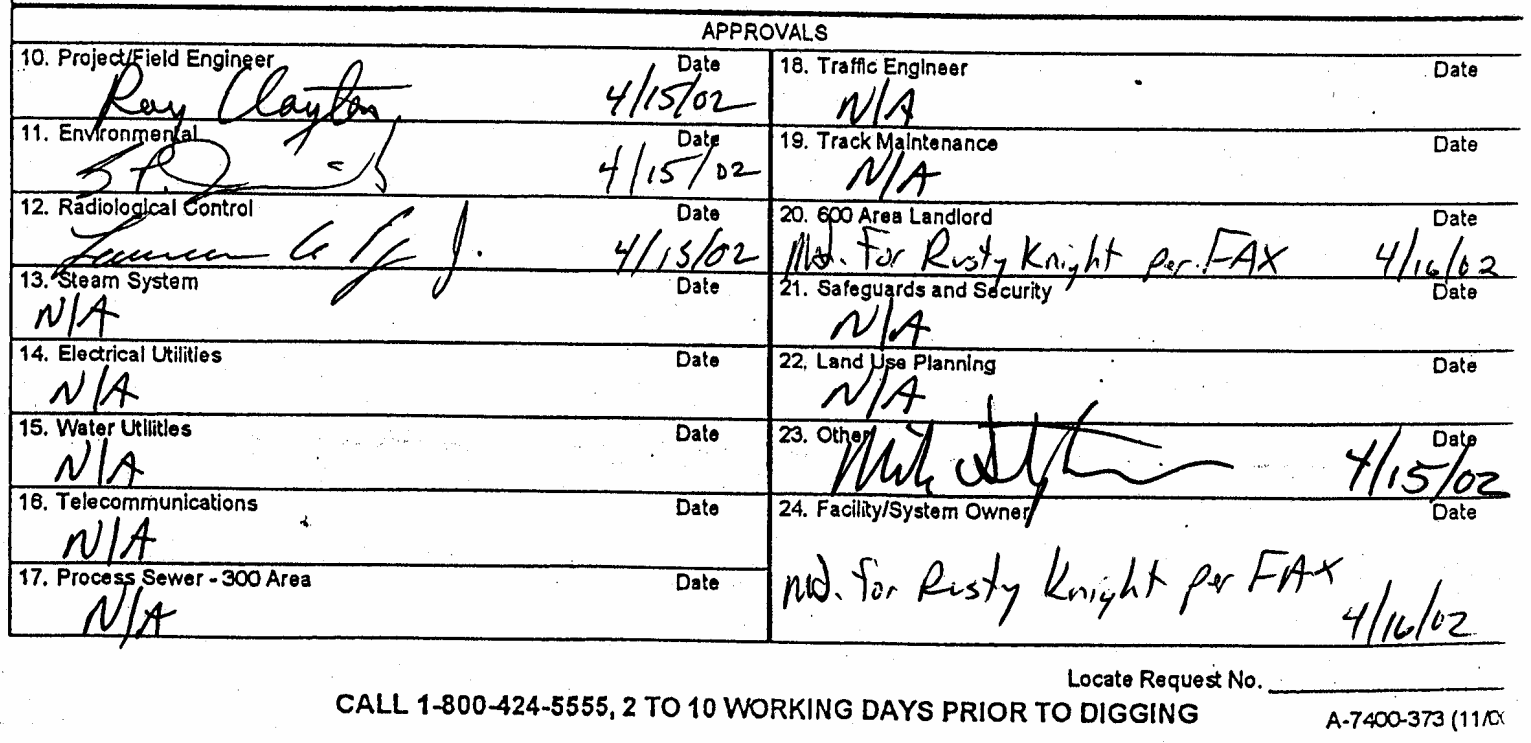




\section{Appendix B}

Clastic Dike: Antiaircraft Site H-42-Army Loop Road Site Access and Conduct Requirements Health and Safety Plan and Site Briefing 


\section{Appendix B: Clastic Dike: Antiaircraft Site H-42-Army Loop Road Site Access and Conduct Requirements Health and Safety Plan and Site Briefing}

\section{B.1.0 Application and Scope}

This document controls Pacific Northwest National Laboratory (PNNL) Science and Technology Project safety and conduct activities related to the Army Loop Road Clastic Dike Site.

It serves as the site safety briefing and provides general requirements for staff, contractors, and visitors involved in performing testing and monitoring activities on the Army Loop Road Clastic Dike Site. The site is located near Antiaircraft Site H-42. The Washington State Plane coordinates are approximately $128500 \mathrm{~N}$ and 573500 E. Figure B.1 shows the location of the Army Loop Road site as being just off Army Loop Road due south of the 200 East Area.

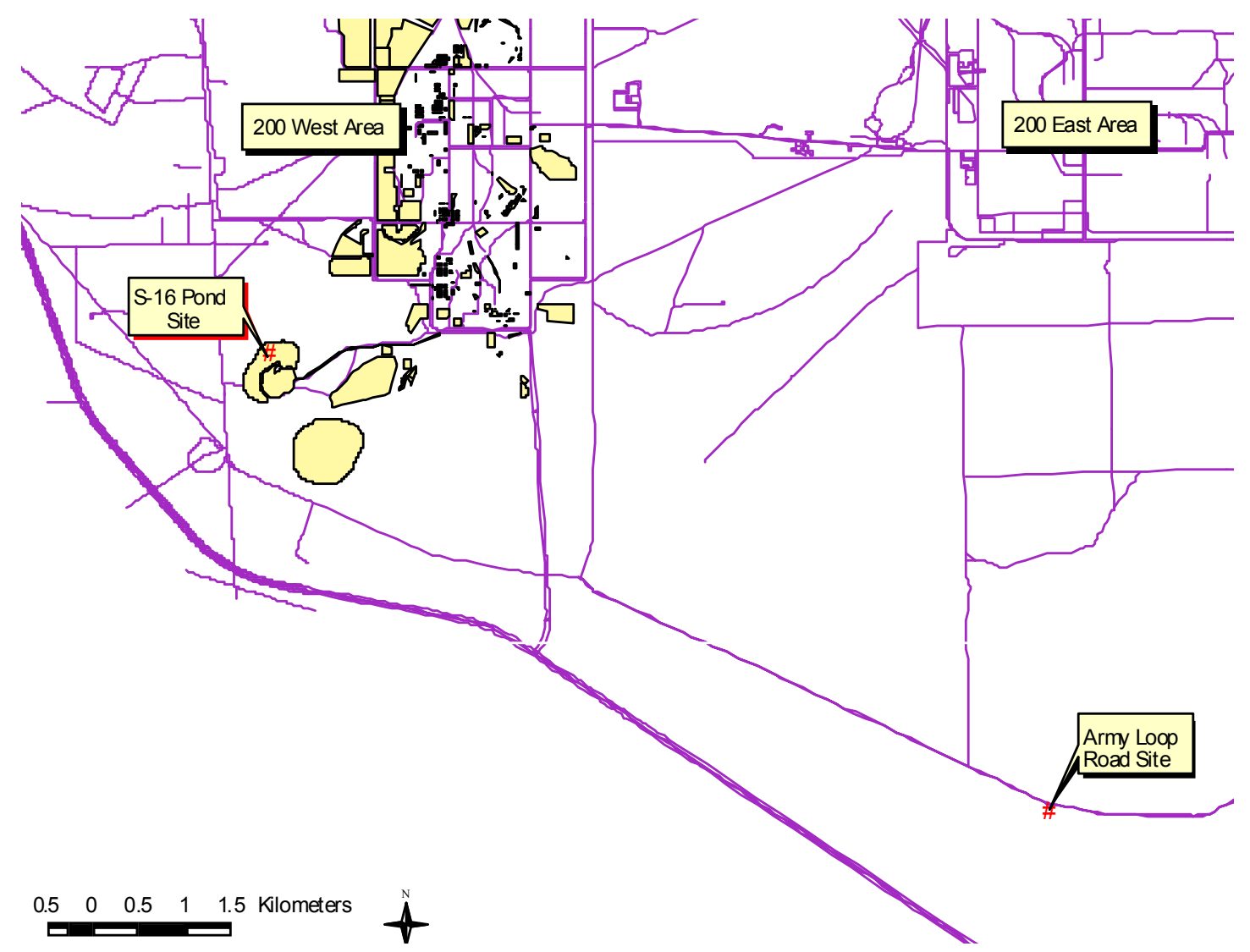

Figure B.1. Location of the Army Loop Road Clastic Dike Site 
Visitors accessing the site must follow safety precautions that pertain to PNNL staff working onsite. Signing of this document indicates that the individual has read the document and is willing to abide by the safety and access protocols specified herein.

Subsequent versions of this document may be prepared if access or conduct requirements change. Notification of subsequent versions will be made to project staff and authorized workers. Each new version of the document will require the review and signature of each worker before that person's continued work at the site.

\section{B.2.0 Responsible Staff}

The person responsible for this document is the PNNL project manager Glendon W. Gee, who can be reached at (509) 372-6096. The alternate responsible person is Anderson L. Ward, who can be reached at (509) 372-6114.

\section{B.3.0 Testing and Monitoring Goals}

The goals of the tests at the Clastic Dike site are to compare innovative and improved methods for quantifying vadose-zone plumes and to obtain flow-and-transport data from the Hanford vadose zone useful for model calibration and verification. The planned work includes activities to monitor water and tracer flow in the vadose zone under controlled conditions with a suite of methods under conditions of known applications of water and tracers. The goals of the project are important to the overall Science and Technology project in that actual field data will be obtained in which vadose-zone flow-and-transport models can be calibrated. The tests will be conducted in collaboration with a number of highly qualified scientists and engineers from other national laboratories and research firms who are participating in the Science and Technology Initiative of the Ground Water Vadose Zone Project for the USDOE.

It is the responsibility of each person working at the site to assure his or her activities do not jeopardize the integrity of the other monitoring activities that are ongoing at the site.

\section{B.4.0 Safety Requirements}

Any accidents or immediate, uncontrollable safety concerns observed by workers at the site should be reported to site emergency services by calling 375-2400 or 911. Note that 911 calls from cellular phones maybe re-directed. For additional assistance, call 373-3800 (Hanford Patrol) or radio the Safety Net at Frequency KOB743 (monitored by Hanford Patrol and by the PNNL Control Room [Station 62]). In the event such communications are not available, a 24-hr First-Aid Station is located at the intersection of Baltimore and $4^{\text {th }}$ Street (Building 2719EA).

Site access and safety requirements refer only to the area within and immediately adjacent to the Clastic Dike Site. Staff should be aware that radiological hazards potentially exist at the site.

\section{EMERGENCY TELEPHONE NUMBERS}

PNNL Emergency

$375-2400$ 
Hanford Emergency Response 811

Hanford Patrol/Fire/Ambulance 811

\section{WARNING SIRENS:}

The following action should be taken relative to warning sirens:

- For all gongs and horns, go to the staging area, Baltimore Ave, 3750 parking lot.

- Wavering Siren (get in vehicle, call emergency phone \# and follow directions).

- Howler (AH-OO-GAH). Get in vehicle drive off the Clastic Dike Site and leave area - preferably away from the criticality area.

Planned siren tests are frequent. Call Dyncorp Emergency Prep. (373-4308) if questions arise regarding specific siren tests.

\section{ACCIDENTS:}

The following actions should be performed if any accidents or immediate, uncontrollable safety concerns are observed by anyone at the site:

Immediately stop work. Evaluate the scene for safety. If safe, lend medical aid or prevent further damage. If unsafe conditions exist, deactivate and turn off applicable electrical and mechanical systems before lending assistance. Immediately notify site emergency services (above). If a telephone is available, call the emergency assistance number (375-2400) and be prepared to describe the accident and your location (the site location is described above). A cell phone (Tel. No. 528-4689) is available in the site trailer and can be used to contact the Hanford Patrol. In the event that the phone is not working, send someone for help to the First-Aid Station at Baltimore and $4^{\text {th }}$ Street (Building 2719EA). Notify your line manager and the project manager (Glendon W. Gee 372-6096).

\section{For general work:}

When drill rigs are on the site and workers and collaborators are on the site, workers shall use hard hats and safety glasses and wear closed-top shoes. Steel toes in the shoes are not required for general work. For specific activities that pose additional potential hazards, such as digging or working with electrical or water supply systems, additional requirement may include protective clothing (long-sleeve coveralls or equivalent work clothes), gloves, steel-toed shoes, or other safety needs. The project manager in cooperation with specific task leaders will analyze hazards and shall identify the additional appropriate combination of safety precautions (e.g., clothes, procedures, training, and supervision) necessary for each type of work. Workers shall follow these requirements and only perform work for which they agree with procedural and safety requirements. Work shall not be performed when ambient weather conditions pose a threat to safety and health. Workers shall use caution in extended work in the full sun. To avoid heat stroke, workers are encouraged drink ample quantities of fluids. In the event of fire, a fire extinguisher is located in the site trailer. 


\section{Additional Safety Requirements.}

The general requirements of this procedure are based on PNL-MA-43 and applicable Standards Based Management System (SBMS) subject Areas. Specific requirements for other activities typically conducted at the site include:

- Workers shall adhere strictly to all postings, caution, warning, and danger signs. Failure to do so shall result in immediate work stoppage. Workers shall pay attention to personal safety.

- The need of a particular job to be controlled by a procedure shall be determined using PNL-MA-43 and applicable SBMS subject areas (e.g., working with chemicals, electrical safety, machine guarding). In this study, the operation of neutron probes is the only task requiring a procedure and is governed by PNL-PSB-10-0. Workers performing these jobs must demonstrate a knowledge of hazards associated with the work before commencing work.

\section{B.5.0 Site Access Requirements}

There are no formal site-access requirements. Access is gained via gravel roads from Army Loop Road (Figure B1), and vehicular traffic is encouraged to travel only on the gravel road ways. Parking of vehicles adjacent to the roads is permitted, but vehicle parking is restricted to the disturbed areas that are adjacent to the roadway. Access into the site from the Army Loop Road Turnaround of vehicles can be accomplished by driving on the disturbed area that is immediately adjacent to the access road. In general, workers and collaborators should be cognizant of monitoring activities and work together under the defined schedule for the selective monitoring activities that are ongoing throughout the duration of the project.

Because there is a remote possibility that radioactive contamination may migrate onto the site, it is recommended that staff walking on the vegetation because of requirements to conduct civil and biological surveys should be aware of the potential for surface contamination via biotic pathways of biologic activity. For this reason, no animal droppings (feces) are to be removed from the surface without first contacting radiation safety and the project manager. In general, the staff are encouraged to walk only in the disturbed areas.

\section{B.6.0 Potential Site Impact Requirements}

Activities that pose the potential to significantly affect monitoring conditions must be authorized and documented by the project manager. Examples of activities that pose such potential include:

1) excavating sediments in unauthorized locations, 2) driving vehicles onto the Clastic Dike site when monitoring is ongoing unless a drill rig or similar vehicle is scheduled and has been authorized for access on to the site. This list is not intended to be complete but is included to provide examples of the type of activities that may pose a potentially significant impact.

It is the responsibility of the project manager to determine if any monitoring or site visit activity poses the risk to cause a significant impact based on the examples provided above and to obtain appropriate approval from the project manager. Before work, resolve with the project manager any uncertainty about 
the potential to cause a significant impact. Guidelines are outlined in PNL-MA-26 (Radiological Control Procedures) and PNL-MA-50 (Facilities Management Department PNL Operations Manual).

An activity is authorized if approval is obtained from the project manager. It is the responsibility of the project manager to determine the level of documentation needed for each unusual activity (no action, memo-to-file, or other documentation). Activities that pose the potential to affect the monitoring project must be documented in the project manager's site file. Workers who observe unexpected operations or conditions at the site must report the incident to the project manager (See Section 2.0).

\section{B.7.0 Training Requirements}

Signing this document provides the authority to access the site and perform monitoring work at the Army Loop Road Clastic Dike Site.

Radiation Worker II training is required for operators of neutron probes. Training records for these activities will be on file with the individual worker and will be available upon request.

\section{B.8.0 References}

PNL-MA-26 Radiological Control Procedures

PNL-MA-43 Industrial Hygiene, Occupational Safety and Fire Protect. Programs.

PNL-MA-50 Facilities Management Department PNL Operations Manual.

SBMS Standards Based Management Systems-Subject Areas 
PNNL-14240

\section{Distribution}

No. of

Copies

\section{OFFSITE}

2 Lawrence Berkley National Laboratory

Department of Earth and Planetary Sciences

MS 4767

1 Cyclotron Road

Berkeley, California 94720-4767

Attn: Donald J. DePaolo

Mark Conrad

Sandra Lilligren

Nez Perce Tribe, ERWM

P.O. Box 365

Lapwai, Idaho 83450

Peter C. Lichtner

Los Alamos National Laboratory

Environmental Sciences Division (EES-5)

MS F-649

Los Alamos, New Mexico 87545

Ernest L. Majer

Lawrence Berkeley National Laboratory

1 Cyclotron Road (MS 90-116)

Berkeley, California 94720

Earl D. Mattson

Idaho National Engineering and Environmental

Laboratory

P.O. Box 1625

2251 N. Boulevard

Idaho Falls, Idaho 83415-2107

Wade Riggsbee

Yakima Nation

1933 Jadwin

Richland, Washington 99352
No. of

Copies

\section{OFFSITE}

James B. Sisson

Idaho National Engineering and Environmental Laboratory, BBWI

P.O. Box 1625, MS-2107

Idaho Falls, Idaho 83415-2107

2 Los Alamos National Laboratory

Environmental Science Group

MSJ495

Los Alamos, New Mexico 87545

Attn: Everett P. Springer

Brent Neuman

Carl. I. Steefel

Lawrence Livermore National Laboratory

L-204

P.O. Box 808

Livermore, California 94551

P. J. Wierenga

Soil, Water, and Environmental Science

University of Arizona

Tucson, Arizona 85721

Ivana Witt

Yakima Nation

1933 Jadwin

Richland, Washington 99352

Distr. 1 
No. of

Copies

ONSITE

1 DOE Office of River Protection

C. A. Babel

H6-60

8 DOE Richland Operations Office

B. L. Foley

A6-38

J. P. Hanson

A5-13

R. D. Hildebrand

A6-38

K. A. Kapsi

R. W. Lober

J. G. Morse

D. Tano

K. M. Thompson

A5-13

H6-60

A6-38

K6-85

A6-38

5 Bechtel Hanford Inc.

R. L. Biggerstaff

E6-35

L. R. Curry

H0-09

K. R. Fecht

B. H. Ford

R. L. Jackson

4 CH2M Hill Hanford Group

R. Khaleel

E6-17

A. J. Knepp

E6-35

E6-35

F. M. Mann

E6-35

1 MACTER-ERS

R. G. McCain B2-62

3 Waste Management Technical Services

M. G. Gardner

H1-11

J. E. Meisner

H1-11

R. K. Price

H1-11
No. of

Copies

\section{ONSITE}

5 Washington Department of Ecology

F. W. Bond B5-18

J. Caggiano B5-18

D. Goswami B5-18

A. Huckaby B5-18

N. H. Uziemblo B5-18

1 U.S. Environmental Protection Agency

D. A. Faulk B5-01

33 Pacific Northwest National Laboratory

R. E. Clayton P8-37

M. J. Fayer K3-33

M. D. Freshley (2) K9-33

G. W. Gee (10) K9-33

G. V. Last K6-81

P. E. Long K9-33

P. D. Meyer BPO

C. J. Murray K6-81

M. L. Rockhold K9-36

R. J. Serne P8-37

C. E. Strickland K9-36

A. L. Ward (5) K9-33

K. Waters-Husted K6-96

M. White K9-36

S. B. Yabusaki K9-36

J. M. Zachara K8-96

Z. F. Zhang K9-33

Technical Report Files (2) 